\title{
Applying Kabeer's Social Relations Approach to Village Health Volunteers in Rural Papua New Guinea
}

\author{
By \\ Ruth Heather
}

A thesis submitted to the Victoria University of Wellington in partial fulfilment of the requirements for the degree of Masters of Development Studies

Victoria University of Wellington February 2010 


\section{Abstract}

In this thesis I explore the effectiveness and sustainability of the Village Health Volunteer system within the East Sepik Women and Children's Health Project (ESWCHP), Papua New Guinea.

The ESWCHP is a well-established project that provides a health infrastructure for primary health care services in rural areas of the East Sepik Province. The ESWCHP supports Church Health Services, and village women who volunteer (Village Health Volunteers) to provide primary care in rural village settings. In 2006, I undertook research to assess the impact of the ESWCHP. The assessment showed that rural people were very supportive of the Project and that it had made a significant, positive difference to health in rural villages. There was however, an overwhelming response to the research from Village Health Volunteers (VHVs) with requests for a greater level of support from rural people and the ESWCHP (in terms of training, payment, and status) and greater consistency of medical supplies.

In this qualitative thesis research, I revisited the 2006 data using a combined theoretical frame of gender and development, participatory development and Sen's capability approach. I developed a detailed method based on Kabeer's Social Relations Approach (1994) to guide the process of interpretation, analysis and representation of memories, notes, and data.

Through the analysis of social relations, I examined questions concerning the effectiveness of the VHV system in the face of escalating maternal death rates and epidemic levels of HIV/AIDs, and its sustainability. The analysis showed that the ESWCHP was facing compounding gender inequalities that put sustainability of the VHV system at risk. The analysis also showed that on the basis of key health indicators, the ESWCHP health infrastructure with its current heavy reliance on VHVs was neither successful nor effective. Research is urgently needed to identify a sustainable and effective model of rural health care to address the rapidly escalating maternal death and HIV rates of rural people in PNG. 


\section{Acknowledgements}

This thesis has been three years in the making. Along with that length of time go numerous people who have gone out of their way to make this thesis possible.

First and foremost acknowledgement must go to my partner in life, Cath Chittenden. Throughout this period there have been traumas, disconnections and reconnections. During this time Cath paid the over NZ\$4000 required for my flights to PNG in 2006, and has continuously supported my personal passion for PNG and its people. She has continued to make allowances for the time I need to complete this thesis on top of full time work.

My thanks must also go to Leonard Chan, who was the Save the Children PNG Programme Manager in 2006 and who facilitated me getting the volunteer assignment, which enabled this work. Bill Humphrey, the then ESWCHP Programme Manager, so willingly took me on as an unknown recruit green to the customs and cultures of PNG, and patiently supported me throughout the process.

Jo Spratt kindly agreed to peer review my draft. Her passionate, persistent and insightful approach to health and development issues continues to amaze me and influences my personal journey into the world of development. Jo's peer review comments strengthened my approach and helped me fine-tuning my arguments; my thanks to her for that.

I would also like to thank Yvonne Tawai. Yvonne is one of those rare creatures - a woman from a matriarchal culture. She was my guide, my mentor, my cultural coach and interpreter and protector during my time in the East Sepik. Yvonne has been the quiet voice in my head as I have reviewed the research and written this thesis. I have a great deal of respect and admiration for Yvonne who was able not only to manage the crossings between her culture and language and mine, but between her culture and language, mine and the cultures and languages of the large numbers of people we met in 2006 . I hope that one day I will get the opportunity to see Yvonne again, and visit her in her home in New Ireland.

I would like to thank Yvonne Underhill-Sem, who has met with me a couple of times, and who shares my passion for PNG and its people. Yvonne visited the ESWCHP just prior to my time there and her report Gender Advisory Support for Grass-Roots Health Projects in Papua New Guinea (2006) has provide key insights toward understanding PNG culture and grassroots issues. 
Jill Ruthven, the librarian for the Victoria University John Bradley library, has shown unswerving support, and assisted with difficulties I often found resulting from being a part time Masters student, with little time to sort out issues of IT access or retrieving well hidden articles of particular interest. Many of the sources particularly those pertaining to the Social Relations Analysis have been found with Jill's help.

I would also like to thank Margaret Street, a retired South Seas Evangelical Society missionary. Margaret was influential in introducing the Village Health Volunteer system into PNG, along with national PNG midwifery training. Margaret was kind enough to meet with me in 2008 and provided a range of valuable insights and historical documents to deepen my understanding of PNG 'custom'.

The excellent thesis 'Christianity, Local Culture and Disaster Relief Theory and Practice in Papua New Guinea: A Case Study of the Involvement of the Combined Churches Organisation in the 1998 Aitape Tsunami Disaster Relief' written by Philip Fountain (2002) inspired me and provided a practical example of what a well-written thesis looked like; for that I am grateful.

My wonderful mother has been my unswerving ally and supporter. She continues to encourage me to follow my dream to become part of the world of development. She graciously proofed this thesis, and I will always be thankful for her presence in my life.

Lastly, but by no means least, I would like to thank Sara Kindon, my supervisor. Sara has gotten to know me, the ups and downs of my life and my struggles at times to balance life, work and study, trying as ever, to do it all at once. Sara has steered my canoe calmly through all the processes that come together to complete a thesis such as this. She has been the best that a master's student could ever have hoped for when embarking on a thesis project such as this, and is deserving of many thank yous.

\section{'Harim tok bilong mama, kos meri karim yu'}




\section{Table of Contents}

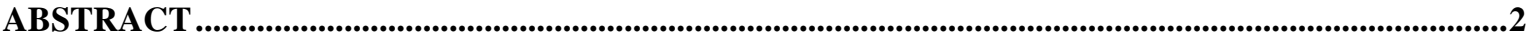

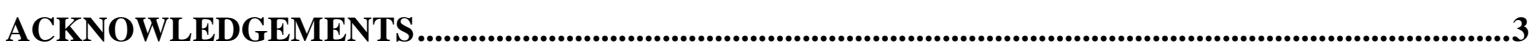

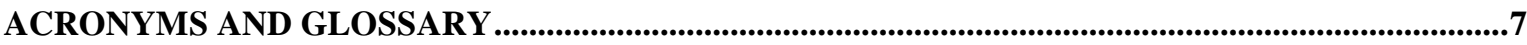

$1 \quad$ INTRODUCTION ..................................................................................................................................9

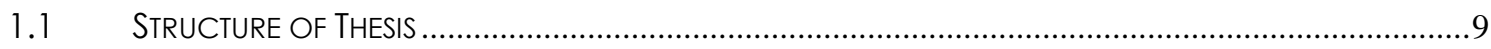

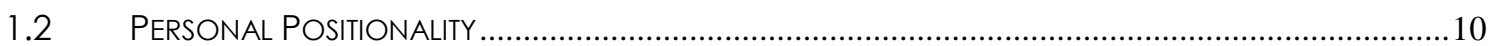

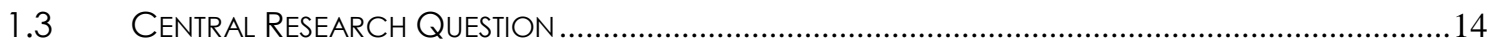

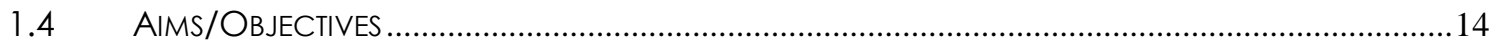

1.5 BaCkground to the EASt SePIK Women And ChILDREN'S Health PROJeCt, PNG ...................14

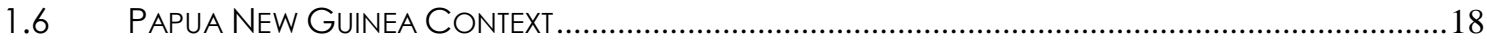

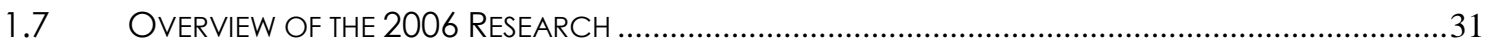

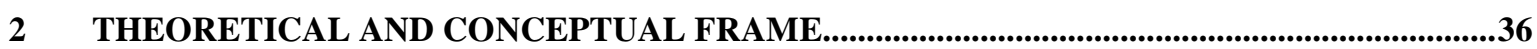

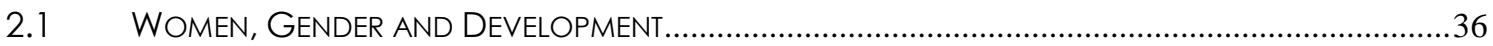

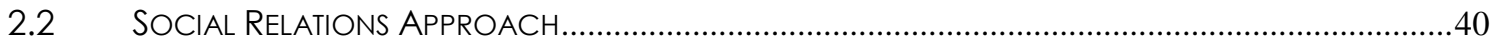

2.3 Women, Gender AND DeVELOPMENT Policy FrameWORK IN PNG .........................................43

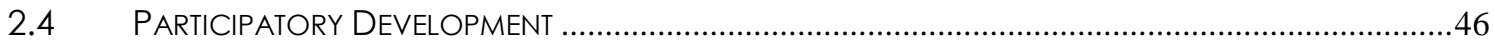

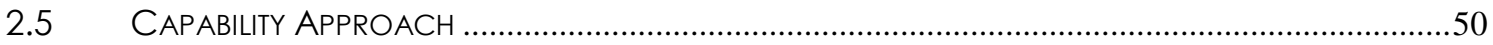

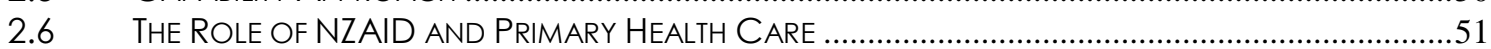

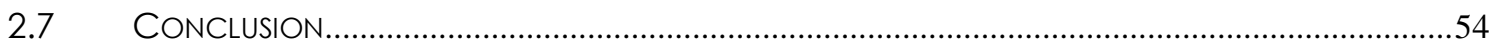

$3 \quad$ RESEARCH APPROACH ..............................................................................................................56

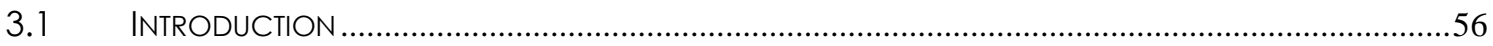

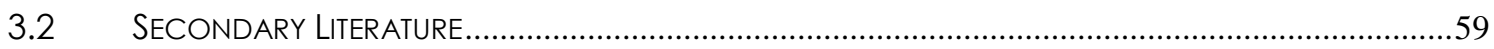

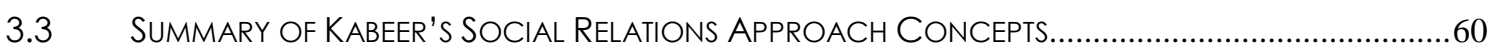

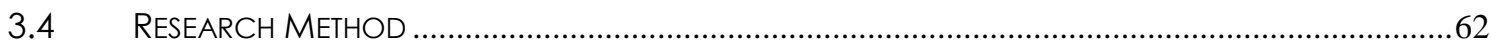

$4 \quad$ INSTITUTIONAL ANALYSIS ..............................................................................................................67

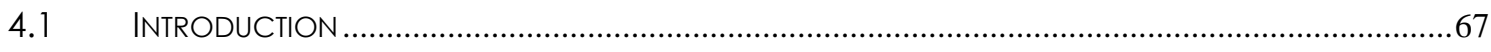

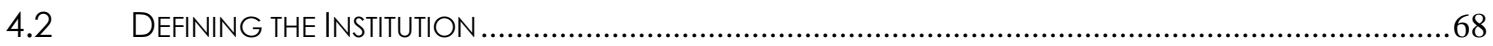

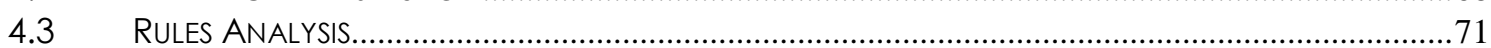

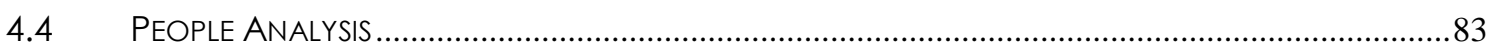

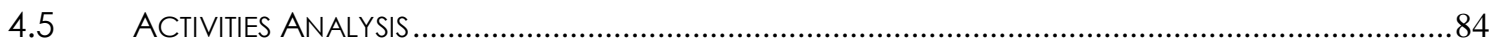

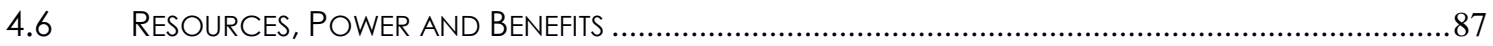

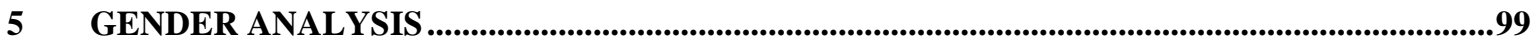

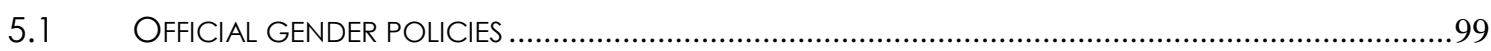

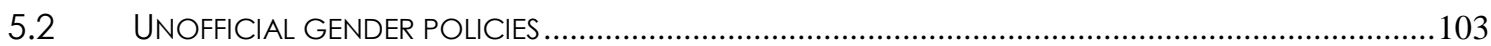

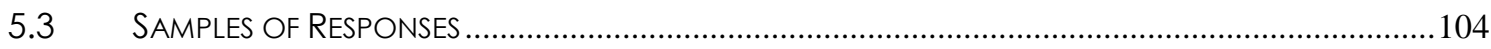

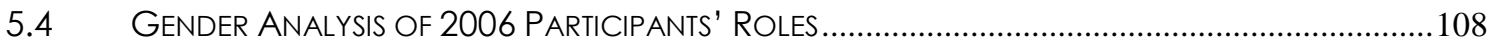

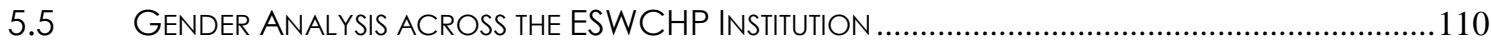

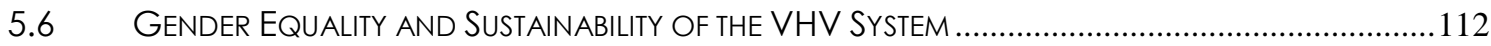

6 IMMEDIATE, UNDERLYING AND STRUCTURAL CAUSES ANALYSIS ................................115

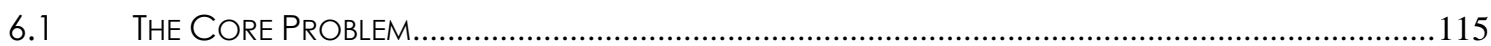

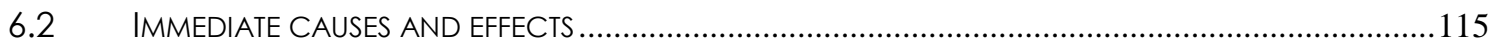

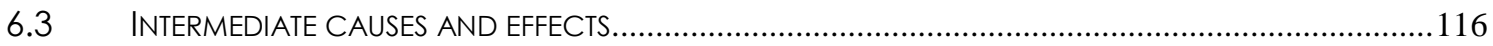

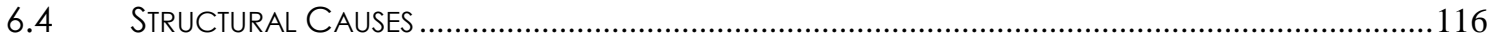

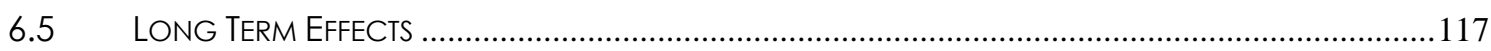

7 RECOMMENDATIONS FOR DEVELOPMENT INTERVENTION ….......................................118

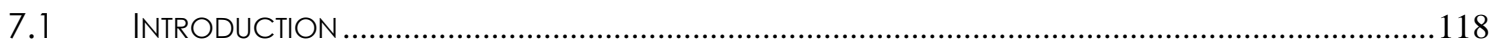

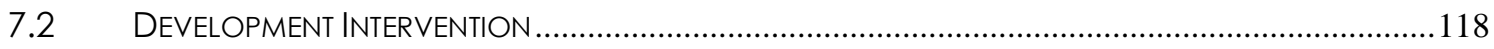

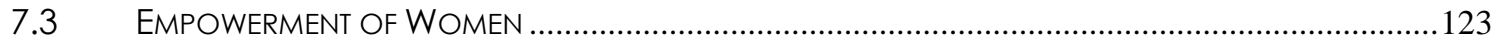

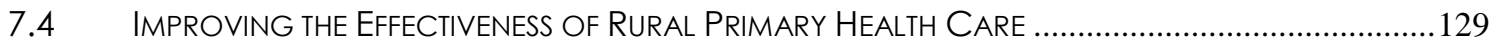

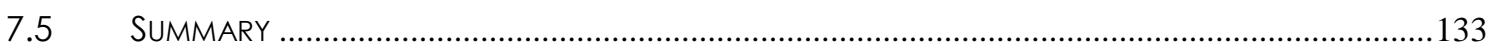

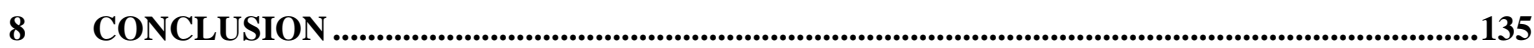

February 2010 Page 5 of $176 \quad$ Ruth Heather 
APPENDIX A: 2006 RESEARCH KEY QUESTIONS .137

APPENDIX B: MAP OF THE EAST SEPIK. .139

APPENDIX C: RESPONDENTS ANALYSIS . .140

APPENDIX D: THE MILLENNIUM DEVELOPMENT GOALS, TARGETS AND INDICATORS.141 APPENDIX E: PAPUA NEW GUINEA GOVERNANCE SYSTEM .0144

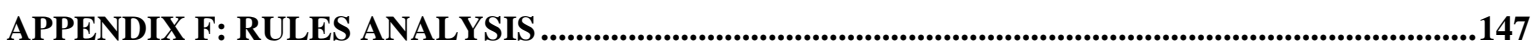

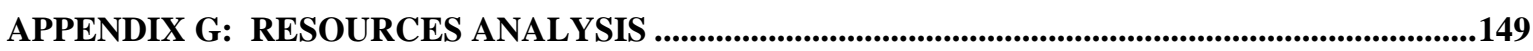

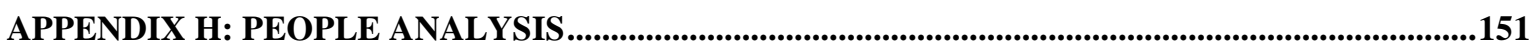

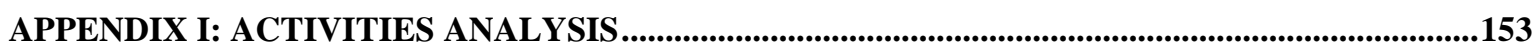

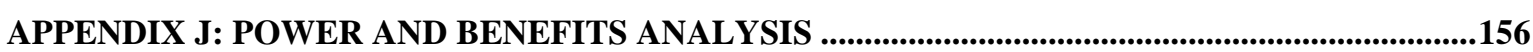

APPENDIX K: IMMEDIATE, UNDERLYING AND STRUCTURAL CAUSES AND EFFECTS

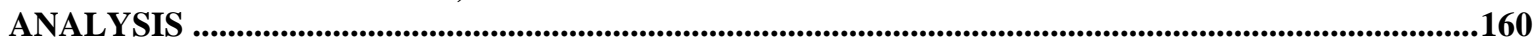

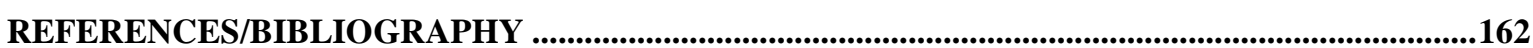

\section{Index of Figures and Tables}

FIGURE 1: ESWCHP AS DEFINED IN PROJECT DOCUMENTATION ................................................ 16

FIGURE 2: MAP OF PAPUA NEW GUINEA ................................................................... 19

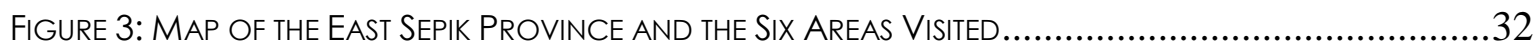

FIGURE 4: DIMENSIONS OF SOCIAL RELATIONSHIPS..........................................................61

FIGURE 5: ESWCHP AS DEFINED IN PROJECT DOCUMENTATION ...............................................68

FIGURE 6 ESWCHP INSTITUTION DEFINED FOLLOWING INSTITUTIONAL ANALYSIS..................................71

FIGURE 7: OVERVIEW OF RESOURCE NEGOTIATIONS WITHIN THE ESWCHP INSTITUTION ...........................87

FiguRE 8: DiagraMMATIC VIEW OF THE BALANCE OF POWER WITHIN THE ESWCHP ............................91

Figure 9: Diagrammatic VIEW OF ReSOURCE AlLOCATION WITHIN THE ESWCHP .............................91

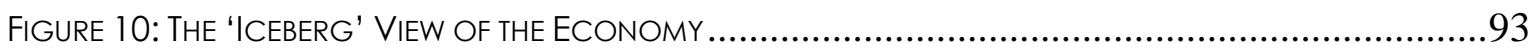

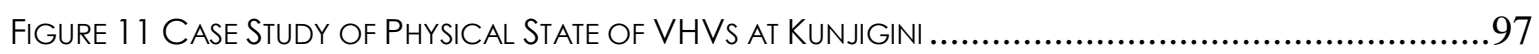

FIGURE 12 MALE PARTICIPANTS IN 2006 RESEARCH: RANGE OF SELF IDENTIFIED ROLES .........................108

FIGURE 13 SELF IDENTIFIED ROLES OF MALE PARTICIPANTS IN THE 2006 RESEARCH ..............................109

FIGURE 14 FEMALE PARTICIPANTS IN 2006 RESEARCH: RANGE OF SELF IDENTIFIED ROLES.......................109

FIGURE 15 SELF IDENTIFIED ROLES OF FEMALE PARTICIPANTS IN THE 2006 RESEARCH...........................110

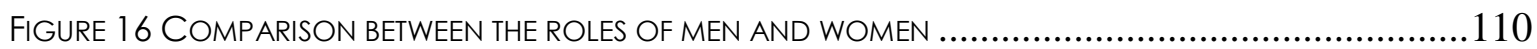

Figure 17: Gender MAKE UP OF ESWCHP ORGANISATIONS AT THE STATE LEVEL..............................111

Figure 18: Gender MAKE UP OF ESWCHP ORGANISATIONS AT THE MARKET LEVEL ...........................111

FIGURE 19: GENDER MAKE UP OF ESWCHP ORGANISATIONS AT THE COMMUNITY AND FAMILY LEVELS......112

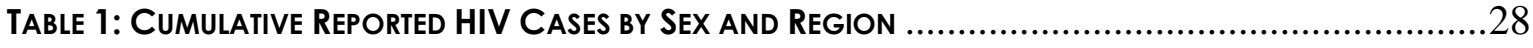

Table 2 The Millennium DeVelopment Goals and Progress...............................................29

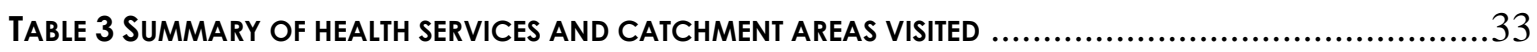

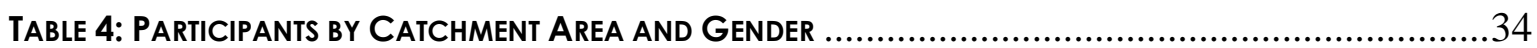

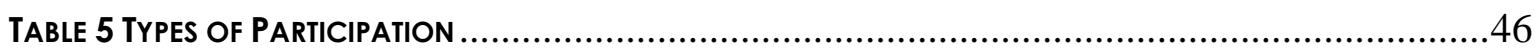

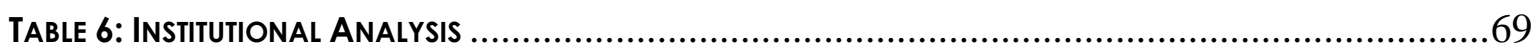

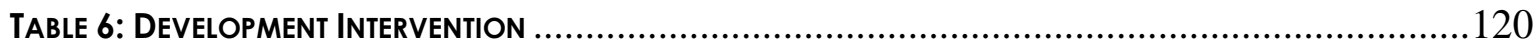

Appendix D Table 1: Governance Arrangements in Papua New Guinea ................................144 


\section{Acronyms and Glossary}

$\begin{array}{ll}\text { ADB } & \text { Asian Development Bank } \\ \text { AusAID } & \text { Australian Agency for International Development } \\ \text { CBD } & \text { Community Based Distributors } \\ \text { CHS } & \text { Church Health Services } \\ \text { DFAT } & \text { Australian Department of Foreign Affairs and Trade } \\ \text { ESCOW } & \text { East Sepik Council of Women } \\ \text { ESWCHP or 'the Project' } & \text { East Sepik Women and Children's Health Project } \\ \text { GoPNG } & \text { Government of Papua New Guinea } \\ \text { MDGs } & \text { Millennium Development Goals } \\ \text { MM } & \text { Meresin Meri or Meresin Man } \\ \text { NDoH } & \text { National Department of Health } \\ \text { NGO } & \text { Non Governmental Organisation } \\ \text { NZAID } & \text { New Zealand Agency for International Development } \\ \text { PNG } & \text { Papua New Guinea } \\ \text { PDoH } & \text { Provincial Department of Health } \\ \text { SCiPNG } & \text { Save the Children in Papua New Guinea } \\ \text { SCNZ } & \text { Save the Children New Zealand } \\ \text { SRA } & \text { Social Relations Approach } \\ \text { UNFPA } & \text { United Nations Fund for Population Activities } \\ \text { VBA } & \text { Village Birth Attendant (a subset of VHVs) } \\ \text { VHV } & \text { Village Health Volunteer } \\ \text { VHW } & \text { Village Health Worker (a name sometimes used for VHVs) } \\ \text { WHO } & \text { World Health Organisation }\end{array}$




\section{Glossary}

Custom or 'pasin bilong

mipela'

ESWCHP Office

Gender

Haus

'in-kind' payment

Kina

Meresin meri

Meresin man

Tok Pisin

Village woman

Voluntia

Wantok
Cultural factors or customs (Korare, 2002)

This term is used to mean ESWCHP staff

'Gender refers to the rules, norms, customs and practices by which biological differences between males and females are translated into socially constructed differences between men and women and boys and girls. This results in the two genders being valued differently and in their having unequal opportunities and life chances.' Kabeer (2003, pp16) House

A payment received by the VHV in return for services. These can take many forms such as childcare, working in the garden (so that the VHV can take time to provide services instead of working in her garden), money, food or other products. These 'in-kind' payments are generally negotiated between the VHV and the person / family receiving the service at the time of service. The value of the 'in-kind' payment is negotiated as well and based on perceptions of the value of the service provided by the VHV

Dollar or money

Medicine woman

Medicine man

Pidgin language commonly used across PNG

Woman within the rural village context whose role is perceived to be largely reproductive: caring for children and family, growing food, keeping house, going to market to sell produce, wife to husband

In the context of this thesis, the term voluntia is used to mean: volunteer - unpaid health worker whose services should be rewarded by the community they serve (NDoH, 1991) Friend or more literally, person who speaks the same dialect and is from the same family group 


\section{Introduction}

This thesis provides two things. Firstly it provides a very personal and cathartic review of an impact assessment I did in 2006 on the East Sepik Women and Children's Health Project (ESWCHP or 'the Project') in Papua New Guinea. I needed to understand what went well and what didn't, and why I was left with unresolved questions, and a sense of discomfort about the relations of power I had by default created through my presence and through the way I conducted the research. Secondly, it provides a documented example of the application of Naila Kabeer's (1994) Social Relations Approach (SRA) to impact assessment data within the context of a development project. As a result, it provides insights and discussion about potential enhancements that could be made to the ESWCHP (and similar health projects) and allows for a critique of how I have applied the SRA (there is no available guide to the application of the SRA so this thesis describes the approach I have developed and followed).

As this thesis centres on the role of the Village Health Volunteer (VHV) I will describe what I mean by VHV. ESWCHP VHVs are generally women who are trained to provide a range of curative and preventative health services (strengthening malaria controls, immunisation, providing clean water, birthing kits, improving family planning, and promoting healthy living). VHVs undertake these activities within village settings and alongside their duties as women such as growing food, caring for family, housework etc. VHVs are unpaid health workers, who are to be recompensed for services by village people through 'in-kind' payments (NDoH, 1991).

\subsection{Structure of Thesis}

Chapter One of this thesis sets the scene for the research. It provides an overview of the 2006 research, the data and experiences, which are analysed in this thesis. In Chapter One I also provide the PNG context and my personal positionality. These underpin this central thesis question of the sustainability of the VHV model of primary health care.

In Chapter Two I discuss the theoretical and conceptual frame within which the analysis takes place; women, gender and development; participatory development; and the capability approach.

Chapter Three provides my research approach. This incorporates the detailed method developed based on Kabeer's Social Relations Approach. Chapter Three also highlights qualitative research methods that have been used to support the analysis and interpretation and highlights limitations of this thesis research. 
In Chapter Four I discuss the institutional analysis. This involves defining the institution upon which the analysis takes place, considering formal and informal rules, who does what, how decisions are made and who benefits. I have relied primarily on transcripts of VHV responses recorded as data in 2006.

Chapter Five provides the gender analysis and considers official and unofficial gender policies. The balance of sexes within the institution is also analysed.

Chapter Six provides reflective discussion arising from the analysis. This looks particularly at gender inequality, its relationship to the role of the VHV and issues of sustainability. Chapter Six also explores issues affecting the effectiveness and sustainability of the health infrastructure. The role of NZAID in ensuring that funded programmes are effective in improving health outcomes is also discussed.

In Chapter Seven I provide options and recommend actions to strengthen and improve rural health care delivery and effectiveness. A Development Intervention is provided as practical culmination of the analysis and recommendations. This provides a practical example that could be used in the field through participation to enhance the freedoms VHVS would seek to expand. Enhancing the freedoms VHVs seek to expand could provide a range of grassroots interventions toward improving rural population health.

Appendices $\mathrm{F}-\mathrm{J}$ provide the detailed analysis conduced through the SRA institutional analysis process.

\subsection{Personal Positionality}

In 2006 I was offered the opportunity of going as a volunteer for Save the Children to PNG, to conduct an impact assessment of the ESWCHP as part of a research team. At the time, the excitement of the assignment and the exotic location in which it was based, along with the fact that the research framework had been developed by those who had done this many times before, meant that I did not take a lot of time to consider the theories and complexities of conducting research in rural PNG. I had no specific research training, nor had I specifically studied gender and development or social relations. I undertook the research as a volunteer for a well known and experienced development NGO, so felt 'safe' in the knowledge that they did research on their programmes regularly and knew what they were doing. I did however, have the experience of a long career working with projects in health and social settings, and establishing strategy, programme plans and monitoring and evaluation programmes based on research to ensure project effectiveness.

The experience that resulted was profound. I loved being surrounded by locals and immersed in the local culture, and was quickly able to understand the local pidgin because 
of its similarity to the Nigerian pidgin I had learnt as a child. I felt immensely privileged to be able to travel widely with the research team and to meet with locals within remote East Sepik rural communities.

I enjoyed the research process, and working closely with the research team and local ESWCHP staff, and hearing about life as it was for locals. I resonated strongly with many of the informal discussions with VHVs, which happened along the way. Many VHVs the research team met with highlighted the conflict they faced between the religious beliefs they held (and the imbedded patriarchal institutions within the church, community and family), and their need to expand the freedoms within their own lives, which were largely dominated by men. My own life has reflected similar struggles. Having been brought up as a missionary child in Nigeria, much of my life's journey has involved finding ways to free myself from instilled religious beliefs along with the associated patriarchal constraints, to have the freedom of self-determination and to be able to build a better life for my children and me. My life also reflected a working mother...working to improve our lives through studying and working, whilst at the same time, attempting to be a good mother. Again this was reflected by many VHVs who talked of the difficulties they faced in trying to improve their lives through training, volunteering or working, without faltering on their other duties within their role of village woman.

Many aspects of life in PNG seemed similar to life as I remember it in Nigeria; particularly the ever-present threat of violence, the vulnerability of women, children, the elderly and the sick, and the power and control held by those in authority such as the police and army. These activated a range of memories and assumed cultural norms that I had developed as a very young child. The elements of power, who held it and how it was wielded in PNG seemed very familiar to me, so it is likely that there are a number of assumptions embedded in my thinking specifically about power.

When I returned to New Zealand I was left with a range of memories and impressions; I was unsettled by the impression that grew within me that somehow I had unknowingly created unequal power relations through my presence and through the way I conducted the impact assessment research. I was left with questions in my mind as to where the balance was. I was increasingly unsettled by memories of the VHVs of the rural village of Kunjigini. Many of these VHVs had travelled more than a day to meet with us; many looked pale and exhausted, their children sickly. We had conducted our research and moved on without even providing the women with something to eat or drink by way of thanks. Although we as a research team learnt from that experience and made sure we were armed with plenty of food and fluid for women and communities we worked with 
from then on, I began to wonder if we had done something wrong somewhere. Why, when I reflected, did I feel all-powerful, and why through the process, did the majority of women seem powerless and yet were so keen to participate that they walked for days to do so? Such questions left me wondering about the gendered dynamics that were at play within the research process, leaving me concerned that somehow I, without realising it, had done something to compound existing power imbalances. I was also left wondering, why did so many women come to have their say? What was it that they wanted to change and/or did their just showing up to meet with us give them mana in some way?

Cornwall (2000) in the search for transformative development, calls for an advancement of capabilities, empowerment and participation alongside a gender aware approach. She calls for more 'attention to be paid to strengthening the capabilities of women - and men, particularly those who are more marginal - to act as 'makers and shapers,' rather than simply as "users and choosers" and identifies a range of skills required to work with difference: advocacy, conflict resolution and assertiveness training. She writes that ' $a$ more fundamental obstacle remains in the quest for equitable development. The ethic of participatory development and of GAD is ultimately about challenging relations of power that objectify and subjugate people, leaving them without a voice. Yet the ways in which 'gender' is framed in both participatory and 'gender-aware' development initiatives continues to provide a barrier to transformation' (p 27-28).

I found these three bodies of development thought (the Capability Approach, participatory development, and gender and development) resonated most closely with my own personal philosophical position - a belief that people want to and will develop themselves in ways that benefit them, and that people should be central to decision making processes that affect their lives. Because the health system was so integral to life within the rural health setting, and services were largely provided by villagers themselves (village women) it is my belief that the views of village people should be central to project decision making processes, and yet as this thesis shows they have the least power and the least influence. What continues to remain unknown is whether or not locals could offer solutions to the issues they raised. This untapped body of information should be of interest both to the ESWCHP and funding agencies as critical to the future direction of the Project.

Improving the health of women, children and their families, as the ESWCHP is trying to do in PNG, is immensely complex and challenging. The impact assessment I completed in 2006 showed without any doubt the positive impact the Project has had on the lives of rural people. However, there are many considerations when working in such a diverse and complex context, to ensure not only greatest effectiveness of kina spent, but to ensure that 
VHV's lives are enhanced and not compromised by their involvement in the ESWCHP, and the services they provide.

Kabeer (1994) describes the roles of women and men within institutional arrangements as being positioned through the gender relational aspects of social relations (pp280). Kabeer describes gender relations as being interwoven into the broader set of social relations that structure the division of resources and responsibilities. She describes many development interventions as having been designed with the expectation that women would provide a significant amount of the labour force, while at the same time denying them financial incentives for their efforts. These interventions have perpetuated women's marginalised status and resulted in 'dissatisfaction, conflict and unmet targets' (Kabeer, 1999, pp23).

When I looked back over the 2006 research and VHV responses I realised that Kabeer's description seemed to fit the ESWCHP. ESWCHP VHVs were women volunteers who provided both curative and preventative health services within village settings (strengthening malaria controls, immunisation, providing clean water, birthing kits, improving family planning, promoting health living). VHVs provided the bulk of the labour resource with no financial incentive for doing so. Instead they were expected to rely on potentially inconsistent and inadequate community support. Many of the VHVs had seemed dissatisfied and their responses to the 2006 research overwhelmingly called for more support in terms of payment, medical supplies, training and status in the community. I began to wonder whether the ESWCHP by design undermined the very people it relied on (VHVs) and if so, whether this had a negative impact on the Project's overall effectiveness.

I began to think about the expectations of VHVs from both the Project and rural communities. VHVs were expected to be the front-line health care providers in isolated settings with little in the way of back up or support from other health care services. They were expected to deal with the wide range of health issues faced by rural people as well as address the very high, rapidly escalating, maternal death and HIV rates. In the light of the level of responsibility placed on volunteers; the cultural context VHVs lived and provided services in, along with overwhelming requests from VHVs for more support, I began to question the sustainability of the VHV system.

These questions remained unanswered for me as I left PNG in 2006 and grew as I reflected on the experience and research process. It is from these questions that my central research question grew. 


\subsection{Central Research Question}

The central research question that I have sought to answer with this research is: 'Is the ESWCHP health infrastructure, with its heavy reliance on VHVs, sustainable, and effective in delivering primary health care to rural people in the East Sepik Province?

\subsection{Aims/Objectives}

I have sought to answer this central research question by through the following aims/objectives:

a. Drawing on Kabeer's Social Relations Approach, explore the social and gender relations embedded within the institutional arrangements of the ESWCHP

b. Identify issues of gender inequality and how these affect sustainability and effectiveness of rural primary health care provision

c. Utilising threads of Sen's Capability Approach, and participatory development provide recommendations for reconsidering issues of sustainability and effectiveness and to improve health care delivery to rural East Sepik people.

An important additional aim was to develop a practical method from Kabeer's Social Relations Approach, and to use this to gain new insights that had not become evident through the 2006 research process.

\subsection{Background to the East Sepik Women and Children's Health Project, PNG}

Save the Children's ESWCHP was designed to 'put in place an integrated, effective and sustainable quality basic family health care delivery system in rural East Sepik' (SCiPNG, unpublished, pp1).

The ESWCHP started in mid 1994, growing out of three initiatives dating back to the early 1980s. The first of these was the founding of a Meresin Meri scheme 1983-1986 by a British volunteer working with the East Sepik Council of Women (ESCOW). It aimed to provide a basic health service, mainly first aid and advisory, to remote areas in the East Sepik Province. The second was a Community Based Distributors (CBD) scheme for family planning, established by the United Nations Fund for Population Activities (UNFPA) working with ESCOW and the Provincial Department of Health (PDoH). The third was a primary health care project aimed at creating village health development committees that used participatory approaches to promote a self-help health care ethic in 
the rural communities. This was established by PDoH but lapsed due to lack of resources and issues of dominance by male health workers (Underhill-Sem \& Peutalo, 2006).

All three initiatives struggled as a result of management issues and difficulties in maintaining strong linkages within organizations between Wewak and the districts with the lack of a uniform volunteerism ethic. In 1993 ESCOW asked Save the Children to partner with them in an effort to revive the Meresin Meri program. Not long after this partnership approach, the UNFPA abandoned their CBD project, which allowed Save the Children to take over the effort. These events lead to the formation of the ESWCHP. That same year, the ESWCHP introduced Village Birth Attendants (VBAs). In the period from about 1995 onwards the collaboration between PDOH and Church Health Services (CHS) strengthened while the linkage with ESCOW weakened (Save the Children, unpublished; Underhill-Sem \& Peutalo, 2006).

The ESWCHP began as an initiative of a women's group East Sepik Council of Women, with the early design bringing together the goals of women's empowerment and health improvement. However, over time the ESWCHP has moved away from gender equality and empowerment of women as one of its central goals (Underhill-Sem and Peutalo, 2006). The current goal of the ESWCHP is 'to improve basic family health within East Sepik rural communities'. To achieve this goal, the Project objective is 'to put in place an integrated, effective and sustainable quality basic health care system in rural East Sepik (Save the Children, unpublished ${ }^{1}$, pp 2)'. Project success is measured against 2 key outcomes:

- Changes in key family health, especially maternal and child health indicators;

- Changes in family attitudes (and practices) toward family planning and health prevention; (Save the Children, unpublished, pp 2);

delivered through the following Project components:

- Institutional capacity building (buildings, vehicles, policy development, management systems and staff);

- Human resource development (strengthening management skill base, training);

- Curative and preventative health services (strengthening malaria controls, immunisation, providing clean water, birthing kits, improving family planning, expanding the VHV network and services) ${ }^{2}$; and

\footnotetext{
${ }^{1}$ ESWCHP Summary Version of the Phase II Project Implementation Document

2 The PDoH Area Medical Supply office manages the purchase, storage and supply of medicines to the ESWCHP Office (who continue to deliver medical supplies to some VHVs); and to the CHS for their clinics and to the VHVs they support. Ensuring the required supplies are available to CHS clinics and VHVs is is a critical aspect of ESWCHP coordination activities.
} 
- Community self reliance in health care (Village Health Development committees and strengthening the educational component of VHV services).

The ESWCHP is one of a number of projects managed by Save the Children in PNG (SCiPNG) as part of its PNG Programme. SCiPNG receives NZAID funding via Save the Children NZ (SCNZ), who act as liaison between SCiPNG and NZAID.

The ESWCHP works in partnership with the Catholic Church Health Services based in Wewak, the Provisional Division of Health, Boram Hospital and the South Seas Evangelical Church based in Brugam. The ESWCHP main office is in Wewak, from which ESWCHP staff travel from Wewak to rural CHS offices and clinics and to villages to support VHVs. The organisational structure of the ESWCHP is shown on Figure 1 below.

Figure 1: ESWCHP as Defined in Project Documentation

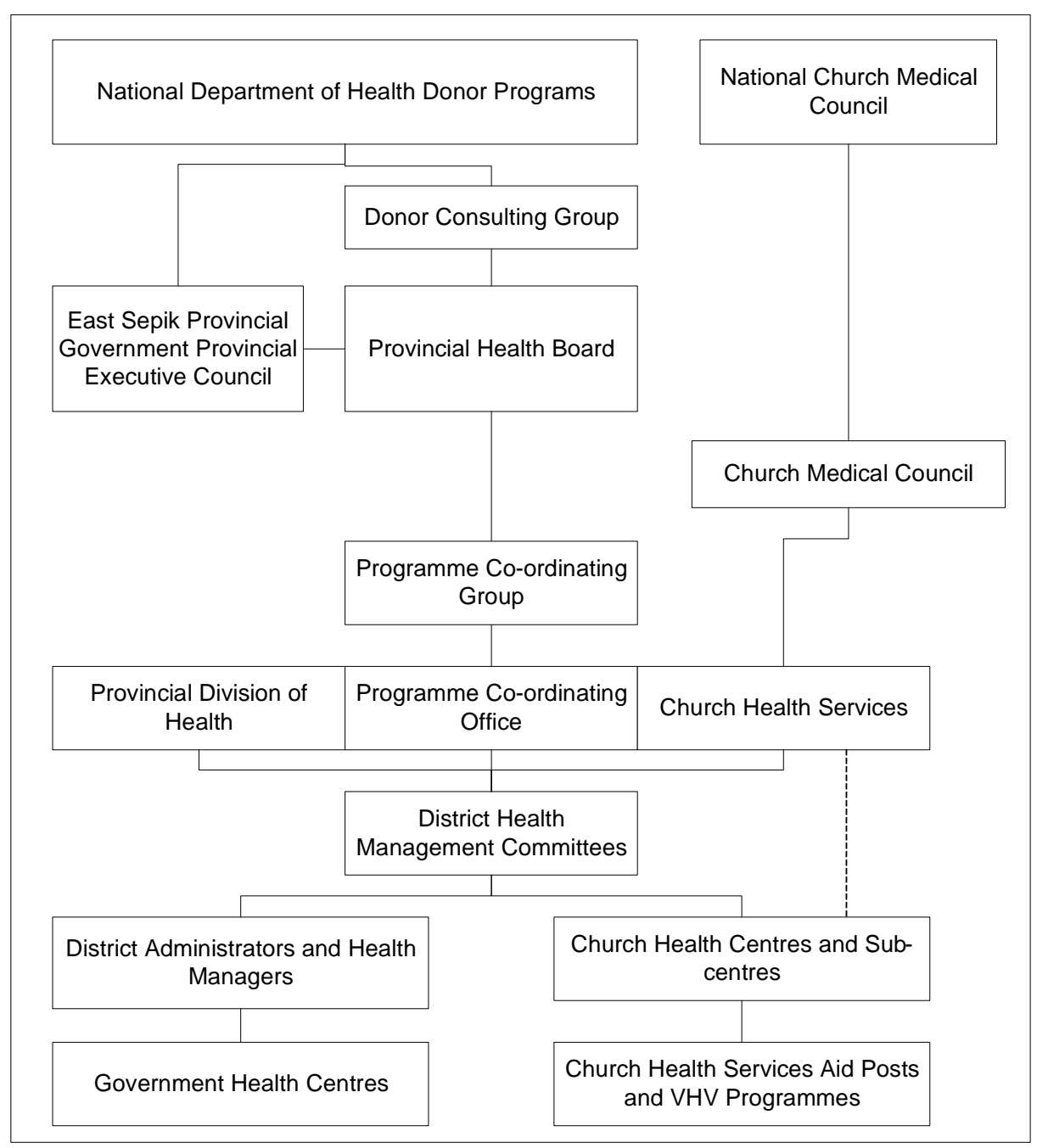

Reference: ESWCHP Summary Version of the Project Implementation Document, pp 14

The ESWCHP is described by NZAID, SCNZ and other development agencies as a programme that works, and is so successful, that it may be extended elsewhere. The 
ESWCHP has gained support from high profile NZ politicians and officials, and significant government funding through NZAID (Save the Children, 2004). The ESWCHP has received and continues to receive significant funding from NZAID as one of its key development interventions in the Pacific (Save the Children; NZAID, www.nzaid.govt.nz).

The status of the VHV (as volunteer) is enshrined in government policy, Project documentation and Project organisational structure and hierarchy. Government policy expects that these women will be paid 'in-kind' for their services through an agreement between the Project and the village elders (generally men) who continue to oversee their work in the villages. The 2006 research showed that if the VHV's work was not perceived to be of value to the elders, or the elders were opposed to it (as sometimes in the case of family planning), 'in-kind' payments were often withheld. Whilst volunteering, these women also continue to conduct their usual responsibilities as women: rearing their children, growing food, keeping house, caring for members of the extended family, going to market etc.

Volunteers are known by various terms (VBA, Meresin Meri and Meresin Man, VHV and VHW) but share volunteer status in that the position is unpaid and supported by the communities the volunteer serves. Underhill-Sem \& Peutalo (2006) argue that while the NDoH National Standards for Volunteers describes the activities undertaken by VHVs are those of the 'voluntia', the naming of grassroots health care providers as voluntia highlights the shift of the ESWCHP from 'well-understood gendered PNG grassroots health care providers to unfamiliar ungendered, community people working for nothing...in effect making the women invisible' (pp16). Instead they propose that the Project return to using Meresin Man and Meresin Meri to more appropriately identify the status and responsibility these roles have in improving overall grassroots health care. I have chosen to use the term Village Health Volunteer (VHV) or the pidgin version 'voluntia' throughout this thesis as this was the term used by Project staff and because it is the sustainability of this voluntia status that I explore in this thesis.

Approximately 80 percent of the East Sepik Province is rural, much of it remote, without road access (i.e. access by plane, boat or on foot). In these areas, the only access to health care for rural people is from VHVs, often without nearby supports in the form of health facilities, or hospitals. Without these VHVs, there would be no ESWCHP, and yet their participation in Project design and activities (such as evaluation) is not obvious. 


\subsection{Papua New Guinea Context}

PNG is located approximately 30km north of the tip of Cape York, Queensland Australia, and comprises the eastern part of the island of New Guinea (abutting the Indonesian province of Irian Jaya to the west) and a series of islands including Manus, New Britain, New Ireland and Bougainville (see Figure 2). PNG is prone to numerous chronic natural hazards as well as the occasional acute disaster situation, on a scale greater than any of its Pacific neighbours. PNG is situated on the boundary between the Pacific and Australian tectonic plates resulting in eight active volcanoes and regular earthquakes, tsunamis and land slides each year (WHO, 2008).

With over 800 languages and approximately 5.3 million people, PNG is one of the world's most diverse countries on the planet - geographically, biologically, linguistically and culturally. Parts of PNG are so isolated by either topographically forbidding terrain (mountains or rivers) or dense forests that some indigenous groups have been able to existed for millennia with little contact with outsiders. Up to 85 percent of the country's population live in remote rural areas relying on subsistence or small-cash crop farming to sustain their livelihoods. Approximately three percent of the roads are paved making many villages accessible only by foot or by river canoe, and travel between areas difficult and expensive. Almost 97 percent of all land in PNG is under customary ownership; either to individuals or through clan ownership arrangements governed by land tenure systems (GoPNG \& UNiPNG, 2004).

PNG has three official languages; English, Pidgin (Tok Pisin) and Motu. Many rural people speak their own dialect along with one of these official languages (Bolger et al, 2005). The average life expectancy in PNG is 54 years and adult literacy is estimated at approximately 52 percent. Social indicators are comparatively low (ranked 133 out of 175 countries in the UNDP Index) and the level of poverty is increasing (GoPNG \& UNiPNG, 2004).

PNG's current population growth rate is currently at least 2.3 percent, resulting in a doubling of the population every 30 years. With approximately 52 percent of the population being female, and 40 percent of the population under 15 , this creates a heavy demand on the young female population who bear the largest share of workload associated with rearing children and caring for the extended family (Australian Department of Foreign Affairs and Trade website; GoPNG \& UNiPNG, 2004; Bolger et al, 2005; WHO, 2008). 
Figure 2: Map of Papua New Guinea

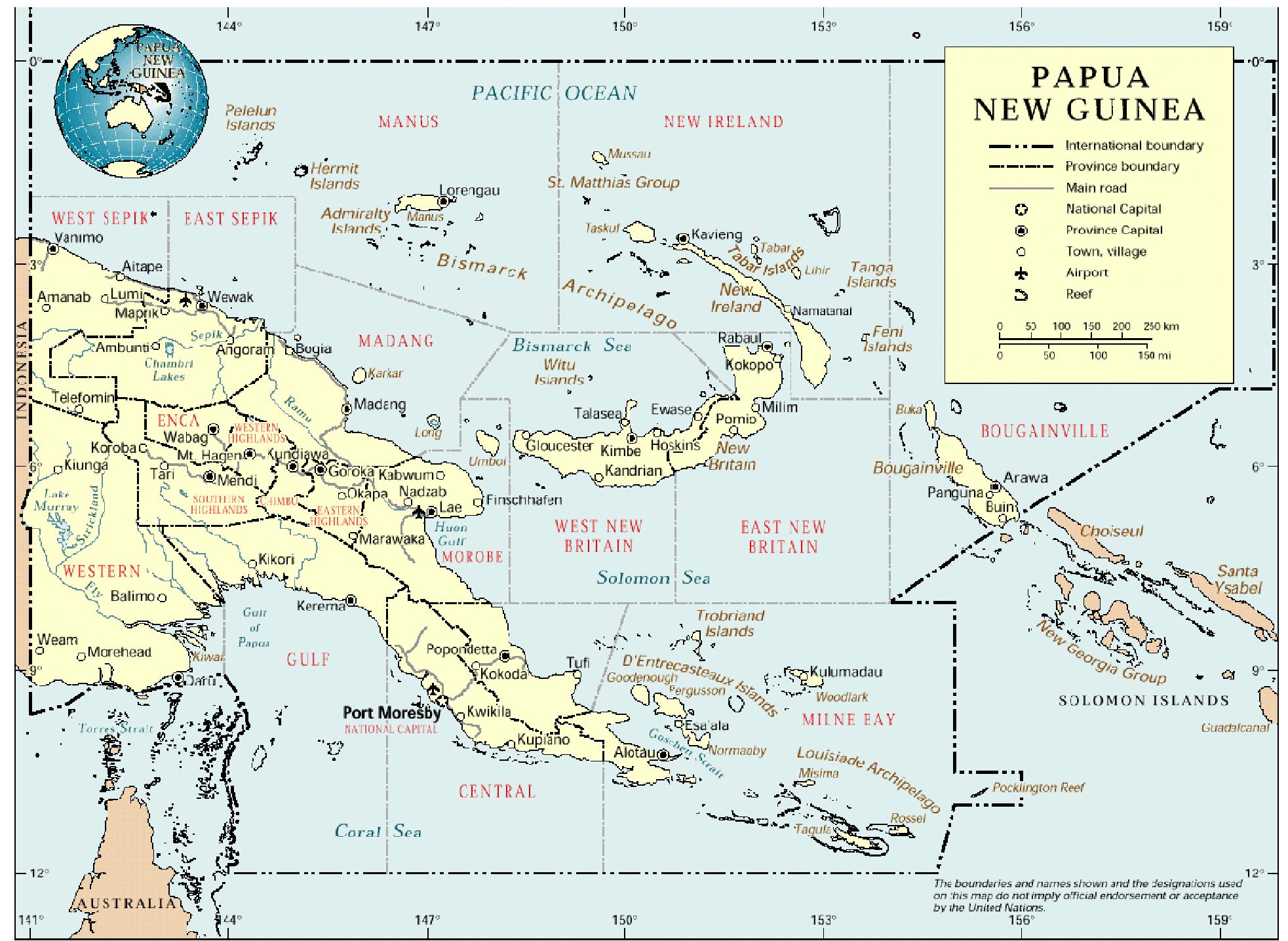

http://www.ida.liu.se/ g-robek/png-PNG UN.gif (accessed June 2009) 



\section{Religion and Traditional Spiritual Beliefs}

Churches play a significant role in PNG and in the East Sepik Province. In the 2000 National Consensus, 96 percent of Papua New Guineans identified themselves as Christian (Gibbs, 2002). There are four main groupings of churches in PNG. The Papua New Guinea Council of Churches includes Lutheran, Catholic, United and Anglican Churches and others. The Evangelical Alliance includes the Apostolic, Baptist, Nazarene, Salvation Army and a growing number of Pentecostal churches. The Seventh Day Adventists provide for a group all of themselves (Gibbs, 2002).

Churches in the 1980s introduced education, provided health and other services that now either continue to be provided by the Church or have been taken over by government institutions (Fountain et al, 2004). Many churches have built up expertise in the East Sepik and provide health services. Within the ESWCHP two churches provide the majority of health services - the Catholic Church and the South Seas Evangelical Church.

Alongside Christian beliefs there continues to be widespread belief in magic, dreams, visions, rituals and spells, blessings and misfortunes; considered to be quite compatible with Christianity (Thomas, 2002). Traditional beliefs concerning physical and mental illness are commonly centred on sorcery, witchcraft, spirit possession, violation of social norms and taboos (Koka, Deanne \& Lambert, 2004, pp29-30). Spirits and supernatural agents are believed to cause illness when an individual or a group has violated social taboos or norms or have failed to fulfil culturally expected obligations (ibid). Alternatively, illness caused by sorcery and witchcraft is often related to frustrations, jealousy, anger and revenge or payback (ibid). Chronic illness and death are almost always attributed to sorcery (ibid), which has considerable significance for health workers in PNG, particularly those working with HIV/AIDs.

Stories of witchcraft, sorcery and torture, along with people going missing are not uncommon. For example, Peter S. Kinjap ${ }^{3}$ (Jan 3 2008) of The National, Papua New Guinea media website describes his experience of witnessing the torture of a young women in a settlement near Mount Hagen, because it was thought she was a witch. The $\mathrm{Age}^{4}$ reports that PNG's Constitutional Review and Law Reform Commission is drafting tougher laws to combat the ongoing incidence of sorcery-related murders across the country, through which at least 50 people died in 2008.

\footnotetext{
${ }^{3}$ http://www.religionnewsblog.com/20258/witchcraft-11

4 Jan 12, 2009, http://news.theage.com.au/world/png-to-toughen-laws-on-sorcery-killings-20090112-
} 7f2y.html 
Sorcery is commonly used to both explain the cause of illness and as a form of treatment. Traditional treatment involves four main types of healing processes: medicines, spells, rituals and counselling. The type of treatment applied is dependant on varied beliefs regarding the cause of the illness. Locals can see western treatment as a cure for the symptoms of an illness, with traditional treatments seen as a cure for the cause (Koka, Deanne \& Lambert, 2004, pp29-30).

Religious and traditional spiritual beliefs may have serious implications for VHVs and others involved in providing primary health services in remote rural locations. In 1991, Margaret Street presented a paper at a VBA workshop in Goroka, in the Highlands of PNG. In her paper she summarised efforts across active birth attendant projects in PNG. Of interest were the local beliefs surrounding maternal blood of childbirth and causes of maternal death. Women attending childbirth in some provinces were then not able to cook for men for a period of time, as the blood was seen as tabu with the potential to harm health. This was inter-related to compensation or payback custom. She states that 'in former times if a birth helper was affected by blood, the father of the newborn killed a pig and gave some of the meat to the helper as compensation for her afflictions. It appears part of the fear of blood is fear of not being adequately compensated for the toil, risk and responsibility of birth attendance. At present, some women work for community respect, others for gifts of food and some for cash payment of up to K5. Compensation issues are resolved by the community (Street, 1991, pp2)'.

Smith (1994) wrote of his experience in living with local people on Kairuru Island ${ }^{5}$ just off the East Sepik coast. In his fascinating book Hard Times on Kairuru Island, Smith describes the importance of understanding history, spiritual beliefs and sorcery, and even things such as time from a local perspective.

My experience as a nurse and midwife is that understanding the belief system (whatever it may be) and how best to work alongside it is a critical aspect of providing intimate health services (such as birthing attendance) in a way that promotes healthy outcomes for mother and baby. During my visit in 2006 I expected to see or hear evidence of the potential conflict between western birthing techniques and traditional beliefs. With the help of Yvonne (who translated where I couldn't understand the Tok Pisin), I was able to examine the ESWCHP training materials for VHVs. These did not include any guidance for

\footnotetext{
${ }^{5}$ Kairuru Island was a place I went to, to rest and recuperate on occasion during my 6-weeks in the East Sepik. I was cared for by Graham Lynch and his local family and friends; and have very fond memories of my times there.
} 
managing situations where traditional spiritual or cultural beliefs (such as those described by Street (1991) and Smith (1994) above interfaced or collided with the western approaches that VHVs were trained to provide.

At no time during my visit did I hear this topic discussed by ESWCHP staff, VHV trainers and coordinators or by VHVs themselves. This suggested to me that either it was too sensitive a topic to be discussed openly in my presence, or it was too sensitive to be openly discussed, or, VHVs were expected to manage these situations in their own way as best they could.

Custom arose in 2 responses to the 2006 research. One was from a woman Rural Health Manager, who responded 'only few believe in custom, otherwise awareness is still going on for clean and a safe delivery' (Heather, 2006, ppRural Health Managers1) to a question as to whether obstetric care had improved. The second was from a male villager when asked 'which aspects of health provision have improved' responded that 'mothers are not trusting and believing the work of the VHV' (Heather, 2006, ppRural People2).

There may have been other more oblique references to custom that I missed in the data. However, there is no doubt in my mind that situations where traditional beliefs collide with western approaches occur, probably regularly, and that VHVs manage these as best they can. If training and support for ESWCHP VHVs in this critical area is absent, then this is of concern and should be addressed by the ESWCHP.

\section{Gender}

Women's rights discussions arose in PNG in 1975 when sovereignty was attained. A gender equality provision was included in the constitution guaranteeing men and women equal treatment before the law (Kidu, 1997; Garap, 1999; Dickson-Waiko, 2006). While PNG has in place a well-developed legal and policy framework on women and gender issues, tensions between human rights and customary law and gender continue and the status of women remains low (Garap 1999, Loveridge \& Kotovojs, 2004; Aisi, 2008). Women in PNG are amongst the most disadvantaged people in their country; disadvantaged in relation to men in that they have: 'lower life expectancy, poorer health, lower rates of functional literacy, lower enrolment rates in primary education, little visibility in formal political participation, and a legal system that favours cultural over women's rights' (Underhill-Sem \& Puatalo 2006 pp 7).

Women in PNG are born into a difficult and demanding largely male dominated and violent society. They learn to work, produce and manage in an extremely tough physical 
and stressful social environment (Garap, 1999). Women's workloads are increasing as a result of farming intensification, the contribution of women to cash cropping, male outmigration, an increasing number of children in schools unable to help and larger family sizes due to higher survival rates (Kidu, 1997). Injuries or disabilities resulting from violence compound the difficult situation rural women find themselves in (Garap, 1999).

Inequality in PNG households, including significant disparity in the equality of household members' workload is common. Women tend to undertake greater workloads than men as they have multiple tasks of caring for children, maintaining gardens and looking after animals. In addition, women's responsibilities for the wider community (through projects such as the ESWCHP) and for income generation and children's education have expanded and continue to expand thereby further increasing the workload of women (Loveridge \& Kotovojs, 2004).

Gender relationships are complex often involving kinship links, generational layering, and infused with power and financial manoeuvrings and often violence. Underneath these complex gender relations men work to appropriate women's reproductive and productive power in such a way as to render women, either as wives, sisters or kinsfolk, either dependent on or indebted to them, be they husbands or kinsmen (Underhill-Sem \& Puatalo 2006).

In PNG high levels of violence, heavy workloads and discrimination in educational and employment settings impact women's lives. Women are considered by men to be inferior and therefore men's interests take precedence over the interests of women and children (Loveridge \& Kotvojs 2004). The most common explanation given for why women in PNG are not recognised as equals in the society is 'cultural factors', or the term more commonly used in PNG, 'custom' or 'pasin bilong mipela' (Korare, 2002, pp 39). These beliefs are deeply entrenched in many social contexts and institutions in PNG.

Many women accept this subordinate role as inevitable but there is a growing number of women showing a greater level of interest in receiving training, particularly in literacy, health, agriculture, marketing and the management of micro-enterprises (Heather, 2006; Garap 1999) and who are lobbying for change through women's groups, church activities and a greater involvement in politics (Korare, 2002).

Carol Kidu, the only female member of parliament in PNG suggested that one of the most significant catalysts for change are the women themselves who have overcome gender stereotypes and negative cultural attitudes to develop their talents and contribute to the 
community in ways that were traditionally reserved for men. Women who have made this step become examples to other women who want to cross that barrier. She argues that there is a significant role that men can play as fathers, husbands and mentors, and that by their encouragement, support and guidance they empower capable women to venture into fields of endeavour and into decision-making roles (Kidu 1997).

'As the traffic slowed, I glanced at the small commotion nearby - an armed policeman was chasing a lady selling betel nut. As he pushed her, her betel nut scattered and some bystanders grabbed them. The rest were confiscated by the policeman. She shouted in defiance but to no effect. The traffic moved on and so did I - but my heart stayed with the woman trapped in a frustrating cycle that denied her access to her potential.'

Lady Carol Kidu, MP, PNG

Excerpt from a paper presented at 1997 Waigani Seminar

Labour markets around the world have a hierarchical structure in which sectors; occupations and activities are segregated by gender (World Bank, 2001). These inequalities between women and men are 'perpetuated largely by taboos and prejudices in the labour market' (Kabeer, 2003, pp 28). In patriarchal societies such as PNG, this means that organisations culture; rules and outcomes are modelled on male values and attitudes. They are often inimical to women, fail to recognise and reward their contributions to the organisation, and therefore recreate and reproduce the gender hierarchies and inequalities dominant in the wider community (March et al, 1999).

While PNG traditions or customs still dictate much of people's lives, there is little doubt that women are viewed and treated differently from their female ancestors. Cultural notions have been greatly distorted to justify or defer consideration of a wide range of issues relating to gender violence and abuse. Wife beating and other forms of abuse are linked to women's high morbidity and mortality rates and to the death or disabling of unborn children. The growing practice of modern-day polygamy is dysfunctional and violent with an increase of violent assaults between wives causing serious injury, death or imprisonment (Garap, 1999).

Women in PNG are known to be subject to intolerable levels of violence (Brouwer et al, 1998; Garap, 1999; Kidu, 2000; Macintyre, 2000; Korare, 2002; Loveridge \& Kotvojs, 2004; Bott et al, 2005). Violence against women is a significant problem at all levels of society, with high rates of violent crime, ongoing tribal disputes in rural areas and 
widespread domestic and sexual violence against women and children. Many women suffer physical injuries that result in permanent damage and disability, including loss of sight, loss of hearing and harm to reproductive organs (Loveridge \& Kotovojs, 2004). Research conducted by Ellseberg \& Heise et $\mathrm{al}^{6}$ (cited in Bott et al, 2005) found that 67 percent of women in PNG had been subject to physical assault by an intimate male partner.

In many areas of rural PNG, intolerable insecurity affects the every day lives of women. Their freedom of movement is restricted for fear of violence and/or rape, they are not safe in their own homes and they do not have confidence in the law or legal system when they are victims of violent crime (Brower et al, 1998). Violence committed toward women includes not only violence from an intimate partner, but also managers hitting subordinate staff, rape and sexual assault, sexual harassment and discrimination (Garap, 1999).

Women in PNG have limited access to political power and few have been successful in election campaigns. At the national level only four women have been elected to Parliament since PNG achieved independence in 1975. This power imbalance is commonly reflected at the grassroots level where men typically hold public political power. Women have minimal opportunity to participate directly in community decision making processes and at times suffer threats by both men and women if they successfully enter into the male domain (Loveridge \& Kotvojs 2004). This context has significant implications for primary health care delivery by women volunteers in rural PNG.

\section{Health in Papua New Guinea}

Papua New Guinea's population health status is the lowest in the Pacific region $\left(\mathrm{WHO}^{7}\right)$. Providing health care in such a diverse and topographically challenging country is problematic and the health challenges facing PNG are enormous. Although up to 87 percent of the population live rurally, in recent years, rural health services have deteriorated significantly. The poor road infrastructure and rugged terrain pose formidable challenges to the effective delivery of health services and access to widely scattered rural communities is often difficult, slow and expensive $\left(\mathrm{WHO}^{8}\right)$. Skilled medical and other health practitioners are insufficient and under resourced, with the shortage and skewed distribution of human resources now a critical issues of national concern (Bolger et al, 2005).

\footnotetext{
${ }^{6}$ Physical Assault on Women by an intimate male partner, selected population-based studies, 1982-2003, study cited in Bott et al, 2005.

${ }^{7} \mathrm{http}: / /$ www.wpro.who.int/NR/rdonlyres/F2B227BB-5514-4760-8910-

426A1F43B1F3/0/PAPUANEWGUINEA.pdf

${ }^{8}$ http://www.wpro.who.int/NR/rdonlyres/F2B227BB-5514-4760-8910-

426A1F43B1F3/0/PAPUANEWGUINEA.pdf
} 
PNG's national health system relies on one national hospital, 18 provincial hospitals, 500 health centres, 45 urban clinics and a network of 2400 aid posts (approximately half of which were closed in 2003 due to lack of staff and supplies) (ibid, pp3). The numbers of mobile maternal and child health patrols and village aid posts, which used to be a feature of health services, has declined in the past 20 years. The reasons for this include inadequate resourcing, difficulty accessing funds through complex centralised channels, law and order issues in some areas, deteriorating roading in others, and lack of supervision and support to community health workers (Cant et al, 2009, pp 7) such as VHVs.

The National Department of Health $(\mathrm{NDoH})$ is responsible for the management of the hospitals while provincial and local governments are responsible for all other services (rural health centres and sub-centres, rural hospitals and aid posts) with approximately half of the rural health centres and sub-centres, operated by Church Health Services (CHS).

The CHS also provide training for many of PNG's health workers including nurses and community and VHVs (Bolger et al, 2005; Australian DFAT, 2008).

In the 1970's the World Health Organisation (WHO) promoted training of Traditional Birth Attendants (TBA) to improve rural access to skilled birth attendants. However, in 1999, WHO concluded that there was no evidence that the training of TBAs had led to reductions in maternal deaths. However, efforts in Pakistan in training TBAs and integrating them into an improved health system showed that the TBA system was achievable and effective in reducing perinatal mortality with a plausible reduction in maternal mortality (Cant et al, 2009, pp 7).

In PNG, a qualitative study of village birth attendants (or VHVs) undertaken in 2001 found that while some VHVs were motivated to help women in their community some stopped assisting because of family or financial pressures or lack of support. Difficulties encountered by the women included that they were ill equipped to deal with obstetric complications. An additional issue was the effectiveness of these volunteers, with consistency and accountability for tasks without regular supervision lacking (ibid).

There is some evidence that the VHV model of basic health care can increase community participation, health seeking and knowledge and thus have an important role. In some countries they have been shown to reduce neonatal mortality, and in some settings they may improve maternal outcomes. VHVs within health infrastructure systems compliment the health post or health centre model that form part of a formal district health network, but cannot replace it. To advance rural population health in PNG, strengthening the 
community health services within the government or church-run health system is with properly trained nurses and community workers is crucial (Cant et al, 2009, pp7,8).

Whilst questions about the effectiveness of VHVs in addressing and improving health statistics remain, major challenges to rural village health continue to escalate. Widespread lack of awareness at the rural village level regarding risk-related and health-promoting behaviour continues, with little involvement by local communities in health-promoting activities $\left(\mathrm{WHO}^{9}\right)$. Key risks include behaviour and environments that increase risks of communicable disease; risks of non-communicable disease created by chewing betel and smoking and risks associated with unsafe sexual behaviour (GoPNG \& UNiPNG, 2004; WHO, 2008). Communicable diseases, including malaria and tuberculosis, remain the major cause of morbidity and mortality in all age groups $\left(\mathrm{WHO}^{10}\right)$.

The maternal mortality rate is a key indicator of the state of national health services. Maternal mortality rates have doubled over the last decade placing PNG amongst the worst performing countries in the world for maternal deaths, and highlighting the poor state of the health service (ibid). Recent projected statistics showed 700-900 maternal deaths per 100,000 live births, compared to Australian rates of around 8 per 100,000 live births $\left(\right.$ NZAID $^{11}$; Mola, 2009). About 53 percent of mothers receive delivery assistance from health professions: nine percent from doctors, 40 percent from nurses and four percent from midwives (Cant et al, 2009, pp4). Child morbidity and mortality are high $\left(\mathrm{WHO}^{3}\right)$, and antenatal clinic attendance and supervised delivery statistics need to be dramatically improved to halt the downward trend in child mortality in PNG.

The statistics for HIV in PNG vary wildly depending on who is providing them and surveillance is poor. However, recent statistics thought to be among the most reliable of the statistics available show that PNG has the highest rates of HIV/AIDS in the Pacific and has a generalized epidemic of HIV/AIDS. Table 1 shows the massive scale of the epidemic in PNG compared to the rest of the Pacific.

Table 1: Cumulative Reported HIV Cases by Sex and Region

\begin{tabular}{|l|c|c|c|}
\hline Region & $\begin{array}{l}\text { Cumulative cases } \\
\text { per } \mathbf{1 0 0 , 0 0 0}\end{array}$ & $\begin{array}{l}\text { Male Reported } \\
\text { Cases }\end{array}$ & $\begin{array}{l}\text { Female Reported } \\
\text { Cases }\end{array}$ \\
\hline Papua New Guinea & 437.4 & 12,432 & 14,598 \\
\hline Micronesia & 64.0 & 254 & 84 \\
\hline
\end{tabular}

\footnotetext{
${ }^{9}$ http://www.wpro.who.int/NR/rdonlyres/F2B227BB-5514-4760-8910426A1F43B1F3/0/PAPUANEWGUINEA.pdf

${ }^{10} \mathrm{http}: / / \mathrm{www}$.who.int/countryfocus/cooperation_strategy/ccsbrief_png_en.pdf ${ }^{11}$ NZAID Health Strategy 2008-2013. 


\begin{tabular}{|l|c|c|c|}
\hline Polynesia & 54.3 & 250 & 105 \\
\hline $\begin{array}{l}\text { Melanesia (excluding } \\
\text { PNG) }\end{array}$ & 34.6 & 414 & 222 \\
\hline
\end{tabular}

Source: Secretariat of the Pacific Community, Reporting Period: to Dec 2008, http://www.spc.int/hiv/index2.php?option=com_docman\&task=doc_view\&gid=249\&Itemid=148 (accessed 1 February, 2009)

The number of people with HIV infections is rising at an exponential rate along with often closely associated illnesses of TB and pneumonia. These rates are projected to continue to grow and are likely to result in correspondingly high rates of ill health, deaths and increased poverty. Urgent action is required to effectively address underpinning issues of gender inequality related to heterosexual HIV transmission in PNG (Schoeffel Meleisea, 2009).

The Millennium Development Goals (MDG) Progress Report for PNG 2004 states that overall progress toward achieving MDG targets has been 'disappointing' and the state of the supporting environment toward achieving solid progress toward the targets (along with monitoring and evaluation capacity for each of the MDGs) ranges from 'Very weak' at worst to at best 'Fair' (GoPNG \& UNiPNG, 2004 pp 41-42). Key MDGs that depend on primary health care delivery through programmes such as the ESWCHP and VHVs specifically include: Goal 4: Reduce child mortality; Goal 5: Improve maternal health and Goal 6: Combat HIV/AIDS, malaria and other diseases. Efforts to reduce child mortality (Goals 4, 5 and 6) are supported by the education and empowerment of women (Sen 1999), Goals 2 and 3. The eight MDGs are shown in Table 2 along with a comment summarising the status of progress toward meeting MDGs 3-6. A complete list of the MDGs, Targets and Indicators is provided in Appendix D.

Table 2 The Millennium Development Goals and Progress

\begin{tabular}{|c|c|}
\hline $\begin{array}{l}\text { The Millennium Development } \\
\text { Goals }\end{array}$ & Progress \\
\hline $\begin{array}{l}\text { Goal } 1 \text { - Eradicate extreme poverty } \\
\text { and hunger }\end{array}$ & \\
\hline $\begin{array}{l}\text { Goal } 2 \text { - Achieve universal primary } \\
\text { education }\end{array}$ & $\begin{array}{l}\text { Goal 2: Literacy rates in PNG at } 61.7 \text { percent with the } \\
\text { East Sepik Province above the national average at } 66.9 \\
\text { percent (GoPNG \& UNiPNG, 2004, pp 14) }\end{array}$ \\
\hline
\end{tabular}




\begin{tabular}{|l|l|}
\hline $\begin{array}{l}\text { Goal 3 - Promote gender equality } \\
\text { and empower women }\end{array}$ & $\begin{array}{l}\text { Goal 3: Female youth literacy projected rates just above } \\
\text { 60percent, compared with male youth literacy projected } \\
\text { rates of just under 65percent (GoPNG \& UNiPNG, 2004 pp } \\
18)\end{array}$ \\
\hline Goal 4 - Reduce child mortality & $\begin{array}{l}\text { Goal 4: PNG remains the worst of the Pacific Island } \\
\text { nations with infant mortality at 64 per 1000 live births } \\
\text { with the East Sepik Province far worse than the national } \\
\text { average (GoPNG \& UNiPNG, 2004 pp22) }\end{array}$ \\
\hline Goal 5 - Improve maternal health & $\begin{array}{l}\text { Goal 5: 700-900, per 100,000 live births - a very high } \\
\text { maternal mortality rate by Pacific standards }\end{array}$ \\
(Mola, 2009)
\end{tabular}

The health system is funded through a range of national and provincial taxation programmes. In addition key funding agencies including NZAID (the lead donor), AusAid and the Asian Development Bank (ADB) work in cooperation with the Government of Papua New Guinea (GoPNG) to advance a coordinated health sector wide approach.

Prioritising the allocation of these scarce funds is problematic with the large majority spent on health infrastructure and salaries rather than front-line service delivery. For example, in 2002, 82 percent of the health budget was spent on salaries, facilities and equipment and basic supplies leaving only 18 percent of the budget for health treatments. By 2007, it is anticipated that only one percent of the health expenditure predicted to be spent directly on health treatments by 2007 (Bolger et al, 2005).

Despite significant investment key health indicators including immunisation, mortality from malaria, malnutrition and the availability of medical supplies continue to decline. Targeting funding to address these key health indicators is further compromised by difficulties obtaining accurate and timely health statistical information. Funding that is

\footnotetext{
${ }^{12}$ These are projected rates as data are not readily available beyond 2000 and estimates are based on female and infant mortality rates

${ }^{13} \mathrm{http}: / /$ www.spc.int/hiv/index2.php?option=com_docman\&task=doc_view\&gid=249\&Itemid=148 February $2010 \quad$ Page 30 of $176 \quad$ Ruth Heather
} 
insufficient and poorly targeted to meet the escalating burden of disease is stretched even further as the country struggles to service the health demands of a population that is growing at a much faster rate than the country's earnings (national GDP).

\subsection{Overview of the 2006 Research}

SCNZ and SCiPNG commissioned the 2006 research jointly in preparation for a formal NZAID mid term review of the ESWCHP (Save the Children, unpublished). I was an ideal candidate for the review as not only was I studying toward the Masters of Development and keen to volunteer, I was also a qualified nurse and midwife who had gone on to specialise in project management and monitoring and evaluation in health and social service settings.

The 2006 research aimed to understand the perceived impact of the ESWCHP, from the perspective of people who received and/or provided rural health services. The research also aimed to glean any insights or ideas from participants as to how the Project could be improved.

The research was organised by Leonard Chan, then Programme Manager Pacific, SCNZ, and overseen in Papua New Guinea by Bill Humphrey, then Programme Manager, ESWCHP, SCiPNG. The research team comprised of me as research lead, Yvonne Tawai, and Ronah Kami. Yvonne was well known and held considerable 'mana' across the East Sepik. Yvonne had played a pivotal role in Project set up and been involved in the Project for over 20 years (including assisting other researchers such as myself). Yvonne was unusual in the patriarchal East Sepik in that she was from one of the matriarchal tribes in New Ireland. She was particularly helpful in helping me to stay safe, to understand the social relations and gender dynamics at play, and to identify how best to work with women in the heavily male dominated culture of the East Sepik. Ronah Kami was the Project Database Coordinator responsible for Project health data, and hailed from a small village about two hours drive from Wewak. Ronah was not so well known across the community, and appeared to be more linked in to the ESWCHP hierarchy and organisational structure. None of the team to my knowledge (including myself) had undertaken any specific training in research practice. Both women were fluent in their own languages, Tok Pisin and English. I had a basic to moderate ability to understand and speak Tok Pisin.

\section{Research Approach Used in 2006}

An Evaluation Framework Workshop was conducted in June 2006 involving Project staff and stakeholder agencies (church health leaders, provincial government representatives) to 
prepare for the 2006 research. At the workshop the key foci of the research was agreed; the key questions were developed (a set of 20) and linked to log-frame output indicators; and respondent groups identified. The questions and respondent groups are listed in Appendix A.

Once I arrived in PNG and had an initial briefing from the Programme Manager, the research team finalised the questions and developed questionnaires with more detailed questions to use to lead focus groups and interviews. The questionnaires for village people and VHVs were translated into Tok Pisin by Yvonne Tawai. The Programme Manager selected four geographical areas for us to visit- Albinama, Kunjigini, Kambot and Angoram as this covered the various church health provider areas. A map including the areas visited is shown on Figure 3 below, and a detailed map of the East Sepik Province is provided in Appendix B.

Figure 3: Map of the East Sepik Province and the Six Areas Visited

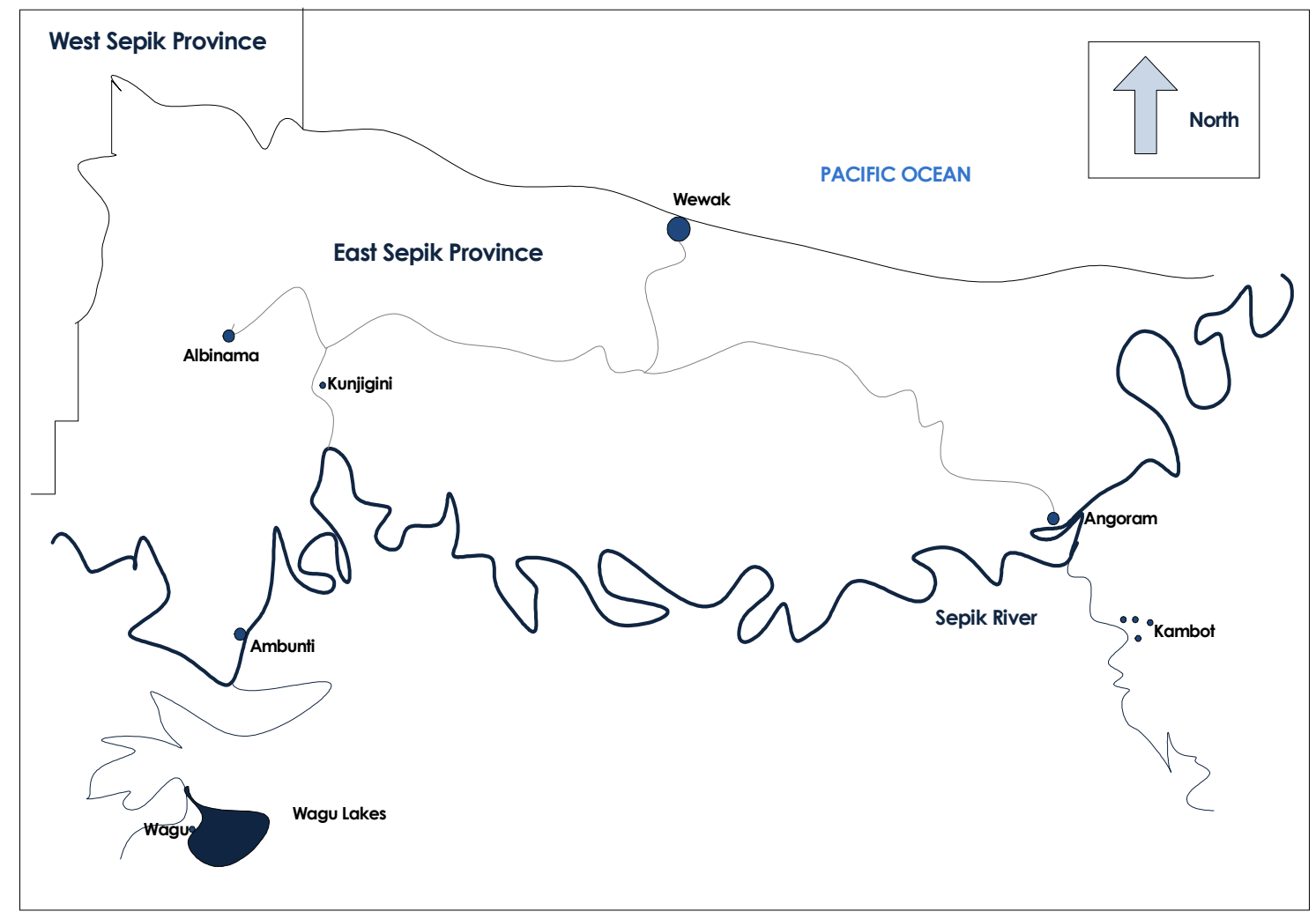

Reference: Hand drawn by the author from a photocopy of the East Sepik Province District Map provided by the ESWCHP. No scale provided. Full map (upon which this drawing is based) is provided as Appendix B.

As the research progressed, we found that we needed less travel time than expected and that we could complete more interviews and focus groups over the six-week period. Also, Yvonne felt that some of the more problematic areas had not been included in the four 
areas nitially chosen, so with the permission of the Programme Manager we added Ambunti and Wagu.

The research team was based in Wewak, the largest town in the East Sepik Province, situated on the coast. The areas the research team visited along with the type of health service and the access description are summarised in Table 3 below.

Table 3 Summary of health services and catchment areas visited

\begin{tabular}{|c|c|c|}
\hline Catchment area & Type of health service & Description \\
\hline $\begin{array}{l}\text { Albinama in the } \\
\text { Maprik District }\end{array}$ & $\begin{array}{l}\text { South Seas Evangelical } \\
\text { Church Health Service }\end{array}$ & $\begin{array}{l}\text { Accessible by road } \\
\text { Provides a focal point for a large } \\
\text { collection of isolated villages accessible } \\
\text { mainly by foot }\end{array}$ \\
\hline $\begin{array}{l}\text { Kunjigini in the } \\
\text { Wosera District }\end{array}$ & $\begin{array}{l}\text { Catholic Church Health } \\
\text { Service }\end{array}$ & $\begin{array}{l}\text { Accessible by road } \\
\text { Provides a focal point for a large } \\
\text { collection of isolated villages accessible } \\
\text { mainly by foot }\end{array}$ \\
\hline $\begin{array}{l}\text { Kambot in the } \\
\text { Angoram District }\end{array}$ & $\begin{array}{l}\text { Catholic Church Health } \\
\text { Service }\end{array}$ & $\begin{array}{l}\text { Accessible by road and river } \\
\text { Remote area } \\
\text { Provides a focal point/transport and } \\
\text { communication hub for a number of } \\
\text { isolated villages }\end{array}$ \\
\hline $\begin{array}{l}\text { Angoram in the } \\
\text { Angoram District }\end{array}$ & $\begin{array}{l}\text { Government Health } \\
\text { Centre }\end{array}$ & $\begin{array}{l}\text { Accessible by road } \\
\text { Small town } \\
\text { Key transport link between rural people } \\
\text { living on the river and Wewak town }\end{array}$ \\
\hline $\begin{array}{l}\text { Ambunti in the } \\
\text { Ambunti District }\end{array}$ & $\begin{array}{l}\text { Seventh Day Adventist } \\
\text { Church Health Service }\end{array}$ & $\begin{array}{l}\text { Accessible by road and river } \\
\text { Remote area } \\
\text { Ambunti town developed around the } \\
\text { government health facility and other } \\
\text { government functions } \\
\text { Provides a communication and travel hub } \\
\text { for locals and tourists }\end{array}$ \\
\hline $\begin{array}{l}\text { Wagu in the Ambunti } \\
\text { District }\end{array}$ & VHVs only & $\begin{array}{l}\text { Small group of very remote villages } \\
\text { accessible only by boat }\end{array}$ \\
\hline
\end{tabular}

Our visits aimed to obtain information from VHVs, rural health centre managers and staff, and rural people from 10 villages in each catchment area. The research team arranged for rural people and village health volunteers to congregate when the research team was scheduled to be there (either at a central village or at the local health centre). In some areas people came from miles around including from villages that we had not targeted or made contact with.

Overall, 307 rural people participated and provided responses to either interviews or questionnaires or both. Of the participants 64 percent were women and 36 percent were 
men. A summary of the participants by catchment area and by gender is shown in Table 4 below. The analysis of participants by their self-identified role within the community is attached as Appendix C.

Table 4: Participants by Catchment Area and Gender

\begin{tabular}{|c|c|c|c|}
\hline Catchment area & Total participants & Women & Men \\
\hline $\begin{array}{c}\text { Albinama in the Maprik } \\
\text { District, including Brugam } \\
\text { and Marienberg }\end{array}$ & 84 & 55 & 29 \\
\hline $\begin{array}{c}\text { Kunjigini in the Wosera } \\
\text { District }\end{array}$ & 91 & 64 & 27 \\
\hline $\begin{array}{c}\text { Kambot in the Angoram } \\
\text { District }\end{array}$ & 16 & - & 16 \\
\hline $\begin{array}{c}\text { Kambuku in the Angoram } \\
\text { District }\end{array}$ & 36 & 20 & 26 \\
\hline $\begin{array}{c}\text { Angoram in the Angoram } \\
\text { District }\end{array}$ & 28 & 23 & 5 \\
\hline $\begin{array}{c}\text { Ambunti in the Ambunti } \\
\text { District }\end{array}$ & 307 & 196 & 111 \\
\hline $\begin{array}{c}\text { Wagu in the Ambunti } \\
\text { District }\end{array}$ & 24 & & 16 \\
\hline Totals & 28 & 2 & \\
\hline
\end{tabular}

It was interesting to note that 28 uninvited participants (26 women and two men) came from Kambuku of their own volition to participate in our research at Kambot (where only men had chosen to participate). The large majority of the uninvited Kambuku participants were either Village Birth Attendants (VBAs), Community Based Distributors (CBDs) or Meresin Meri/Man (MM) and had to walk approximately four hours (from memory) to attend, so clearly participating in the research process was of value to them. Their responses were gratefully received, albeit with some surprise, by the research team.

To undertake the research, people were organised into respondent group by type and gender, provided with the relevant questionnaire and divided into small focus groups. Each group was provided with a pen and paper, was asked to discuss the questions collectively and come up with one answer for each question. They were also invited to write down any comments, issues or suggestions that were not covered by their answers to the questionnaire. Some rural health staff and VHVs were interviewed individually. All the information provided by respondents was put into data spreadsheets by the research team (Heather, 2006). 
Analysis of the information found overwhelming responses with regards to two key themes:

- VHV's needing greater consistency of medical supplies; and

- VHV's needing more support (in terms of status, education and 'in-kind' or other payment).

Two other themes emerged that were not as pronounced but were significant:

- VHVs and rural people not receiving adequate service from local government health facilities (in the way of medical supplies to VHVs or clinic services);

- Specific case studies highlighted by respondents as common examples of the difficulties village people and VHVs faced.

These themes were discussed at length with the Programme Manager and a set of recommendations agreed upon which are documented in the narrative report of the 2006 research (Heather, 2006). 


\section{Theoretical and Conceptual Frame}

To consider whether the ESWCHP VHV system is sustainable, I have chosen as the main underpinning conceptual frame, women, gender and development specifically through the gender analysis framework of Kabeer's Social Relations Approach. I extend the discussion of women, gender and development to its specific application within PNG.

I then broaden the theoretical and conceptual frame by describing participatory development and capability approaches, which interweave and compliment the SRA in the analysis.

This thesis is set in the context of rural primary health care funded by NZAID. I briefly outline what is meant by primary health care, and the critical role NZAID plays in enhancing development and health outcomes through the ESWCHP.

\subsection{Women, Gender and Development}

A brief review of policy approaches to women, gender and development is necessary as a foundation for understanding the implications of women's involvement within the development context. Women, gender and development in PNG, like in many countries around the world, has gone through phases: welfare; women in development (WID); empowerment approach; and gender and development (GAD) (Dickson-Waiko, 2006).

The welfare approach dominated Third World development from the 1950s to the 1970s and was the first to include a focus on women. The welfare approach can be traced to the social welfare model used in many Third World countries by colonial authorities. The purpose of the welfare approach was to bring women into development as better mothers (Moser, 1993, pp 59). It was based on three assumptions: that women are passive recipients of development, rather than participants in the development process; that motherhood is the most important role for women in society; and that childrearing is the most effective role for women in all aspects of economic development (ibid, 59-60). Women's roles in reproductive activities were stressed giving rise to projects that assisted women in homemaking, caring and nurturing, and addressed practical needs particularly in the areas of food, aid, malnutrition and family planning (Karl, 1995; Dickson-Waiko, 2006). The role of women in production was largely ignored (Kelly, 2002).

Prior to 1973, PNG government policies and processes carried a welfare orientation reflecting a 'traditional' Western perception that women were primarily concerned with reproduction and household maintenance (Dickson-Waiako, 2009, pp282). Welfare 
advancement initiatives resulted in community activities across PNG, involving mainly men. During the 1960s and early 1970s courses held through women's clubs and churchwomen's groups became popular (ibid). The welfare approach implemented in PNG during this period had some benefits for PNG women, and continues to be considered appropriate in areas such as health and nutrition, and is sought after by grassroots women themselves (ibid).

It appears likely that the welfare approach influenced the early beginnings of the ESWCHP with the establishment of the Meresin Meri scheme in the early 1980s (to improve basic first aid and health knowledge), and the following CBD scheme to advance family planning.

By the 1970s, numerous studies had showed that women had been adversely affected by development projects. Women's status was declining in developing countries and the welfare approach had failed to bring about anticipated lasting change. Frustrations with the welfare approach's limitations led to the development of the Women in Development (WID) approach. WID advocates called for greater integration of women into the development process moving away from previous assumptions that entire households would benefit from projects aimed at men.

Three policy approaches emerged from the WID discourse: equity; anti-poverty; and efficiency (Karl, 1995; Moser, 1993). The equity approach began during the early years of the United Nations Decade for the Advancement of Women held between 1976-1985. Proponents of the equity approach advocated for the recognition of women's economic contribution alongside their reproductive role (Kelly, 2002 pp 16). The equity approach focussed on raising women's status by reducing inequality between women and men. Active participation of women in the development process was promoted to address women's strategic gender needs ${ }^{14}$ directly through top down state intervention (Karl, 1995). This approach however remained unpopular with development agencies and criticised as being irrelevant to the daily lives of Third World women as a result of its basis in Western feminism (Kelly, 2002). 'Politically, the majority of development agencies were hostile to equity programmes precisely because of their intention to meet strategic gender needs, whose very success depended on an implicit redistribution of power' (Moser, 1989 pp181).

\footnotetext{
${ }^{14}$ The term 'strategic gender needs' is a concept developed by Maxine Molyneaux and refers to what women require in order to overcome their subordination (Karl, 1995). 
The anti-poverty approach was developed as an alternative to the equity approach and aimed to reduce income inequality through increased economic equality. The anti-poverty approach focussed on enhancing productivity to meet women's practical gender needs ${ }^{15}$ and linked women's poverty to under-development instead of female subordination. The equity approach did not challenge existing social relations or customs so whilst women's workloads may have increased, this was not often accompanied by an increase in status or benefit to women's lives (Kelly, 2002).

The third and now most predominant WID approach is the efficiency approach, which emerged in the late 1980s in the wake of the debt crisis. Development planners began to realise that women's participation was essential to the success of development projects. The efficiency approach aimed to ensure that development was more efficient and effective through women's economic contribution and equated women's participation with equity. The efficiency approach assumed that women were an under utilised labour force which could be exploited at low cost, with women's time being elastic and able to be stretched to include tasks that fell on them as social services declined (Karl, 1995). Much like the antipoverty approach, women's workloads increased by working longer hours and performing more unpaid work, resulting in little overall benefit to women's lives. It was during this time period (late 1980s-early 1990s) that the ESWCHP came into being. It appears that the ESWCHP is predicated on the assumption that women's capacity can stretch to accommodate the demands of providing primary health care to their communities, for little or no return for their additional workload.

WID programmes tended to treat the symptoms rather than the underlying causes of gender discrimination and inequality. Critics of WID policy perspectives acknowledged the greater visibility of women in the development process, but criticised the often resulting ad-hoc, or 'add-on' solutions which resulted in tokenism and marginalisation of women's strategic needs (Karl, 1995; MacDonald et al, 1997; Chant, 2000). Where women were confined to economically devalued roles in the domestic arena, they and their daughters had shorter life expectancies, poorer health status and fewer life choices when compared with men and boys in their own cultures and elsewhere. Poorer women were far more likely to experience conflicting demands on their time from these managing both reproduction activities and production activities with their attempts to balance them leading to a variety of adverse outcomes including:

${ }^{15}$ The term 'practical gender needs' is a concept developed by Maxine Molyneaux and 'refers to what women require in order to fulfil their roles and tasks; for example training and access to child care services' (Karl, 1995 pp97). 
- Longer working hours than men in their families;

- Greater fatigue and nutritional deprivation; and

- Withdrawal of children, especially daughters, from school in order to relieve their mothers from domestic chores (Kabeer 2003).

Unintended marginalisation of women in development programmes led agencies to rethink WID and consider new ways of bringing women from the margins into the centre of economic development programmes and organisations. This rethink required increased women's participation in development programmes, and for women's perspectives, needs and concerns to become fundamental to the process of development.

Frustrated with the failure of WID approaches to bring about improvements in the lives of women in the South, Southern feminists began to advocate for women of the South to organise themselves to effect change (Kabeer, 1994 pp 223). The first post-WID approach (also known as the 'women and development' or the 'empowerment approach') aimed to strengthen women's self-reliance by means of supporting grassroots mobilisation (Chant, 2000 pp 8). The earliest and most well known proponent of the empowerment approach was Development Alternatives with Women for a New Era (DAWN). Founded in 1984, this group brought together women researchers and activists from around the world (Kelly, 2002, pp20). DAWN emphasised the importance of listening to the voices of women from the South, and addressing the strategic needs of women by changing the distribution of power at all levels.

The empowerment approach was the first framework to have arisen from the South and represented a drastic shift away from previous approaches in which power was concentrated in the hands of Western development planners and practitioners. The empowerment approach was potentially very transformative as it directly challenged existing social relations and distributions of power and associated resources. For this reason it was not particularly favoured by development agencies and governments (Kelly, 2002) such as PNG.

Criticisms of WID over time became building blocks for a new gender and development (GAD) paradigm (Chant 2000). Rather than focussing exclusively on women, supporters of GAD emphasised the importance of transforming unequal gender relations. GAD advocates called for a focus on 'gender relations' and the integration of a gender perspective in all development activities, and at all levels of the development planning process. GAD focused on empowerment of the disadvantaged and on the transformation 
of unequal social relations that inhibited the advancement of freedoms (Parpart et al, 2000). The GAD approach understood women to be agents of change and stressed the need for women to work together to be more effective politically, moving away from earlier approaches where women were often passive recipients of development assistance (Rathgeber 1990).

As the GAD approach developed it became clear that pervasive societal attitudes were embedded within development organisations and bureaucracies often recreating and reproducing gender inequalities and hierarchies. This awareness resulted in a call for organisations to 'mainstream' gender - to integrate gender concerns into every aspect of an organisation's priorities and procedures' (March et al, 1999, pp10) challenging existing allocations of authority and resources, as well as cultural norms.

Efforts to persuade policy makers and planners of the importance of gender issues, had not resulted in more women obtaining positions of power within development agencies, and discriminatory incentives, procedures and active resistance continued to effectively block women's advancement. Consideration of women's alternative vision of development continued to be severely limited. Activists' and scholars' attention began to turn to the analysis of institutions, and how rules and practices might be challenged and changed (Young, 2002). While the family was seen as the basic institution, which set the tone for gender relations within a society, it was becoming clear that other institutions were equally gendered and reproduced women's inequality in varying degrees (ibid, pp324).

Gender analysis frameworks emerged initially in response to the realisation of the significance to development of the differing roles of men and women and the socially constructed inequalities of gender. A number of studies (Boserup, 1970; Kabeer, 1994) illustrated failures of development interventions, attributable at least in part to the neglect or lack of knowledge or women's productive and reproductive roles (Karl, 1995).

A suite of practical gender analysis frameworks and tools have been developed to assist agencies in understanding the social relations of gender in the work place and in project planning including well known tools such as the Harvard Analytical Framework, the Moser Framework, the Women's Empowerment (Longwe) Framework and the Social Relations Approach (SRA) (March et al, 1999).

\subsection{Social Relations Approach}

In looking for an approach upon which to research my central thesis question, the SRA was attractive in that it provided a complete framework for institutional analysis and social 
relations with the goal of human wellbeing and development (March et al, 1999; Kabeer, 1994). The central problematic of the SRA is not women's integration into development, but rather, 'the social structures, processes and relations that give rise to women's disadvantaged position in a given society (Razavi \& Miller, 1995, pp27)'. The SRA provided a framework for development with gender as a central component, which I considered critical to the analysis of the issues VHVs faced as they provided services in the field. I wondered whether looking at the problems of gender inequality, sustainability and effectiveness through the lens of social structures, process and relations might uncover insights I had not seen as a result of the 2006 research process.

The Social Relations Approach (SRA) to gender and development planning was developed by Naila Kabeer at the Institute of Development Studies, Sussex University, UK in collaboration with policy-makers, academics, and activists, primarily from the South.

Whilst I was unable to find literature that definitively specified the academic body of thought from which the SRA was initiated, the literature suggests that the SRA is a gender analysis framework embedded within GAD that focuses on the empowerment of women. The SRA emphasises the transformation of the social relations of gender through women's self empowerment. 'Because there are risks and costs incurred in any process of change, such change must be believed in, initiated, and directed by those whose interests it is meant to serve. Empowerment cannot be given; it must be self generated. All that a gender transformatory policy can hope to do it to provide women with the enabling resources which will allow them to take greater control of their lives, to determine what kinds of gender relations they would want to live within, and to devise the strategies and alliances to help them get there' (Kabeer, 1994, pp97). The policy implications of social relations analysis, therefore, involve the political project of women's self-empowerment, with emphasis placed on women's NGOs and participatory planning (Razavi \& Miller, 1995, pp32).

The SRA was first published by Kabeer in Reversed Realities; Gender Hierarchies in Development Thought, Verso, UK, 1994 and has been used by government departments and NGOs for planning programmes in a number of countries (March et al, 1999 pp 102).

'Social relations analysis commences with the premise that development planning needs to take account of both the relations of production and the interrelated range of relations through which needs are met (Razavi \& Miller, 1995, pp 28)'. A critical concern of social relations analyses are the social relations embedded in the range of institutions through which social groups acquire resources: the household, the community, the market and the 
state (Kabeer, 1994, Fernando, 1997). Poor people, often women, are often excluded from formal institutional allocations of resources. Instead they draw on other resources, access to which is determined by their social relations, which play a critical part in their survival strategies. The interconnectedness of gender, class, ethnicity and nationality commonly place women in a complex situation in which it is difficult to identify and articulate their strategic interests ${ }^{16}$. These interests may not be as immediately obvious to women, or to sympathetic policy makers, as needs emerging out of existing daily routines and responsibilities might be (Fernando, 1997).

Institutional arrangements typically place men in privileged positions, providing them with greater power and creating embedded inequalities. Men may de-emphasise the gender inequalities that exist and through their greater access to resources, manipulate them to promote and defend their own interests. These inequalities are generally socially constructed religious, cultural and biological norms widely held in society at large and subscribed to by both women and men.

The SRA provides a framework for analysing existing gender inequalities in the distribution of resources, responsibilities and power, and for designing policies and programmes which enable women to be agents of their own development. The SRA gives emphasis to identifying and analysing how differences in 'social relations of every day life' (Fernando, 1997, pp154) interact with the social, economic and political relations between men and women. The SRA sees ending women's subordination as more a reallocation of economic resources, but instead involves the redistribution of power.

The main concepts of the SRA are described in Kabeer (1994) and March et al (1999). I have summarised these in Chapter Three, Research Methods, as the basis for the detailed practical research method that I used.

Understanding the social relations inherent in an institution or community can identify mechanisms by which marginalised people can choose to act as agents to effect positive changes to their lives. The analysis must look not only at issues of inequality, but also at positive and equal relations and how these can be supported and enhanced, building on solidarity, reciprocity and autonomy (March et al, 1999). Social relations are ever changing. Conflictual and collaborative aspects of gender relations involve men and women in a constant process of negotiation and renegotiation. The priority therefore, must

\footnotetext{
16 'The term 'strategic interests' refers to what women require in order to overcome their subordination'
} (Karl, 1995, pp 97) 
be to provide women with greater bargaining power within this process of negotiation (Kabeer, 1992; Razavi \& Miller, 1995).

The SRA provides a useful framework to help identify the power or relations of authority and control that result from unequal distribution of resources within an institution (Iyer, 2005), and on the basis of these relations, point the way toward effective greater equality through institutional change. Participation of local communities is required to identify the institutional relationships and inequalities for the SRA analysis, and from there, to identify the appropriate mechanisms through which to effect positive change and greater equality and advance the freedoms in their lives in a way that they value (Sen, 1999).

\subsection{Women, Gender and Development Policy Framework in PNG}

PNG has a well-established legal and policy framework that requires the promotion of equality in opportunity to participate in and benefit from development. A number of national policies and programmes relating to women's empowerment and gender equality issues exist, the development of which, was guided by the National Women's Policy. These include the Medium-term Development Strategy; the Gender Equity in Education Policy; the National Platform of Action; and The Pacific Plan of Action (Aisi, 2008).

\section{The Eight Point Plan}

In 1973, 'Women's equal participation' became part of a national 'Eight Point Plan'. The conceptual basis of women's equality was the WID approach, which while recognising that women were active participants in the development process, was concerned with fundamental issues of equality which transcend development (Dickson-Waiko, 2009, pp284). The Eight Point Plan highlighted the importance of women's equal participation, in the new independent state.

\section{The Constitution}

When PNG sovereignty was obtained in 1975 commitment to gender equality and equal treatment before the law was cemented within the Constitution (Dickson-Watson, 2006; Garap 1999). The state constitution formalised the relationship of women with the state by stating as its second goal: "for all citizens to have an equal opportunity to participate in, and benefit from, the development of our country' (King et al, cited in Dickson-Waiako, 2009, pp284). The Eight Point Plan was integrated into the constitution as the 'Eight Aims'. PNG joined the UN and the WID approach adopted by the UN and many bilateral 
donors. Pressure on the national government from UN and bilateral donors resulted in development programmes and activities (such as training programmes) for women (ibid).

The constitution provided official recognition of women's disadvantaged position in society in calling for a rapid increase in the equal participation for women in all forms of economic and social activity. However, despite this official recognition of women's subordinate status and, development for women has continued to remain a low priority (ibid, pp 285).

\section{National and Provincial Women's Councils}

In 1975 a coordinator was appointed to oversee PNG's involvement in the UN International Year activities, which including holding the first national convention for women, from which the National Council of Women was formed. In 1979 the National Council of Women Incorporation Act paved the way for the establishment of 20 provincial councils of women. The National Council of Women was recognised as an alterative vehicle through which women's programmes, information and education would be advanced (ibid, pp286).

Between 1982 and 1987 the National Women's Development Programme (NWDP) was established. This first coordinated government strategy for women emphasized training, and numerous workshops and training programmes were run on topics from food preparation to family health and family planning, technology and literacy. The NWDP reflected a shift in approach from welfare to 'equal and productive partners' arising from the changing discourse on WID. Women's Officers were appointed in each province, and volunteer community women's organisers (CWOs) appointed in the districts to mobilise women and set up provincial councils of women ${ }^{17}$.

A National Women's Coordinating Committee (NWCC) was set up in 1983, to advise the government on policy, programmes and training for women. The membership of the NWCC included representatives from women's church groups and other women's groups such as the Young Women's Christian Association. The NWCC was successful in establishing a women's agenda within both the bureaucracy and civil society and in raising awareness about women's participation in development. The NWCC paved the way for the creation of the national Women's Policy.

${ }^{17}$ Interestingly the idea of rural community volunteers emerged at this time. The CWOs were volunteers who were given a daily allowance to cover transportation and food costs and who undertook the groundwork in rural areas (Dickson-Wiako, 2009) 
The national Women's Policy was launched in 1991 following ten years of development and extensive consultation through women's leaders at national and local levels, the National Council of Women, churchwomen's groups and government agencies and departments (Dickson-Waiko, 2009). The National Women's Policy aimed to contribute to 'increased participation by women as both beneficiaries and agents in the development process and improvement of the quality of life for all' (Loveridge \& Kotvojs, 2004).

The Women's Policy reflected the WID approach, describing women as 'both beneficiaries and agents in the development process' (Dickson-Waiko, 2009, pp285). The Women's Policy placed responsibility for improving planning on policies and programmes that impacted women on a number of key government departments, such as Health, Education, Agriculture and Planning. Some implementation of women's projects and activities has been evident in New Ireland, Oro, Gulf and Sandaun Provinces, but national attention to gender issues has remained ad hoc (Dickson-Waiako, 2009).

Since independence however, politicians appear to only pay lip service to gender and development policies. Despite the National Women's policy and becoming signatories to the United Nations Convention on the Elimination of Discrimination Against Women (CEDAW) in 1994 and, the Bejing Platform of Action in 1995, governments have pursued development strategies that do not support gender equality (Korare, 2002). Instead male dominance in politics has been promoted with culture and tradition used as legitimising rationale behind their actions. As a result, women have continued to be excluded from major decision-making and the issues of importance to women continue to be largely ignored (Dickson-Waiko, 2009).

Since 1972, only five women have succeeded in becoming members of parliament. However, the number of women attempting to enter the political arena has grown. In 1977 10 women stood for election, and in 2002 there were 60 women candidates. Women often face severe difficulties gaining political party nomination so are forced to stand as an independent, and often find it difficult to raise the resources needed for political campaigning (Thomas, 2002).

Bureaucratic structures required to implement the Women's Policy and women's development have not been well developed. Some provinces have well-organised councils to advance women's development, but the majority appear to be indifferent to addressing the women's development issues (Dickson-Waiko, 2009). 
Review of the National Women's Policy is well overdue. Critical changes have occurred since its inception including decentralisation of government responsibilities and systems and the ratification of CEDAW and the Bejing Platform of Action mentioned above. A new commitment is needed that will address gender mainstreaming within state; provincial and local level government. Issues of lack of coordination between policymakers, women's civil society groups and NGOs need to be addressed. Greater national focus on gender and development issues is required so that women 'regardless of class, ethnicity, religion and locality, begin to experience real changes in their lives' (Dickson-Waiko, 2009, pp294).

\subsection{Participatory Development}

Participatory development has evolved over time to mean different things to different people. For some, participation means a 'warm sense of togetherness, common purpose and mutual understanding; for others it is a management tool that can help shift costs to recipients whilst enhancing project effectiveness. For yet others, participation evokes recognition and enhancement of people's ability to speak out, to act and determine their own development through fundamental changes in power relations (Cornwall, 2000 pp8).

There is a continuum of how the term participation is interpreted and used by development agencies. This continuum ranges from passive participation, where people are involved merely by being told what is to happen, to self-mobilisation where people take initiative independently of external institutions (Pretty et al, 1995) and is summarised in Table 5 below.

Table 5 Types of Participation

\begin{tabular}{|c|c|}
\hline Type & Summary of characteristics \\
\hline Passive participation & People participate by being told what is to happen or has happened. \\
\hline $\begin{array}{l}\text { Participation in } \\
\text { information giving }\end{array}$ & $\begin{array}{l}\text { People participate by answering questions posed by extractive researchers } \\
\text { using questionnaire surveys or similar. People do not have the opportunity to } \\
\text { influence proceedings, as findings are not shared nor checked for accuracy. }\end{array}$ \\
\hline $\begin{array}{l}\text { Participation by } \\
\text { consultation }\end{array}$ & $\begin{array}{l}\text { External people listen to people's views. External people define both } \\
\text { problems and solutions and may modify these in light of people's responses. } \\
\text { External people do not share decision making with local people. }\end{array}$ \\
\hline $\begin{array}{l}\text { Participation for } \\
\text { material incentives }\end{array}$ & $\begin{array}{l}\text { People participate by providing resources such as labour in return for food, } \\
\text { cash or other incentives }\end{array}$ \\
\hline $\begin{array}{l}\text { Functional } \\
\text { participation }\end{array}$ & $\begin{array}{l}\text { People participate by forming groups to meet predetermined objectives. } \\
\text { Involvement tends to be after major decisions are made. }\end{array}$ \\
\hline $\begin{array}{l}\text { Interactive } \\
\text { participation }\end{array}$ & $\begin{array}{l}\text { People participate in joint analyses, which leads to action plans and the } \\
\text { formation of new local institutions or the strengthening of existing ones. These } \\
\text { groups take control over local decisions and have a stake in maintaining } \\
\text { structures or practices. }\end{array}$ \\
\hline
\end{tabular}




\begin{tabular}{|l|l|}
\hline Type & Summary of characteristics \\
\hline Self-mobilisation & $\begin{array}{l}\text { People participate by taking initiatives independent of external institutions to } \\
\text { change systems. The develop contacts with external institutions for resources } \\
\text { but retain control over how resources are used. }\end{array}$ \\
\hline
\end{tabular}

Abridged from Pretty et al (1995), pp61

However, what remains fundamental to participatory approaches is the ideological position that requires the involvement of local people in any decision-making processes that affect their lives (Beazley \& Ennew, 2005; Brock \& Pettit, 2007) i.e. 'everyone who has a stake has a voice and a choice' (Cornwall 2003, pp 1325).

Participatory development first appeared in the late 1950s and 1960s when postcolonial governments began to attempt to mobilise their populations for development at local and community levels. Throughout the 1970s and 1980s participatory development became widespread. Non-governmental organisations (NGOs) took on greater responsibilities and provided services that had previously been provided by the state. NGOs became innovators developing grassroots participatory approaches and methods. Self-help groups started appraising, planning, implementing, monitoring and evaluating, inventing new methods for themselves (Chambers, 2005 pp 98). By the late 1980s a new stream of participatory development had emerged, known as Participatory Rural Appraisal (PRA). Typically PRA approaches and methods involved the use of visuals and tangibles done by local people themselves, often in small groups. Some of the most well known and most widely adopted were semi-structured interviewing, focus group discussions, preference ranking, mapping and modelling and seasonal and historical diagramming. These methods highlighted local people's previously unsuspected capabilities. Marginalised people showed far greater ability to describe, present, diagram and analyse their realities than development practitioners had previously thought possible (Chambers, 2005 pp101). Participatory development sought to expose the diversity, which allowed differences between people and communities, encouraging and enabling local people to express their realities (Mohan, 2002).

By the 1990s, participatory development had entered almost every field development activity. PRA methods and approaches continued to evolve. Activities and processes called PRA became 'simply part of what participatory development had been and remains: a braided stream of ever-mingling methods, approaches and traditions. Participation, in 
name if not in reality, is now part of almost every development activity' (Chambers, 2005 pp100-101).

One of the strengths of PRA is that when sensitively used it can open up discussion and allow for action in areas of human deprivation and suffering which have previously been ignored or regarded as difficult or threatening. PRA has enabled such sensitive subjects as sexual and reproductive health, violence and abuses and defecation to be 'aired, analysed and tackled' (Chambers, 2005 pp 97).

Pretty et al (1995) suggest that long term economic and environmental success arises when people's ideas and knowledge are valued and power is given to them to make decisions independently of external agencies (pp60).

However, 'the question of who participates and who benefits raises a number of awkward questions for participatory development. Distinguishing, how, at what stages, and in what, becomes crucial for determining the shape 'participation' takes in practice...' (Cornwall, 2000, pp8, 11). Some organisations, whilst appearing participatory, in fact exclude members of the community, avoiding much needed challenges to embedded discriminatory institutional and structural constraints (Mohan, 2002). When located in the gender context, participation could serve to recreate existing gender inequalities and exclude those already marginalised. Simply increasing the numbers of women involved does not necessarily address the more fundamental issues of power, between women and men, and between women and women. Ignorance of existing local inequalities by development practitioners may result in their reinforcement. Existing power structures may be reinforced due to development practitioners' reliance on these to gain access to marginalised people. Constraints on women's participation are well known. Examples include logistical constraints, constraints on women's time, through to social constraints including seclusion, norms about women's capabilities, the absence of a 'critical mass' of women and cultural taboos preventing women from speaking (Cornwall, 2000).

Innovative NGO experience shows that where space is created for women's own voices to be heard, either through participatory processes, or needs identification or by organisational practices that encourage participation, a different set of needs come into view. Previously hidden categories of women's needs have been identified along with the interconnectedness between the different aspects of women's lives (Kabeer, 1994). An example of the convergence of 'outsiders' perceptions of women's needs, and those identified by women themselves can be found with the Pigs and Participation project in the Northern Thai Highlands. The project found that whilst women were well aware of the 
role livestock played in their lives, this had not been sufficiently recognised or supported by government liaison officers or development practitioners. Development practitioners and government officers were keen to explore a range of income generating farming activities with the women. However, women relied on their income from livestock and preferred caring for pigs over the more monotonous and strenuous tasks associated with crops such as rice. The demand for pork was high in the region and the slaughtering of pigs an important part of spiritual and cultural events. The project resulted in improved support to women's pig rearing activities and improved relationships between village women and government officers, and a greater level of trust surrounding women's participation (Martins \& Ratanakeree, 1993).

Rowlands also highlights the critical need for participation through this quote of rural women in the Honduras: '...we knew what was happening to us and that we had to find our own solutions. People from the outside couldn't do that for us...they would only know what we had told them about things, but the people who knew about our problems were us' (Rowlands, 1997 pp2). The women quoted knew the problems they faced, and they knew how to resolve them.

Ruth Saovana-Spriggs is a Bouganvillean who worked with rural women to help them tell their stories to ensure that aid programmes and projects were appropriate to meet their needs. She argued that too often lack of local knowledge and participation when aid projects are designed and implemented (Saovana-Spriggs \& O'Collins, 2002) reduced their effectiveness.

Pretty et al (1995) argue that if the 'objective is to achieve sustainable development then nothing less than functional participation will suffice' (pp62). Unfortunately I saw no evidence of functional participation during my 2006 visit, nor was functional participation part of the 2006 research process.

As mentioned in Chapter One, over 300 people chose to participate in the impact assessment research in 2006, some who had not been invited, and chose to participate of their own volition, at some significant cost to themselves. This highlighted to me how important participation was to them. When I look back now at how I conducted the 2006 research, I see that the participation of rural people and VHVs was limited to information giving only. Whilst rural people and VHVs provided their views in response to predetermined questions, they had no involvement in how their responses were used, and were not consulted in the outcomes or recommendations from the research. 


\subsection{Capability Approach}

Cornwall (2000) highlights the need for a greater level of attention to be paid in development to strengthening the capabilities of women and men, in particular those who are marginalised, to create a gender-aware approach to participatory development.

Sen's (1999) capability approach (CA) treats the freedoms of individuals as the building blocks of development. The CA pays particular attention to the 'expansion of the capabilities of people to lead the kind of lives they value - and have reason they value' (Sen 1999, pp18). 'Capabilities are people's potential functionings, and functionings are beings and doings' (Robeyns, 2005, pp 65). Sen argues that development should focus on 'expanding the substantive freedoms that people have' (Sen, 1999 pp 297) for leading a valuable life. Development should enable the expansion of capabilities such as being able to be healthy, be involved in politics and hold political views, working, being physically safe and enjoying positive states of being. 'The capability approach stipulates that an evaluation of individual or social states should focus on people's real or substantive freedoms to lead the lives they find valuable. This freedom is called a person's capability. Someone's capability hence refers to her empowerment, the power that she has to be the person she wants to be and to have the kind of life she wants to lead' Robeyns (2001, pp 4). The CA requires people to be viewed and act as 'agents' - people who act and bring about change who have the ability to set and pursue their own goals and interests and whose achievements can be judged in terms of their own values and objectives (Kabeer, 1999; Robeyns, 2005). Agency encompasses the 'meaning, motivation and purpose, which individuals bring to their activity, their sense of agency, or 'the power within' (Kabeer, 2001, pp21, cited in Paterson, 2008). Agency can take the form of bargaining and negotiation, deception and manipulation, subversion and resistance, as well as more intangible, cognitive processes of reflection and analysis, exercised by individuals as well as by collectivities (Kabeer, 2003).

Sen describes a variety of social institutions (market, government, non governmental, and community) as contributing to the process of development precisely through their efforts to enhance and sustain individual freedoms. Sen highlights the important contribution that access to resources can make to people's well being. Inequalities in access to resources can be significant causes of inequalities in capabilities (Sen, 1999).

Robeyns (2005) argues that an analysis of gender inequality should not only map the gender inequalities in functionings and capabilities but also analyse which inequalities in 
resources cause gender inequalities in capabilities and functionings. This is especially important in assessing which policies create or reduce gender inequality because intervening in the distribution of resources is a crucial way of affecting the distribution of capability well being.

CA aligns and supports the SRA in that it attempts to unpack gender inequality by identifying institutional impacts on freedoms, with a view to self-determined advancement of capabilities that people have reason to value. This thesis research is trying to uncover the freedoms VHV's would seek to advance, and identify how the Project might support the advancement of these freedoms to the benefit of VHV's and rural communities.

Understanding the freedoms VHV seek to expand will form part of the creation of a development intervention for VHVs in Chapter Seven in partial response to the central question of this thesis.

In this chapter I have summarised three theoretical frames; gender and development, participatory development and the capability approach, and discussed their relevance as underpinning components of my analysis. Within the gender and development discourse, Kabeer's Social Relations Approach stands out as a useful framework from which to analyse social and power relations within an institutional context. In the next chapter I will describe the detailed methodology I developed from Kabeer's SRA as a practical guide to the analytical process. First though I will review the role of NZAID in the Project.

\subsection{The Role of NZAID and Primary Health Care}

Health is fundamental to development. In Asia, where the largest reductions in poverty have been achieved, 30-50 percent of economic growth between 1965 and 1990 has been attributed to favourable demographic and health changes (ADB, cited in Cant et al, 2009, pp3). Close linkages exist between maternal and child mortality and morbidity, human development and poverty (UNICEF, 2008, pp2). NZAID as the major funding agency for the PNG health sector wide approach and specifically the ESWCHP has a key role in ensuring that development goals are enhanced and achieved.

NZAID uses the ESWCHP as a case study in its current health strategy document, 'Ending Poverty begins with Health' as an example of NZAID's ongoing commitment to health. 'In the remote East Sepik province in PNG, NZAID is investing \$10.2million dollars to 2011 in a Save the Children NZ project which trains village health workers to deliver primary health care to their communities' (NZAID, pp 6). 
The Ministry of Health, NZ has on its website a document that attempts to define what is meant by primary health care as part of a review undertaken for the Ministry of Health and the Treasury in 1999 (Malcolm et al, 1999). This document states that the World Health Organisation (WHO) 'has defined primary health care as:

- Based on a philosophy of equity and social justice

- A strategy concerned with intersectoral collaboration

- A level of care that is the first point of contact with the health system

- A set of activities that includes basic clinical services

- This view is widely accepted both internationally and in New Zealand' (Malcolm et al, 1999 pp2).

Malcolm et al (1999) go on to describe the operational composition of primary health care as comprising:

- Generalist care - the provision of basic clinical services

- Comprehensive holistic care-concerned with all aspects of individual and family, and provided by an interdisciplinary team

- Continuing care - concerned with the continuing health of individuals and families within the context of their family and community

- Accessible care - the point of first contact and means of entry to the wider health system on an equitable basis

- A strong emphasis on community participation and community development' (pp2).

The NZAID Health Strategy 2008-2013 states that 'Primary health care includes as least: education concerning prevailing health problems and the methods of preventing and controlling them; promotion of food supply and proper nutrition; an adequate supply of safe water and basic sanitation; maternal and child health care, including family planning; immunisation against the major infectious diseases; prevention and control of locally endemic diseases; appropriate treatment of common diseases and injuries; and provision of essential drugs; and involves health and all related sectors and aspects of national and community development.'

The NZAID strategy goes on to state that the key features of primary health care are:

- ' it is affordable - basic health care that is universally available

- it is acceptable - community participation in defining and implementing health priorities 
- it is accessible - equitable access to basic health care by all in a community giving priority to those most in need

- it is intersectoral - health care that cuts across all aspects of the community, not just the health sector' (NZAID, pp5)

The NZAID website ${ }^{18}$ states that 'worldwide, 70 percent of those living in 'extreme poverty' are women and children. One third of all women and girls experience physical and sexual violence and girls are twice as likely as boys to die from malnutrition and preventable diseases. Empowering women is essential if those caught up in this cycle of poverty, violence, hunger and inequality are to be able to fulfil their role in society.' Women are increasingly being seen as active agents of change affecting and improving their lives: 'the dynamic promoters of social transformations that can alter the lives of both women and men' (Sen 1999, pp 189). Sen shifts the focus of women as 'patients' or recipients of the development process to agents of development processes and change that affects their lives. He notes that empirical data shows that women's wellbeing is strongly influenced by 'women's ability to earn an independent income, to find employment outside the home, to have ownership rights and to have literacy and be educated participants in decisions inside and outside the family' (Sen 1999, pp191).

Enhanced women's agency through empowerment and education can have dramatic effects on child mortality rates (Sen 1999, Kabeer 1993). Literacy is more powerful an influence in reducing child mortality than any other known variable (Sen 1999, pp 196). Data from 25 developing countries suggested that 1-3 years of maternal schooling reduces child mortality by 15 percent while an equivalent level of paternal schooling achieved a six percent reduction (Kabeer 2003, pp 129). Several studies show that mothers' education consistently affect the chances that:

- Women will attend antenatal clinics;

- Births will be attended by trained medical personnel

- Complete immunisation of children will take place

- $\quad$ Sick children will receive timely and effective medical care (Kabeer 2003, pp 130)

In light of the above, enhancing women's empowerment and in particular women's literacy must surely be considered as a central goal for the ESWCHP to achieve reduction in child mortality rates alongside addressing other key health indicators (such as maternal mortality rates) through creating a health infrastructure.

${ }^{18}$ Accessed 22 June 2009 
Carol Kidu, PNG MP promotes literacy as 'first and foremost as the people's pathway to developmental knowledge in childcare, nutrition, health, housing, agriculture, environment and so on' (Kidu $\left.1997^{19}\right)$.

Evidence also suggests that women's empowerment may lead to the health and education outcomes promoted by the MDGS. Poorer women who are empowered are more likely:

- To seek out contraception and maternal health services;

- To ensure the survival and health of their children and other family members;

- To promote the education of their children;

- To reduce gender discrimination against daughters in health and education and seek a better life for them than they may have had themselves; and

- To negotiate successfully for 'safe sexual practices' both within and outside marriage so as to reduce risks of HIV-AIDS (Kabeer, 2003)

\subsection{Conclusion}

In this chapter I have described three theoretical frames: women, gender and development which provides the main theoretical and conceptual frame and participatory development and the capability approach.

Kabeer's SRA provides a framework for analysing the social relations of gender within institutions such as the ESWCHP, with a focus on the empowerment of women to achieve the outcomes they desire. Kabeer sees women as key agents for social change. She writes that 'the capacity of those who have a stake in challenging the status quo to deal with...resistance cannot be taken for granted; it has to be built up through processes of empowerment' (Kabeer 1999 cited in Paterson, 2005, pp11).

Participatory approaches require participation and leadership of development recipients, allowing space for local people to be involved in development activities that impact their lives. Sen's capability approach interweaves with the two previous approaches in that it too promotes local people as agents of change - change in the way that from their grassroots perspective, adds value to their lives. Participatory approaches and the capability approach align and support the SRA. I have summarised this alignment by providing the following three quotes:

${ }^{19}$ www.pngbuai.com 
Kabeer: 'the expansion in people's ability to make strategic life choices in a context where this ability was previously denied to them' (cited in Paterson, 2005, pp11).

Cornwall (2003): 'everyone who has a stake has a voice and a choice' (pp1325).

Sen (1999): 'No longer the passive recipients of welfare-enhancing help, women are increasingly seen, by men as well as women, as active agents of change: the dynamic promoters of social transformations that can alter the lives of both women and men' (pp189).

Lastly I have briefly outlined what is meant in this thesis by primary health care, and the critical role of NZAID in ensuring development and health outcomes through its funding of the national sector wide health approach and specifically the ESWCHP.

In the next chapter, I expand on the SRA and describe the research approach used to conduct the institutional analysis. 


\section{Research Approach}

\subsection{Introduction}

In this chapter I discuss the research approach and the methodology I used for qualitative interpretation and representation of the 2006 data.

The conceptual and theoretical frame of women, gender and development complimented by participatory development and the capability approach sets the context for the research approach. The SRA provides a framework through which to identify the power or relations of authority and control that result from unequal distribution of resources, allowing for an understanding of the configuration of relations at play within an institution (Iyer, 2005). The CA requires a viewfinder that seeks freedoms that people want to extend for themselves and that they see add value to their lives. These can then be addressed through participation: hearing the voices of the community and in particular the VHVs who provide the basic services the ESWCHP was set up to provide and refining the project to assist them in enhancing their capabilities.

This research is qualitative in nature and aims to understand not what can be counted (as in quantitative research), but instead how human beings (namely VHVs and rural people) experience their world and how their experience affects that which can be counted (ie rural health statistics). Qualitative methods are characterised by in-depth, intensive approaches seeking subjective understanding of social reality. Qualitative methods are shaped by the research question and the researcher; the attitude of the researcher to the research subjects, and the intended outcome or consequences anticipated (Dwyer and Limb, 2001).

This thesis involves qualitative review of the data from the 2006 interviews and focus groups, along with my recollections from participant observation. It also involves recollections of my relationship with the research team and the many discussions we shared, first hand information I gleaned from participants in informal discussions and my own reflections on discussions, events and relationships.

The qualitative research process for this thesis commenced not with interviews or focus groups (as these were conducted in 2006) but with qualitative interpretation and representation of the data. In Qualitative Methodologies for Geographers (Dwyer and Limb, 2001), Jackson and Crang discuss the rigorous approach required when interpreting qualitative data. They suggest that there are no hard and fast rules to interpretation and avoid providing a step-by-step guide. Instead Crang (2001) provided details of the 
interpretive process he went through involving mind maps and thematic coding systems produced during his analysis; much of which was similar to the process that I intuitively went through and it was affirming to read this detail in the literature.

Jackson highlighted issues for consideration in the interpretive process (Jackson, $2001 \mathrm{pp}$ 210) to provide for rigour and transparency. I found many of the issues Jackson raised useful in guiding and cross-checking my interpretive process; in particular:

- The need to distinguish between different levels of coding at various degrees of abstraction;

- Avoiding 'cherry picking' of selective quotes through systematic coding and interpretation;

- Stating clearly how the process of interpretation was conducted

- Including discussion of the silences of absences of information in the data

- Considering personal positionality in relation to the interpretive process as an integral part of the research process

- Reading each interview transcript in turn, followed by reading across transcripts to search for similarities and differences, connections and contradictions among the various participants

- Acknowledging that many different readings can coexist

- Being explicit about the methods used to interpret the data (Jackson, 2001 pp 210).

Where possible, I have integrated consideration of these issues into the methodology in this chapter.

Two key points arise when this research is considered in the context of the issues above. Jackson (2001) advises that qualitative research is strengthened through a process of interpretation and validation. Jackson also advises that the 'interpretation of qualitative material should pay as much attention to the silences, absences and exclusions' (Jackson, 2001, pp 207) within responses as to the more obvious themes that arise. I have not been able to seek validation of my interpretation from other team members, nor test with them where the possible gaps or silences might be. I have instead relied on my recollections of the testing of assumptions and interpretations in 2006 (with the research team and ESWCHP Manager) and must accept the limitations of this research.

Jackson (2001) describes 'the need to acknowledge that many different readings can coexist and concomitantly, the impossibility of a single, definitive interpretation (pp 201)'. 
For example, one of the An example of the different readings I sought to uncover: I knew from informal discussions with the research team and the VHVs that in some areas many VHVs were unhappy with the support they were receiving from CHS. In 2006, the Project had recently transferred the responsibility of medical supplies to some of the CHS as a trial, with the aim to extend this to all CHS over time. Many VHVs informally stated to me that this transfer had resulted in delays in access to medical supplies; VHVs having to collect medical supplies rather than them being delivered; delays as a result of communication difficulties (ie VHVs did not have access to radio, so were not always aware of when the supplies were available to be picked up from the CHS) and in some cases CHS retaining VHV medical supplies for CHS clinics so minimal or no supplies were available to VHVs. I got the sense that VHVs did not feel comfortable making blatant, written statements about this; rather it came through subtly in the responses to questions about the length of delays in receiving medical supplies from CHS. For example, to the question 'how long to you have to wait before your supplies are replenished?' responses included 'it depends on the transport for us to come and get our supply - it will take one or two weeks after three months' and 'small amounts of supplies finish quickly' (Heather, 2006, pp VHVs75).

These may seem like small issues, but in PNG these are critical. Primary health care is difficult if not impossible without critical medical supplies, placing the VHVs in a difficult position facing expectations from their communities, yet not having the supplies to deliver the service. Also, collecting medical supplies for some VHVs meant either a walk of a day or more, and for others, an expensive canoe trip and difficulties obtaining access to canoes and fuel (generally owned or appropriated by men). Again, these were significant costs that the VHVs would have to bear in order to provide these volunteer services. Collectively they represent critical issues of sustainability of rural health care.

These VHV responses indicated critical issues: both impacting VHV ability to provide a basic health service, and also indicating the marginalization of VHVs in being able to voice their needs safely, and have these needs met.

Where possible I have identified as many different possible readings from responses as I could, and searched other responses to confirm or correct my interpretation.

A further consideration of importance here is representation. Some raise questions about the role of the researcher which can be viewed as one of 'unequal power relation as they interpret the lives of others' (Dwyer \& Limb, 2001, pp9). Others raise questions about whether interpretation is actually possible, but rather a range of 'truths' exist and suggest 
that it is knowing whose truth is represented is what is important (ibid). This thesis undoubtedly embodies 'my truth' as I have interpreted the theoretical frames, the data, literature, and health statistics along with my recollections and my personal positionality. As a result, this thesis offers not simply the 'representation' of the voices of others, but the construction of new ideas, new linkages and suggestions that go beyond what the people have said in their responses or I have interpreted through the analysis.

\subsection{Secondary Literature}

Literature on the practical application of the SRA was not easily found. There were numerous papers examining or explaining the SRA (for example Razavi \& Miller 1995; March et al, 1999; Gorman et al, 1999; Iyer 2005; Warren, 2007). I could find only one paper that had used the SRA, by Winford Masanjala (2007). Masanjala systematically applied the social relations framework (alongside other methods) to study the impact of the HIV epidemic on livelihoods in rural Africa. Masanjala then extended the analysis to consider the role that unequal social relations and livelihoods may play in the transmission of HIV. This allowed Masanjala to demonstrate that 'social factors associated with gender differences shape the HIV risk environment...through asymmetrical sexual relations, economic inequalities and population movement' (Masanjala, 2007, pp1037). While Masanjala describes the results of the analysis, a description of the methodology for how the SRA was used was not included, so whilst this was interesting work, I was not able to use it to assist the development of my methodology or my analysis.

There were a number of documents from which I was able to draw to support my analysis as listed below:

- ESWCHP Summary Version of the Phase II Project Implementation Document

- Phase II Program Design Summary: Logical Framework

- East Sepik Women and Children's Health Project (Phase II), Summary Version updated for the Second Funding Cycle (May 2006)

- Evaluation Framework, Stage 4, 13, September, 2006

- Gender Advisory Support for Grass-Roots Health Projects in Papua New Guinea (Underhill-Sem \& Peutalo, 2006)

Along with the above documents I was able to refer to the research report (Heather, 2006) I had written along with the data (Heather, 2006) gained from the interviews and questionnaires. There were also a number of $\mathrm{NDoH}$ and $\mathrm{PDoH}$ documents that I was able to refer to whilst I was in the East Sepik but not able to bring back to New Zealand, nor 
able to obtain access to since. These documents provided the National and Provincial policy framework within which the ESWCHP institution existed. Margaret Street however was able to give me a copy of an earlier version of the National Department of Health Provincial Guidelines for Village Birth Attendant Programmes (1991), which I have used as a reference point, and which from memory seemed very similar to the more recent version I was able to access while in the East Sepik.

\subsection{Summary of Kabeer's Social Relations Approach Concepts}

Before I describe the detailed method that I followed to conduct my analysis, I first summarise the key concepts within Kabeer's SRA (1994).

\section{Social Relations Approach Concept 1: Development as increasing human well- being}

In the SRA, development is defined as primarily improving human well-being through addressing 'survival, security, and autonomy, where autonomy means the ability to participate fully in those decisions that shape one's choices and one's life chances at both the personal and collective level' (March et al, 1999, pp103). This requires development interventions to be not only technically sound but contribute to the broader goals of survival, security and human dignity, inclusive of all those tasks which people perform to reproduce human labour, those which poor people carry out to survive and those which people perform in caring for their environment which ultimately provide for their livelihoods.

\section{Sociall Relations Approach Concepł 2: Social Relations}

'Kabeer uses the term 'social relations' to describe the structural relationships that create and reproduce systemic differences in the positioning of different groups of people' (March et al, 1999 pp 103). Social relations determine where individuals sit within the social hierarchy, what they can do, what powers they have and the resources they can access, and what their roles and responsibilities are. Social relations include gender relations, class, race, ethnicity etc. Social relations can change, through changes at the macro level or through human action.

Social relations determine access to resources and people's capacity to take advantage of opportunities of change. Poor people are often excluded from formal allocation of resources so access support for their survival, their workload, and their subsistence way of living through other means such as family or community networks. 


\section{Social Relations Approach Concept 3: Institutional Analysis}

'Kabeer defines an institution as a framework of rules for achieving certain social or economic goals', which ensure the 'production, reinforcement, and reproduction of social relations', creating and perpetuating 'social difference and social inequality' (March et al, 1999 pp104). The underlying causes of gender inequality are reproduced across a range of institutions including the household, family, community, market place, the state and the international aid industry. Kabeer challenges, as a myth, the notion that institutions are ideologically neutral and instead promotes scrutiny of the actual rules and practices of institutions to uncover core values, assumptions and embedded gender relations and inequities. Kabeer also challenges as a myth the idea that institutions are independent of each other. The SRA asserts that changes in one institutional sphere (eg access to increased resources through a development project) will automatically impact a range of other interrelated institutions (such as relationships within the family and the community). The SRA institutional analysis looks at five 'distinct, but inter-related, dimensions of social relationships that are common to all institutions and significant to the analysis of social inequality: rules, resources, people, activities and power'. These dimensions are summarised on Figure 4 below.

Figure 4: Dimensions of Social Relationships

\begin{tabular}{|c|c|}
\hline Rules: how things get done? & $\begin{array}{l}\text { Rules allow or constrain: } \\
\text { - What is done } \\
\text { - How it is done } \\
\text { - By whom it will be done } \\
\text { - Who will benefit }\end{array}$ \\
\hline Activities: what is done? & $\begin{array}{l}\text { - Who does what? } \\
\text { - Who gets what? } \\
\text { - Who can claim what? }\end{array}$ \\
\hline $\begin{array}{l}\text { Resources: what is used, } \\
\text { what is produced? }\end{array}$ & $\begin{array}{l}\text { - Human resources (eg labour, education, skills) } \\
\text { - Material resources (eg food, assets, land, money) } \\
\text { - Intangible resources (eg information, political mana, } \\
\text { goodwill or contacts) }\end{array}$ \\
\hline $\begin{array}{l}\text { People: who is in, who is out, } \\
\text { who does what? }\end{array}$ & $\begin{array}{l}\text { Institutions deal with people and are selective about: } \\
\text { - Who they allow in and whom they exclude } \\
\text { - Who is assigned various resources, tasks and } \\
\text { responsibilities } \\
\text { - Who is positioned well within the hierarchy }\end{array}$ \\
\hline $\begin{array}{l}\text { Power; who decides, and } \\
\text { whose interests are served? }\end{array}$ & $\begin{array}{l}\text { - Unequal distribution of resources and responsibilities } \\
\text { - Official and unofficial rules that promote unequal } \\
\text { distribution } \\
\text { - Authority and control to promote practices which entrench } \\
\text { privileged positions }\end{array}$ \\
\hline
\end{tabular}

Adapted from March et al, 1999, pp106-108 


\section{Social Relations Approach Concept 4: Institutional gender policies}

The SRA classifies institutional gender policies depending on the degree to which they recognise and address gender issues (March et al, 1999):

Gender blind policies are those that do not recognise that differences between the sexes exist, and thereby recreate existing gender biases often tending to exclude women.

Gender aware policies recognise the differing and sometimes conflicting needs of women and men along with the differing priorities, and often, unequal constraints they face when acting as either participant or beneficiary of development activities and outcomes. Gender aware policies can be further divided as follows:

Gender neutral policy approaches - these policies recognise the different needs and constraints faced by the different sexes, and use this knowledge to target and benefit both sexes, striving to overcome biases within the development process that exist within a given society.

Gender specific policies - respond to the identified needs of either gender.

Gender re-distributive policies - aim to transform existing distributions to create gender equity. These policies may work on women's or men's practical needs or target strategic gender interests.

\section{Social Relations Approach Concept 5: Immediate, underlying and structural causes}

This brings together all previous concepts and explores the immediate underlying and structural causes along with their effects on the various people involved, for the purposes of planning a development intervention and documenting this either in tabular form, or as a written report.

\subsection{Research Method}

To enable me to answer my central research question drawing on Kabeer's SRA (1994) I needed to create a method, which could be used practically for the analysis. Kabeer stated that a narrow application of the SRA would highlight how gender inequality was formed and reproduced in institutions (March et al, 1999, pp 102)'. However, it was not clear exactly what was meant by a narrow application and while the SRA provided a structured framework, no method for how the analysis was undertaken within the framework is described. In the absence of such guidance and in an attempt to undertake a "narrow application' of the SRA I developed the following set of tasks for my overall approach: 
1. Define the ESWCHP using Kabeer's four key institutional locations of the state, the market, the community and family/kinship:

a. Identify the organisations and groups that exist within the ESWCHP institution

b. Identify the location of each organisation or group in accordance with Kabeer's four key institutional locations

2. Identify rules 'owned', enacted and monitored by each different organisation and group within the ESWCHP institution.

For each rule identified, I attempted to apply an 'owner' or controller/enforcer of the rule. In some cases I found that more than one group appeared to 'own' a rule. This suggested tensions between different groups who shared a rule and that it was possible that the rule would vary depending on the circumstances at hand. I also found examples of where a rule was that an organisation or group owned the activity or concept. For example - Village Leaders 'owned' how community services were provided within the village by agreeing who was chosen as VHV, and then setting the type and level of community services, through their support (or lack of support).

3. Identify the activities conducted by each different institution and organisation

4. Identify the benefits achieved through the rules and activities and who 'owns' these benefits

5. Bundle together like with like to summarise how rules, activities and benefits fall amongst the institutions and organisations within the ESWCHP

6. Assess the available documents, data and the analysis completed above to identify the presence of gender policies

7. Complete a cause and effect analysis (Concept 5 and Concept 6) to explore the immediate, underlying and structural factors creating the problems identified in responses (and documented in the institutional analysis) and document in the table format suggested (March et al, 1999, pp 110-111)

8. Design a Development Intervention using the suggested table format (March et al, 1999, pp 112-114).

I conducted an institutional analysis of the ESWCHP using guidance from March et al (1999) and Kabeer (1994). Having completed Concept 3 Institutional Analysis above, I 
progressed through Concepts 4, 5 and 6, and completed an immediate and underlying structural causes and effects analysis and a Development Intervention.

\section{Definitions}

There are a number of terms used within the SRA that are not defined. I therefore had to establish my own. Explanations of my interpretation and use of each term are described below.

Policy Written rule or set of rules, commonly found in governmental organisations. These policies describe the parameters of how structures work and within which activities take place. Sometimes will describe the activities that must take place (eg Village leaders must sign an agreement with the ESWCHP in order to initiate VHV services)

Accepted way of doing things - may or may not be written down, commonly found in organisations

May be official or unofficial

Rule Established way of doing things, that may or may not be written down

Prescribe the way something must be done.

May be official or unofficial

Activity Tasks or actions

Power Ability of an individual within an institution to access and manipulate a range of resources

Jackson (2001) emphasises the importance of being explicit about the methods used to interpret qualitative data so that the process is transparent and limitations are easily identified. In the paragraphs that follow I detail the methods I used and the processes I followed.

To enable interpretation, the 2006 responses had been systematically recorded into a database by the research team and coded by respondent type (eg VHV, village man, village woman and so on) and village. Responses were also coded so that they remained linked to the question the response was specific to. 
I firstly reread all the data, to reconnect with it for this research, and remind myself of the process I used for coding and recording the information. I then systematically reviewed the data again, documenting my interpretation and analysis on the detailed tables (which are attached as Appendices F-K). I then reviewed the data again, searching for themes or congruencies crosschecking responses from different codes for consistencies and divergences. Straus, cited by Crang (2001) 'emphasised that the constant comparative method of checking codes against each other was more 'verification' than inductive - that is checking that the categories used were consistent and supportable, asking how and why one category of responses differs from or echoes from another (pp 219)'. One of the tools that I used to assist in this crosschecking was a code map (a useful example of a code map is provided by Crang, 2001 pp 225). In this way I was able to record topics, subtopics, isolated comments, congruencies and divergences so as to create a system of categories that could be summarised into themes for reflection. In this way, whilst I did not have access to research team members, the cross checking that I was able to do on my own did go some way toward validating my interpretation.

I summarised themes and divergences from the analysis then checked them back against the 2006 Narrative Report and considered the similarities and differences, and changes to my positionality. I then considered my detailed analysis again to provide the reflections and suggestions that are documented in Chapter Six.

As I reviewed the detailed data, I looked not only at how people had responded to the question they were asked in 2006, but also sought nuances and key learnings from their words, and from similar responses and groupings of responses.

\section{Considerations}

As I prepared to undertake the research, and indeed throughout the process, concerns that I had when I did the original report once again emerged, even though I was applying a different logic to the analysis. For this reason I have adhered strictly to the SRA where possible to ensure that, irrespective of the findings, they are developed through use of the SRA, rather than as a result of my previous work and associated assumptions.

\section{Ethical Considerations}

This thesis represents a review of research conducted in 2006 on behalf of SCNZ and SCiPNG. In 2006, I completed an ethics committee approval application. Discussions about the research with the VUW Ethics Committee Coordinator at that time concluded that there were no obvious ethical issues within research design, mainly because the 
research involved largely a paper based process and intimate personal information was not involved. As a result Ethics Committee approval was not required.

I have considered the ethics of writing a thesis surrounding a current Save the Children project. I was concerned firstly to know that SCNZ was comfortable with me revisiting the 2006 data, and secondly to confer over my interpretations and finally my recommendations. During 2008 and 2009 I met infrequently with the SCNZ Pacific Programmes Manager to discuss the progress of this research. My freedom to use the 2006 data again was affirmed verbally in these meetings, and the Pacific Programmes Manager welcomed my analysis and suggestions for Project enhancement as a healthy part of the development process. Unfortunately I was not able to complete a substantive draft of this thesis in time for review and discussion before the Pacific Programmes Manager left New Zealand for work overseas.

As Crang (2001) points out 'there are many truths and realities, and there is no one correct interpretation. So we have a process of making interpretations of others' interpretations...however complex and difficult that may be' ( $\mathrm{pp} 216)$. The writings in this thesis have been distilled from my experiences throughout the research process. New ideas and understandings have been constructed that go beyond what respondents have said (Limb and Dwyer, 2001). Mohammed (2001) suggests that the 'authority of representation rests not on answering the question 'is this true?' but instead considering 'whose truth' it is' (pp 113). The views within this thesis are my 'truths', based on my analysis, my recollections and my positionality (Butler, 2001), and do not reflect the views of Save the Children or any other agency. I have also attempted where possible to expose the multiple meanings that exist within or beneath these 'truths'. The interpretations I have made in this thesis are mine alone and may align or differ with interpretations that others may make. No changes to the 2006 data have been made through this research process.

In this chapter I have outlined my overall research approach underpinned by the theoretical frame of three complimentary approaches of the gender and development, the capability approach and participatory development. I have described in some detail the methodology I have developed and used based on Kabeer's SRA, and qualitative research methodologies. In Chapter Four, I define the ESWCHP institution, and describe and discuss the detailed institutional analysis. 


\section{Institutional Analysis}

\subsection{Introduction}

In this chapter I draw on understanding from Kabeer (2004) to define the ESWCHP institution, considering what elements of the health care infrastructure in PNG and the East Sepik should be included, and those that should be excluded. Once I have defined the institution, I consider the locations of each organisation within the ESWCHP in accordance with Kabeer's institutional location methodology. I then discuss the institutional analysis utilising Kabeer's SRA Concept 3 (March et al (2000). This involves looking at five distinct but inter-related dimensions of social relationships that are common to all institutions and significant to the analysis of social inequality: rules, resources, people, activities and power (and benefits). This chapter provides discussion across these dimensions. The detailed analyses, are appended as follows:
Appendix F: Rules Analysis
Appendix I: Activities Analysis
Appendix G: Resource Analysis
Appendix J: Power and Benefits Analysis
Appendix H: People Analysis

SRA Concept 4, Institutional Gender Policies analysis (March et al, 2000) and discussion follows in the next chapter, Chapter Five. SRA Concepts 5 and 6, the Immediate, Underlying and Structural Causes analysis (March et al, 2000) is attached as Appendix K. Chapter Six provides reflective discussion arising from the detailed analyses and the Development Intervention. Finally, the analyses culminate in recommendations and completing a Case Study: Designing a Development Intervention provided in Chapter Seven.

Throughout this chapter I have relied primarily on Project documentation and transcripts of responses recorded as data in 2006. At points I have provided quotes from responses. This is done so that the perspectives of the participants are expressed in the words they used. Where the words they used did not make grammatical sense in the English language, I have summarised the quote, and indicated this in the text.

Sen and Grown (1987) argue that the perspectives of poor and oppressed women provide a unique and powerful vantage point from which to examine development programmes and strategies. In this same way, the participation of the local East Sepik people, the VHVs 
and the responses they provided created a significant body of information upon which to assess the social relations at play within the ESWCHP institution.

\subsection{Defining the Institution}

In order to conduct an institutional analysis, the ESWCHP needed definition. Kabeer (1994) defined an institution as a framework of rules for achieving certain social or economic goals. This was distinct from an organisation, which was the specific structural form that an institution may take. Using Kabeer's definition of an institution, the ESWCHP could be defined in a range of ways, depending on who was defining it and the purpose for which it was being defined. How the institution is defined (what organisations are included) is important because this defines the scope of the analysis. For example, key aspects of gender inequality could be missed if organisations that held power were not included in the institutional analysis. Alternatively, results could be skewed if only those agencies that held power were included, and those without power excluded.

The ESWCHP organisational structure of health services is shown in Figure 1 earlier in this document. I have redrawn Figure 1 and highlighted in green in Figure 5 below, those organisations and groups that I experienced as having a part to play in moving health care resources from the state level to the grass roots at the country and kin levels. The organisations in green are those I have included within my definition of the ESWCHP institution.

Figure 5: ESWCHP as Defined in Project Documentation 


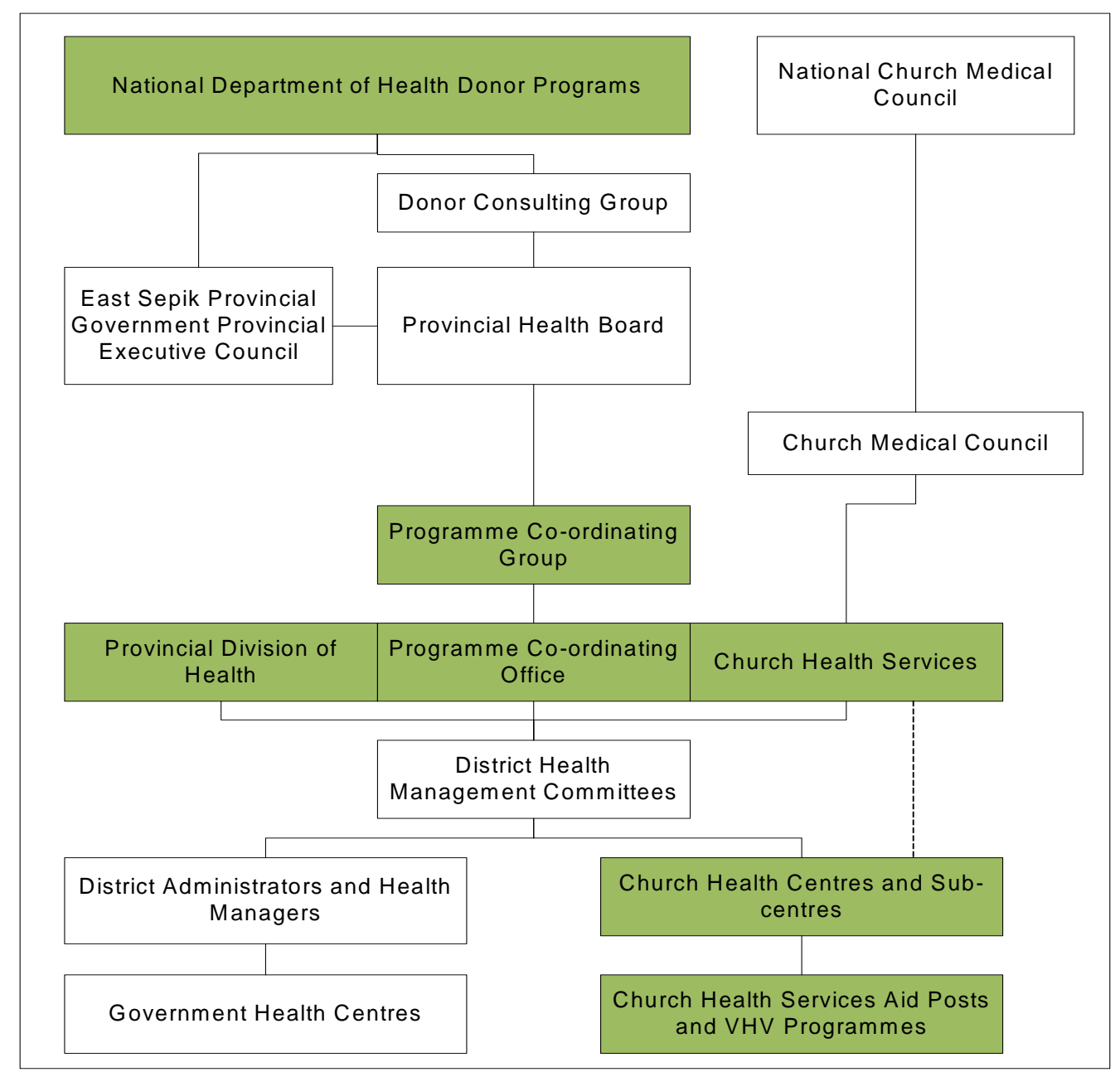

Reference: ESWCHP Summary Version of the Project Implementation Document, pp 14

I have excluded from my definition of the ESWCHP institution those organisations with which either I had no involvement, or I could see no obvious interconnection with, or influence on, grass roots health care provision. The excluded organisation and groups are shown in transparent boxes in Figure 6 above.

The SRA Concept 3 institutional analysis is shown on Table 6 below. The column titled Organisation/structural form contains those institutions I have included within my definition of the institution. Table 6 also identifies the key role of each organisation thus providing the supporting rationale as to why I have included them. Each of these organisations and groups interrelate and rely on each other in some way to provide grassroots primary health care.

Table 6: Institutional Analysis 


\begin{tabular}{|c|c|c|}
\hline $\begin{array}{l}\text { Key } \\
\text { institutional } \\
\text { locations }\end{array}$ & $\begin{array}{l}\text { Organisation/structural } \\
\text { form }\end{array}$ & Key role within the ESWCHP \\
\hline State $^{20}$ & $\begin{array}{l}\text { NZAID } \\
\text { National Department of } \\
\text { Health } \\
\text { Provincial Department of } \\
\text { Health }\end{array}$ & $\begin{array}{l}\text { Provides the majority of funding for the ESWCHP } \\
\text { Prescribes national health policy and standards } \\
\text { Provides health care services and infrastructure } \\
\text { essential for ESWCHP to interface with }\end{array}$ \\
\hline Market $^{21}$ & $\begin{array}{l}\text { Save the Children NZ } \\
\text { Save the Children in } \\
\text { Papua New Guinea } \\
\text { Catholic Church, South } \\
\text { Seas Evangelical } \\
\text { Church }\end{array}$ & $\begin{array}{l}\text { Receives NZAID funding and supports SCiPNG } \\
\text { through providing funding and required } \\
\text { management support and expertise } \\
\text { Receives NZAID funding via SCNZ and in return } \\
\text { provides ESWCHP management and } \\
\text { coordination in support of CHS } \\
\text { Central part of the ESWCHP and provides rural } \\
\text { health services. ESWCHP is transferring } \\
\text { management of VHV networks to these CHS }\end{array}$ \\
\hline$\underset{22}{\text { Community }}$ & $\begin{array}{l}\text { Save the Children in } \\
\text { Papua New Guinea } \\
\text { Village leaders } \\
\text { Local NGO stakeholders } \\
\text { (eg East Sepik Council } \\
\text { of Women) } \\
\text { Women's groups }\end{array}$ & $\begin{array}{l}\text { Provides grass roots support and coordination to } \\
\text { VHVs } \\
\text { Liaises and forms VHV agreements with village } \\
\text { leaders } \\
\text { Liaises with and supports CHS and village } \\
\text { leaders and VHVs } \\
\text { Provide support and communication network for } \\
\text { VHVs and CHS }\end{array}$ \\
\hline $\begin{array}{l}\text { Family/ } \\
\text { kinship }\end{array}$ & $\begin{array}{l}\text { Villages } \\
\text { Households } \\
\text { Families } \\
\text { Extended families }\end{array}$ & $\begin{array}{l}\text { Receive health care and provide support to VHVs } \\
\text { Support VHVs through 'in-kind' payment } \\
\text { Support VHV in providing services (eg arranging } \\
\text { transport for sick patient) } \\
\text { Be a VHV and provide services }\end{array}$ \\
\hline
\end{tabular}

Adapted from SRA Concept 3 (March et al, 1999)

To illustrate my definition of the ESWCHP institution, I have amended Figure 5 to include the broader range of organisations and groups I have included. My definition of the ESWCHP institution is shown is Figure 6 below. The directional arrows indicate in which direction authority flows. For example, Save the Children NZ reports up to NZAID on the progress of the ESWCHP, while it may set direction and organisational rules for Save the

\footnotetext{
20 These organisations are enshrined in legislation as part of the state and are state funded.

${ }^{21}$ These organisations exist based on funding for services. They are supported by donor agencies to provide health services either for or through the ESWCHP.

22 These groups and organisations are community funded and exist only through community support.

February $2010 \quad$ Page 70 of $176 \quad$ Ruth Heather
}


Children in PNG, which in turn, sets organisational rules and direction of the ESWCHP Office.

Figure 6 ESWCHP Institution Defined following Institutional Analysis

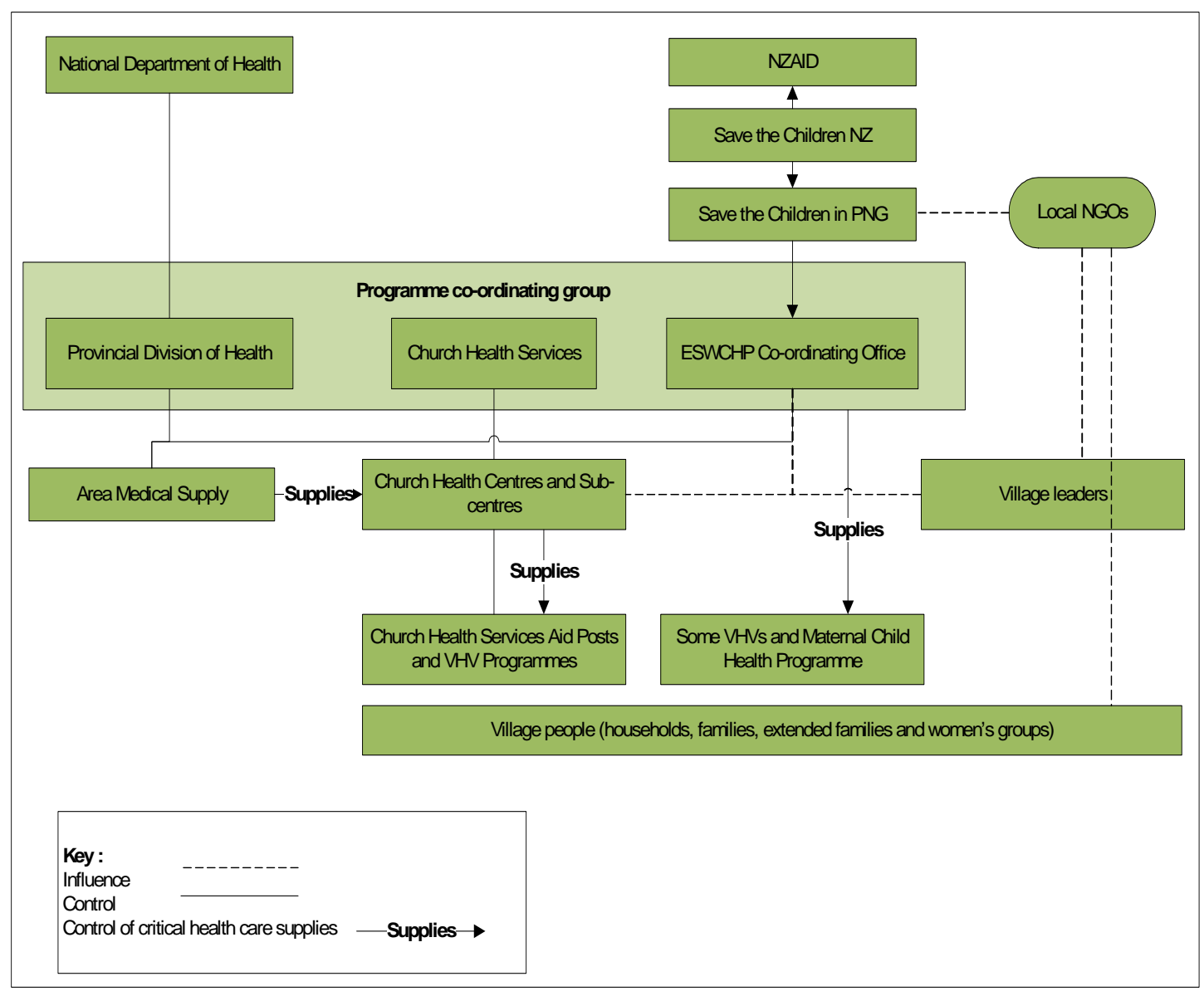

\subsection{Rules Analysis}

Kabeer's institutional analysis requires firstly an assessment of the rules (official and unofficial) that govern institutional behaviour and move resources from one place to another. The detailed rules analysis is shown in Appendix F, and documents the rules I identified based on my personal experiences and from analysing the research data. A range of rules exists within the institutions that make up the ESWCHP, which I discuss in accordance with the key institutional locations as shown on Table 5.

\section{State}

NZAID

From reading Project documentation, and from my meeting with the NZAID PNG Programme Manager during my 2006 visit, I was aware that NZAID provided the majority of funding for the ESWCHP. I was also aware that in return, NZAID required regular 
reports on Project achievement and fiscal management. The 2006 impact assessment for example was conducted to meet a NZAID reporting requirement of ESWCHP.

When conducting the institutional Rules Analysis, I expected to see NZAID policy requirements evident within the institutional hierarchy: embedded in Project documentation; obvious as a key influence on Project activities and ways of working; in discussions with Project and CHS staff, and in the way VHVs were supported. However, as the analysis progressed, the absence of rules set by NZAID, except for those noted above, became increasingly obvious. In fact I could find no evidence through the analysis of any influence from NZAID.

This gap I believe is of particular importance. As outlined in Chapter ???? NZAID has a key role in advancing development outcomes in the areas of health and gender. I expected to see these requirements built into Project documentation, come through in the analysis of the interviews with Project staff, CHS staff and VHVs.

I expected to see NZAID official and unofficial rules influence the Project in at least the following areas:

1) That NZAID required the ESWCHP to provide evidence of the impact of the ESWCHP through the monitoring of identified key health indicators of rural people ie that key health indicators would be clearly identified within Project documentation and well known across the Project, supported with active monitoring processes, that eventually fed into performance reporting to NZAID.

I expected to find evidence in the rules analysis that bore out NZAID requirements even if they were not specifically stated as a requirement of NZAID. To illustrate this, I repeat two questions that were asked of rural health managers in the 2006 research, and provide samples of responses ${ }^{23}$, with an explanation as to what could have come through but was absent.

\section{'Which aspects of health provision have improved as a consequence of training health managers?'}

Sample of responses:

${ }^{23}$ I have tried where possible when including samples of responses, to choose individual responses that reflect the majority of responses. 
'Aspects of health provision have improved.'

'VHV...activities have improved and also immunisation coverage by mission run health facilities.'

'Reduced workload especially small/minor illnesses that are treated by VHV and only major illnesses are referred to health sub centres.'

'Good Mother and Child Health programme conducted with the help of VHV'

'Safe Motherhood including antenatal care, supervised deliveries, family planning'

(Heather, 2006, ppRural Health Managers1)

\section{Has obstetric care improved? How do you know?}

Sample of responses:

'Yes, less maternal mortality rate, no record of deaths in the health sub centre record.'

'Yes, by seeing increased population in smaller villages that has VHV programme. Many mothers do deliver their babies with the assistance of VBA (VHV).

(Heather, 2006, ppRural Health Managers1)

Whilst interesting, responses do not clearly identify any prioritisation of activities, nor link any activities with the role of NZAID as funding agency. Rural health managers are relatively senior within the ESWCHP, so some understanding or articulation of the link of efforts to funding could reasonably be expected, IF it was a prominent part of ESWCHP. I would suggest that for a focus on key health indicators to become a prominent driver within the ESWCHP, it would need to be required (as an official rule in contract and/or Project documents) by NZAID.

2) Embedding the empowerment of women in all Project activities and ways of working, particularly around gender equality and women's empowerment

The NZAID website cites gender equality as one of NZAID's priorities. The website states that 'NZAID's strategic approach is to ensure that women's empowerment and gender equality are actively pursued in all development activities...gender equality is both an MDG in its own right and also a key means to achieving all MDGs... ${ }^{24}$. It is interesting to note however that the ESWCHP is not one of the projects listed by NZAID as 'examples of NZAID's support for gender equality and women's empowerment (ibid).'

${ }^{24} \mathrm{http} / / /$ www.nzaid.govt.nz/what-we-do/gender-equality.html

February $2010 \quad$ Page 73 of 176 
As I reviewed the Project documentation and 2006 data it became obvious that this was a gap. Only one response out of all responses mentioned gender. So whilst NZAID states that it enhances gender equality and women's empowerment through it's work, and through the projects it funds, it does not appear to require this of the ESWCHP. No official or unofficial rules were evident within the ESWCHP institution that worked to empower women or support gender equality. There was no evidence of gender awareness, gender training, or even equality in employment practices. The Gender Analysis is discussed in more detail in the next chapter.

The rules analysis left me with one unanswered question with regard to NZAID. Where did NZAID sit with regards to the official rule that VHVs were volunteers, and therefore not recompensed financially for their services? Was there an unofficial rule in place by default as a result of NZAID's support of the status quo? As I started to try to answer this question, I realised it was related to Kabeer's question in the analysis of 'who benefits?' I will continue this discussion under the Benefits Analysis heading below.

\section{National Department of Health}

The PNG National Department of Health provided a policy framework for rural primary health care (DoH, 1991). This policy framework defined the responsibilities of the National $\mathrm{DOH}$, the Provincial DOH, rural health staff, Church Health Services, the community, VHV coordinators and the VHVs. The DoH policy defined the status of VHVs as voluntia, and put VHVs under the management and authority of the village committee. Village committee responsibilities were defined as including such activities as deciding whether they want to support a VHV programme in their community; appointing a committee (that is equally represented by both sexes) to be actively involved in managing the VHV; selecting village women to be trained as VHVs; providing a community birthing house; and establishing the ways in which the trained VHV would receive payment for services to the community, whether cash or 'in-kind'. The DoH guidelines state that 'it must be remembered that VHV's are volunteers not paid health workers and they should not be asked to do too much work. Their services should be rewarded by the community they serve (DOH, 1991, pp 13)'.

The DoH policy (1991) also defined the legal and ethical responsibilities of the community council for the VHVs particularly with regards to issues of payback or retribution. A letter of agreement between the ESWCHP and the village committee was to be signed, thus signalling the commencement of the VHV's training, and followed by services to village 
people. CHS were to provide training and support, with the ESWCHP providing medical supplies and 'incentives' in the way of soaps, kerosene etc.

This policy framework provided a set of formal institutional rules that governed how key aspects of the ESWCHP institution functioned. These institutional rules were clearly evident and replicated in ESWCHP documentation, and enacted within the Project organisational structure, priorities and day-to-day activities.

\section{Provincial Department of Health}

The most obvious official rule pertaining to the PDoH was its responsibility for the allocation of access to and responsibility for the supply of medical supplies. Responsibility for medical supply was delegated to the PdoH Area Medical Supply Office (AMS) Manager. Government health services, the ESWCHP CHS clinics and VHVs were all dependant on the AMS for all their medical supplies, which were critical to providing health care. This rule gave the AMS Manager a significant amount of power across the entire ESWCHP institution - this is discussed further below.

No other rules arising from or surrounding the PDoH were evident through the analysis.

\section{Market}

\section{Save the Children NZ (SCNZ)}

Although I am certain there were official and unofficial rules laid down by, and within SCNZ, these did not come through clearly in either Project documentation, or through responses.

Just prior to leaving PNG, talk within the ESWCHP Office began to include Rights of the Child, which I deem to be a formal rule. This rule seemed new at the time, and efforts to integrate it into Project in the early stages. On reviewing my notes from the 2006 research, Project documentation and responses I saw no evidence of the Rights of the Child, or other rules I might have expected to see, such as in the areas of human rights, gender equality and women's empowerment, and organisational policies. I am sure that some of these rules (such as organisational policies) were in place, but they remained completely hidden from the analysis. The reasons for the lack of visibility of SCNZ rules also remained hidden from the analysis.

I would have expected SCNZ to attach both official and unofficial rules to SCiPNG use of NZAID funding, and these to be embedded in Project activities. It may be that these rules were in place, but just not evident through the analysis. It may be that SCNZ does not 
clearly establish rules for SCiPNG, because they act as distinct agencies each creating their own set of official and unofficial rules. Whether this is or isn't an important gap remains an open question. However, exploring a potential gap between these two Save the Children organisations is not the main thrust of this thesis, so I will leave the discussion here. I would however, raise the point that if Save the Children or others consider this gap warrants further analysis, it may also be pertinent to consider whether NZAID rules (both official and unofficial) seemingly absent from the analysis fall into the gap, and do not get translated on to SCiPNG and the ESWCHP.

\section{Save the Children in PNG (SCiPNG)}

In this institutional location, SCiPNG worked to access greater levels of funding to provide services. Rules surrounding and set by SCiPNG and the ESWCHP Office reflected the role of a management office and coordinating body that I had expected to see. The ESWCHP Office balanced the needs of the various groups and organisations within the institution and defined requirements to ensure that performance reports met the expectations of the funding agency (for example, by increasing numbers of VHVs, VHV training sessions, distribution of medical supplies, reporting on health statistics etc).

The ESWCHP also determined the coordination processes that were required in order for organisations and groups to access Project resources. The ESWCHP worked in partnership with the PDoH and CHS to establish rules within which these partnerships functioned to enable CHS to access funding. The importance of relationship management, coordination and partnership are shown clearly in the Project Organisational structure (shown in Figure 1). Decisions made by the Programme Coordinating Group (chaired by the ESWCHP Programme Manager) were then dictated out through the institutional hierarchy. It was through this group, that it was decided the catchment areas would no longer be supported directly by the ESWCHP Office, but instead VHVs would receive support directly from the CHS. Decisions such as this became formal institutional rules that changed responsibilities and practice. Numerous responses from VHVs indicated their discomfort with receiving support from CHS instead of directly from the ESWCHP. For example in response to questions about whether VHVs were getting enough medical supplies from CHS, to be able to treat village people, VHVs stated:

'its on the hands of the nurses'; 'no one was getting the medicine from the church'; 'church are not going on patrol to see them [VHVs]' (Heather, 2006, VHVpp22). 
Project decisions like this one made by the Programme Coordinating group, did not allow for VHV involvement or participation in the decision-making process. To me, the VHV responses above conveyed a level of frustration. My assumption based on responses such as these was that VHV frustrations were directed at a perceived lack of ability to influence decisions such as this one, or to influence CHS activities to support VHVs in the field.

I observed clear differentiation between the roles of women and men within the ESWCHP institution. This suggested to me that gender based rules existed that placed people in roles according to gender based expectations. This is discussed in the next chapter, Gender Analysis.

\section{Church Health Services}

From my observations in 2006, I noted there were constraints within CHS regarding who was able to be involved and who did what, signalling the presence of both official and unofficial rules. Religious doctrines prescribed a range of official and unofficial policies surrounding social behaviour. To belong to a particular religion, there were official rules around religious beliefs and social behaviour. The church defined religious beliefs and the extent to which these were to be adhered to as part of service provision. Official rules within Catholic catchment areas dictated decision-making hierarchy, by gender and religion. Discussions with the research team, and Catholic VHVs clarified that the Priest was able to dictate any aspect of life within the village including whether or not the men were able to have vasectomies, the women use family planning methods or whether HIV/AIDs education was able to be provided. For example, when asked whether VHVs gave them what they needed to protect their sexual health, many rural people responded affirmatively. However in amongst the affirmative responses was the occasional negative response such as this one from a village man:

'it is also against the church belief it will encourage prostitution and not being faithful'; and this response by a village women:

'yes the VHV gave us enough condom, but only to the married people and not to young people' (Heather, 2006, ppRural People20).

The priest held the most senior position within the Church community and was therefore able to overrule any decision made by others, including VHVs and senior CHS managers.

Underpinning the official religious rules, were unofficial rules. It appeared that there was an unofficial policy that required people to espouse the relevant religious doctrine, or show their beliefs obviously through their actions (praying, singing or attending church etc). 
This was most obvious amongst staff in the Catholic Health Services. At times I sensed what could almost be described as an attitude of fear or trepidation, if discussion moved into areas against religious doctrine or outside the authority of the church. It appeared that women, who espoused the relevant religious doctrine and participated in appropriate religious activities, had the greatest chance of career progression.

Official rules within CHS related to formal qualifications such as qualified nurses, occasionally doctors, trained health assistants and others. Qualifications created a range of official rules around authorities and scope of decision-making, setting qualified staff well above non-qualified staff (such as VHVs or drivers). Formal qualifications seemed to form a level of protection against personal blame in case of poor patient health outcomes.

Rules surrounding management responsibilities were less formal. It appeared that people were appointed to management positions largely on the basis of ability and experience rather than necessarily hierarchy within the church, although that often went together. For example, in the Catholic CHS the most senior nun was also the most experience manager, and held the position of Catholic Health Secretary. For the South Seas Evangelical CHS the Health Secretary position was held by an experience Pastor. Women held a number of Rural Health Manager positions, although the detailed roles analysis (later in this chapter) shows that the proportion of women managers was low compared to men.

CHS generally had ready access to medical supplies, ambulances and controlled how, when and in what context these were made available. For example, in 2006, VHVs in Kambot described how often the ambulance was not available when required to transfer a sick patient to Boram Hospital in Wewak - the manager or other senior staff member for other activities would have commandeered it for personal use. CHS control over access to critical medical infrastructure and supplies could have significant impact on the health and well-being of the local population.

\section{Community}

\section{Save the Children in PNG (SCiPNG)}

In this institutional location, the SCiPNG ESWCHP drew on local people to staff many of its operations. As a result, many of its rules and activities were directly linked into local cultures and mores. Within the ESWCHP, many staff have familial and or cultural links to grass roots people, and in fact often live in village settings when not at work in Wewak (ie for holidays or other leave). This brought unofficial cultural rules into the office setting, 
most obviously seen through gender-based allocation of roles - discussed in detail in the following chapter.

The ESWCHP in this institutional location, provided support directly to VHVs thereby establishing unofficial rules for the types and levels of support required. This included working with village leaders to promote and ensure ongoing support for VHVs from communities.

The ESWCHP also set official rules for the level of support CHSs' were to provide to VHVs. It seems from responses that these levels were treated as unofficial rules by some CHS and not necessarily adhered to, particularly in the area of medical supply. Instead, the CHS established its own set of unofficial rules, such as ensuring CHS clinics had sufficient medical supplies (even if this meant stripping supplies out of VHV medical supply bundles) prior to providing any supplies to VHVs. Another unofficial rule set by CHS was whether or not VHVs were required to pick up their supplies from the clinic or whether the CHS would arrange for delivery. This seemed to be dependant on CHS willingness to pay for transport costs. In many cases it appears that this cost was transferred to VHVs, whereas previously, when the VHVS were directly supported by the ESWCHP, supplies were delivered.

These unofficial rules and their impact on VHVs came through clearly in responses from both VHVs and CHS rural staff.

\section{Village leaders}

Village leaders appeared to own a range of rules pertaining to life in the village and the roles of men and women. Village leaders decided whether or not the village had a VHV, who the VHV was, and whether or not the villagers supported her (through providing her with a meresin haus, and 'in-kind' payments for services rendered). The VHV contract was agreed between the Project and the village leaders, not with the VHV.

Discussions with the research team in 2006 revealed that community leaders were generally men; often older men or men with particular responsibilities or influence. This was at odds with the $\mathrm{NDoH}$ official policy requirement that the community committee responsible for managing the VHV should reflect the sexes equally.

The institutional analysis of 2006 responses indicated that village people listened to the VHVs advice if the community leaders were supportive, for example: 
'I see that the community leaders stand with me and my work is good' (Heather, 2006, pp VHVs12).

There were no responses that directly stated that community leaders did not support them, but numerous responses about the lack of community support for example:

'it is altogether hard because the communities are not supporting the volunteer work' ; 'we want to work, but there is no support from the people and the leaders' (Heather, 2006, pp VHVs79).

\section{Local NGOs}

While the ESWCHP began as an initiative for women with strong links into local women's NGOs, there was little evidence of their involvement in 2006. They were not formally part of any Project meeting, and frustrations from some of the older women ESWCHP staff were voiced at the lack of representation and interface particularly with the East Sepik Council of Women. There were no rules that I observed in 2006, or that were revealed through the analysis regarding local NGOs. The table in Appendix F does not contain a column for local NGOs. This reflects the absence of rules and participation in the ESWCHP by local NGOs.

This is another gap highlighted by the institutional analysis.

\section{Women's Groups}

Women's groups did not feature amongst responses, or in Project documentation. I do remember however, VHVs and Project staff mentioning these groups. My recollection of these discussions between women were that "while the men made decisions, the women just got things done' and that these groups were a way for women to discuss community activities, and consolidate support for each other.

This is another gap highlighted by the institutional analysis.

\section{Family/Kinship}

Village people

The analysis showed that village people generally shared rules with village leaders. Where village leaders generally made decisions, village people had the power to enact (or not) these decisions through their actions. This dynamic could place the VHV in an interesting and at times difficult position, if the village leaders and village people were in conflict and the VHV and/or her services were caught in the middle. In the cultural context of PNG, and the gender inequality and risks of violence to women in general, this could become 
particularly problematic. Underhill-Sem \& Peutalo (2006) made a recommendation highlighting how important it was that the ESWCHP address personal issues faced by VHVs: 'Pay more attention to advocacy activities such as negotiating and updating village contracts; liaising with grassroots health care providers regarding personal issues (illnesses, threats from community, family strains)' (pp iii). Examples of the complexity in which the VHVs at times found themselves caught were disputes over the haus meresin or birthing hut. In some villages the community committee wanted the facility to be built but the village men did not agree or did not want to build it, so no haus meresin was built. This meant that women were then required to give birth in their homes, which were not always suitable, and undermined the position and status of the VHV as shown in a quote from a VHV... 'they don't come to see me because I don't have a labour room or haus' (Heather, 2006, pp VHVs61). VHVs also spoke of experiences where groups of men commandeered birthing huts to play cards, gamble and drink, making the hut unavailable to the VHV and birthing woman, and put them at risk if they tried then to access the facility.

\section{VHVs}

I did not observe or see from the analysis, any rules that had been put in place by VHVs. Numerous VHV responses highlighted their success through influence and education rather than through the setting of official or unofficial rules. For example:

'we give health talk to our community on family planning and there are changes to the lifestyle through spacing families' and 'We see that the health talk brings change to the community, they follow personal hygiene, they clean the village and make clean toilet areas. They look after the body and cook good food to eat. They all listen and follow (Heather, 2006, pp VHVs12)'.

VHVs were subject to official and unofficial rules from cultural and community mores, the ESWCHP and CHS. VHVs needed to be able to balance the unofficial rules of village life by meeting her responsibilities for child rearing, growing food and caring for the extended family along with housekeeping (Korare, 2004). In addition to this, VHVs needed to adhere to the rules provided as part of VHV training, and meet community expectations for primary health care services.

The official 'voluntia' status may support VHVs' empowerment through training and service to the community. Their lack of formal and lengthy training, left VHVs, along with being outside a formal health service, left VHVs open to personal blame and 
retribution in cases of poor patient health outcomes. The status and safety of the VHV were potentially at risk if the community did not support their actions, through payment for services, or in the case of retribution should the community be unhappy with events or the result of care (for example in the case of maternal or infant death, or death of an adult if the VHV is not able to provide adequate health treatment).

Although women have traditionally been healers in their communities, the services voluntia are expected to deliver through the ESWCHP represent a greatly expanded role (as discussed earlier in relation to the welfare approach and WID efficiency approach). Voluntia often work long hours and as a result find it difficult to fulfil their traditional gender roles in relation to family and production (Underhill-Sem \& Peutalo, 2006), placing them at times at risk of violence. For example, VHVs 'have reported incidences of violence inflicted by husbands when meals have not been delivered on time or when gardens have been left unattended' (Underhill-Sem \& Peutalo, 2006 pp 29). The way that the institutional rule has been established by the $\mathrm{DoH}$, is that the community pay the VHV either in cash or 'in-kind' (DoH, 1991). If this payment is not forthcoming, the VHV may find herself unable to meet all her other responsibilities, and could be placed at risk of violence from her family and community if they feel she has not met their needs adequately.

Official and unofficial rules have established the hierarchy the VHV find themselves in. As the institutional analysis will show, these women provide the majority of the labour resources, with the least amount of power and for limited benefit, and are generally dominated by men. In the context of the violent communities ESWCHP VHVs live and work in, these unofficial rules relating to their position in the hierarchy can make them vulnerable to violence personally, and / or ill-equipped to deal with violence toward the people they provide health services to.

Much of the violence experienced directly relates to childbirth (Garap, 1999) and the results of violence can therefore become part of the context of the health care VHVs are called on to provide. Issues of violence did not come through in the data, as it appears that is it rarely discussed openly, particularly with outsiders such as myself. However two response from VHVs may have been referring to violence: 'We send two of the pregnant mothers who have bad marks to hospital' (Heather, 2006, ppVHV 58) and 'there's no help from the Police' (Heather, 2006, ppVHV 63).

In addition, the VHV may find herself at the heart of complex cultural issues if perhaps the child she delivers is born to an unwed mother, the result of infidelity or rape, or if the February 2010 Page 82 of 176 Ruth Heather 
labour has been brought about prematurely due to a severe beating. In the latter case potential health issues for both the mother and child may arise linked to high maternal morbidity and mortality rates and to the death or disabling of unborn children (Garap, 1999). This NDoH official rule puts VHVs under the management and authority of the village leaders. Should the village leaders decide they do not support the VHV in the case of issues of payback or retribution, the potential for significant abuse and violence cannot be ignored.

In summary the NDoH Policy put in place official policies that determined the institutional hierarchy and arrangements by which rural primary health care via ESWCHP, CHS and VHVs should be delivered. It appears that policies (official rules) were set nationally and provincially, and enacted through the ESWCHP and CHS structure and activities with little input from communities or VHVs. The official NDoH policy combined with unofficial community rules set by culture, community leaders and village people created variable environments for VHVs, varying access to medical supply, levels of support, and putting VHVs at significant risk of violence. VHVs often faced problems resulting from unofficial grass-roots cultural rules, family disputes, disagreements between the women and men of the village and differences between factions within the community.

The rules analysis bore out Kabeer's (1994) argument that women (in this case VHVs) were embedded in communities on which they relied to survive; and that it was the poor people, usually women, who were excluded from formal institutional allocations of resources.

The rules analysis has also showed that without an explicit focus by the Project on the issues VHVs face they can lose traction in their negotiations within the complex social relations (Underhill-Sem \& Peutalo, 2006), which impacts their ability to deliver health care and remain safe.

\subsection{People Analysis}

Kabeer's institutional analysis (March et al, 1999) required an assessment of which people are selected to do the roles that they do, who is allowed into the institution to do what roles, who is not allowed in, and who does what. The detailed analysis (attached as Appendix H) did not show conclusively which people were chosen to participate and for what roles. The Rules, Resources, Activities and Institutional Gender Policies analyses provided a greater insight than the People Analysis with regards to who did what and who participated in what roles within the ESWCHP. 


\subsection{Activities Analysis}

Kabeer's institutional analysis required an assessment of the activities that took place within the institution; essentially, 'what gets done' within the institution. I completed the analysis based on a review of the data and the memories of my experience in 2006 . The detailed activities analysis (attached as Appendix I) showed that activities appeared broadly consistent with those required to manage the provision of primary health services in a de-centralised health system (Thomason et al, 1991; Bolger et al, 2005).

\section{State}

NZAID did not feature in the analysis as being obviously responsible for any particular activities.

The NDoH and PDoH were responsible for regulatory, training and monitoring activities.

\section{Marke†}

SCNZ did not show up through the analysis as being obviously responsible for any activities.

The SCiPNG ESWCHP Office was responsible for activities consistent with a coordination role, such as providing regular liaison with CHS and VHV coordinators, supporting VHV training events, monitoring CHS progress, holding coordination meetings with key stakeholders, and monitoring the overall management and progress of the institution.

The majority of health service activities fell within the responsibilities of CHS (including supervision and oversight of VHVs). CHS provided support to VHVs by way of training, liaison, and the provision of medical supplies. CHS were also responsible for nurse assessments on patients referred by VHVs, and transport to hospital in Wewak if further medical attention was required. CHS maintained and managed resources such as ambulances, fuel, and a wider range of medical supplies than was available to VHVs.

\section{Community}

The SCiPNG ESWCHP Office was responsible for activities consistent with a coordination role, such as providing regular liaison with CHS and VHV coordinators, supporting VHV training events, and supporting VHVs as required. ESWCHP Office staff undertook regular visits to villages.

Village leaders, local NGOs and women's groups' activities were not obvious in the analysis. The main role of village leaders was to enter into an agreement with the ESWCHP to establish VHV services, and then to oversee and support the VHV. The lack 
of prominence in the analysis of village leaders activity, may suggest that unless the Project proactively requires village leaders to refresh their agreement, and to provide active support of the VHV it may not occur. This finding is in alignment with the Underhill-Sem \& Peutalo (2006) recommendation provided above that the ESWCHP should 'Pay more attention to advocacy activities such as negotiating and updating village contracts; liaising with grassroots health care providers regarding personal issues (illnesses, threats from community, family strains)’ (pp iii).

The absence of activities for which local NGOs and women's groups were responsible reflects the lack of interconnectedness of the ESWCHP with these groups.

\section{Family/Kinship}

Village people featured within the analysis as either providing support through payment 'in-kind', building haus meresin or listening to what the VHVs had to say and following their teachings around healthy lifestyles, as evidenced by the following quotes from rural people:

'There was a change in the community when the VHV came into the village that slows down the sick and the mother[s] look after their children well and the community was clean' (Heather, 2006, ppRural People2).

and

'build good toilet, good water supply, look after village and good food' (Heather, 2006, ppRural People22)

and

Before there was no changes in the village when our houses were not ventilated, no mosquito nets, grass was long near the houses, no proper toilet and water to drink...now all this have totally changed' (Heather, 2006, ppRural People23).

Village people also featured in the responses where they did none of these things, such as in this response from a village man:

'common type of sickness do appear when we forget to remind the community cooperation from all the people is also required in order to help the VHV' (Heather, 2006, ppRural People13).

It was interesting to note that the majority of responses from rural people suggested that they were quite supportive of VHVs, whereas responses from VHVs overwhelmingly asked for greater levels of support. This confirms again the Underhill-Sem 
recommendation (mentioned earlier) that the Project should proactively advance advocacy work with communities to negotiate and update contracts. This would include clarification of expectations and agreement between VHVs and village people as to appropriate levels of support.

\section{VHVs}

VHVs provided the bulk of front-line basic primary health care and health promotion, including family planning advice and supplies (when available). They did this alongside the other activities they were responsible for as part of their role as village women. Activities undertaken by village leaders and village people as part of their role within the ESWCHP were related to supporting VHV services, through building haus meresin, providing access to fuel, and 'in-kind' payments for services rendered.

While rules are made at the National, Provincial and CHS/Project level, the bulk of the activities for front-line primary health care fell to voluntia, without the corresponding ability to control these activities (through rules) and access essential supplies (through power). They are not paid, so unless they are well supported and protected by village people, are at risk of compounding levels of required activities just to make ends meet. Some excerpts from responses of VHVs to questions about the issues they face and the level of support are summarised below...

'We work seven days a week but get no support from the community. We face problems with our family and our husbands complaining about money, who say 'you are not paid by that job' and that we should stop the voluntary job. We don't have time to find the small amount of money needed to look after our family. We are finding it hard as we all have kids in school and are running out of money and food.'

'I find it hard to look after families as well as working because there is no support from the community' (Heather, 2006, ppVHVs79).

The activities analysis suggested an alignment of the ESWCHP to the WID efficiency approach as discussed previously. The efficiency approach assumed that women were an under utilised labour force which could be exploited at low cost, with women's time being elastic and able to be stretched to include tasks that fell on them as social services declined (Karl, 1995). Women's participation was deemed equity. The efficiency approach aimed to ensure that development was more efficient and effective through a greater contribution from women. The ESWCHP exists in the context of scarce funding, inconsistent government funding for rural health services and therefore relies heavily on donor funding. 
In this context it seems logical for the Project to find the most cost effective way possible for providing the majority of the activities required for basic primary health care to rural and remote villages. The Project has done this, through extending the existing role of rural women to encompass primary health care delivery, and provides training and some support through CHS. I would suggest that the process of determining the most appropriate cost effective model for primary health care is the responsibilities of institutions within the State and Market locations and is related to Kabeer's question of 'who benefits'. This question is explored in more detail below.

\subsection{Resources, Power and Benefits}

Kabeer's institutional analysis (March et al, 1999) required an assessment of how resources and power were used and created within an institution. The detailed analyses are attached as Appendix $G$ and $J$ and are based on a review of the Project documentation, the 2006 data and my personal recollections and notes.

\section{Resource Negotiations}

All organisations within the ESWCHP institution appear to be engaged in the process of negotiation of resources as shown in Figure 7 below.

Figure 7: Overview of Resource Negotiations within the ESWCHP Institution

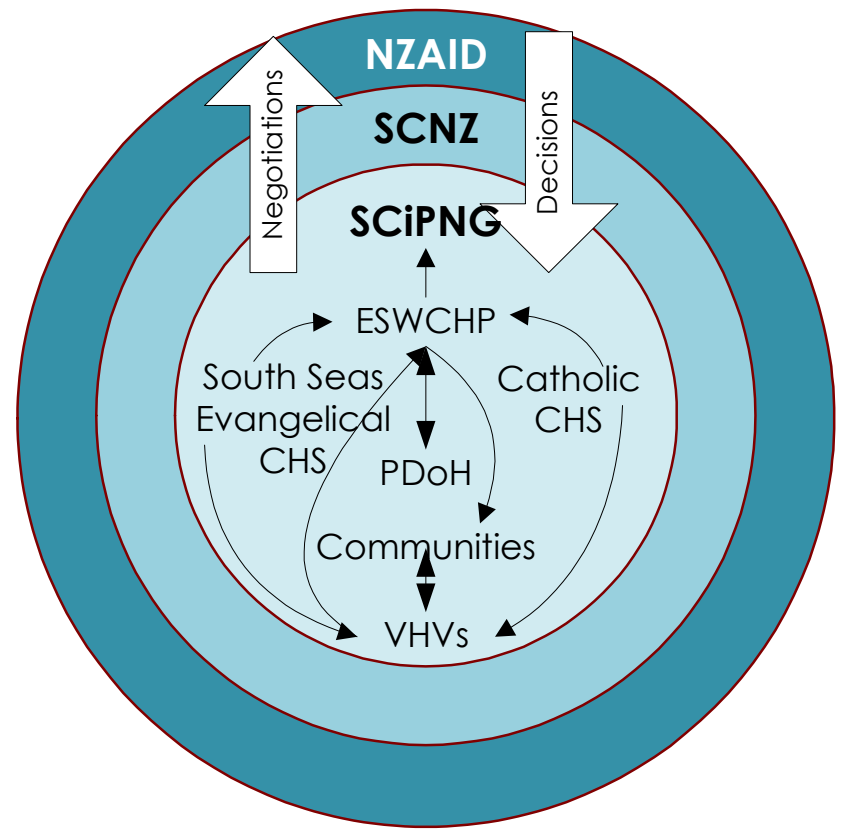

Resource negotiations seem to occur within two distinct settings. The first setting is the negotiation for Project funding, which appeared to take place between the Market and State located organisations of SCiPNG, SCNZ and NZAID. It appeared that to confirm annual funding levels, SCiPNG negotiates with SCNZ to agree resource levels; SCNZ then negotiates with NZAID. (It should be noted here that I have not had access to SCNZ staff 
to confirm this, so these are my assumptions based on the institutional hierarchy and available Project literature.) The ESWCHP Summary Version of the Phase II Project Implementation Document (ESWCHP PID) identifies 'funding sought' as PNGK18 003 000 spread over 7 years. In light of this, I have assumed that the ESWCHP PID is a key negotiation tool for SCiPNG; and that it is this document, once agreed with SCNZ, that is used as the basis of negotiations for funding between SCNZ and NZAID. Whilst PDoH and CHS stakeholders may have influence in providing the initial resource request (through the development of the ESWCHP PID, I could see no evidence of their direct involvement in negotiations with either SCNZ or NZAID. Whilst the negotiations go up the institutional hierarchy, the decisions come down, from NZAID, via SCNZ to SCiPNG, as shown by the white arrows in Figure 7 above.

The second distinct negotiation setting involves agencies at the State, Market Community and Family/Kinship institutional locations: PDoH, ESWCHP Office, CHS, Communities and VHS. This second setting also involves negotiations between CHS, communities and VHVs, who constantly seemed to be in negotiation for facilities, vehicles, fuel, medical supplies and better reward/pay.

Communities and VHVs seemed to negotiate informally and consistently with the ESWCHP Office and with CHSs to attempt to increase the resources they have access to. Every opportunity was taken to conduct resource negotiations. Numerous responses in the 2006 data appeared to more aligned to direct requests for additional resources rather than responses to research questions; suggesting that some respondents saw the research process as an opportunity to negotiate for additional resources. Examples of these sorts of requests follow:

Quotes from village women:

'We have a major need in the village when the medicine finishes. We are finding it hard to get the supplies from the health centre. Would you make a schedule for every month to supply medicine? If you provide your own transport, that would make it easier for the VHV' (Heather, 2006, ppRural People28).

'The VHV needs an outboard motor and a canoe to do work, especially in getting medical supplies to the village when there is a shortage of medicine' (Heather, 2006, ppRural People44)

'Should VHVs be paid? Get a kind of payment from SCF like soap and biros?' (Heather, 2006, ppRural People46) 
'My concern is, it's about time the VHVs must be paid for what they are doing. It's their tenth year now to be as volunteers. This will really motivate them to do their work' (Heather, 2006, ppRural People52)

Quotes from VHVs:

'My need is can the organisation help us by paying us with some money?'

'Can we be on payroll?’ (Heather, 2006, ppVHV78).

In addition to these sorts of responses, a handful of letters were received requesting additional resources.

Pressure from Communities and VHVs flows through to CHS who in turn, negotiate with the PDoH around medical supply and with the ESWCHP Office for resources.

Negotiations between ESWCHP, PDOH and CHS appear to be more formalised. The ESWCHP Summary Version of the Phase II Project Implementation Document (Save the Children New Zealand, Unpublished) identifies the following coordination groups who appear to participate in resource negotiations:

- The Programme Coordination Office, whose purpose is to 'enable the three main stakeholders to make joint decisions'(SCiPNG, Unpublished, pp13). The document does not identify who the three main stakeholders are; I have assumed they are the ESWCHP and the Catholic and South Seas Church Health Services.

- The Programme Coordinating Group, which meets quarterly to make management decisions as necessary. The group is chaired by the Provincial Administrator and includes representatives from ESWCHP, PDOH and CHS.

- The Donor Coordinating Group, which meets on a semi-annual basis. 'Participants will include donor and senior departmental representatives. Discussions will focus on funding responsibilities, bottlenecks, reporting status etc' (SCiPNG, Unpublished, pp13).

I attended one of the Programme Coordinating Group meetings and was present to hear discussions around Catholic CHS requests for an additional vehicle and staff housing, so was able to see these resource negotiations in action.

The ESWCHP Office seemed to stand alone as the one party all resource negotiations went through. 


\section{Power}

State

$\mathrm{NDoH}$ and PDoH policy makers were few in number and likely to be male (DicksonWaiako, 2006) with the ability to dictate gender balance across the health infrastructure through policy. The key resources that policy makers had access to personally, was a personal salary that would have set them apart from most rural people, status and the ability to wield their power to influence. The power and influence policy makers were able to wield was far ranging. However, policy makers access to power, specifically with respect to the ESWCHP was limited. They had little access to day-to-day decisions and no obvious ability to directly access or influence project funds or resources.

\section{Market}

Project funds flowed from state institutions down to the market level (ESWCHP Office, CHS) where largely men held decision making authority to determine how these scarce funds would be prioritised and used. Those at the market level of the ESWCHP institution wielded the most power and had access to the most resources. The organisations of the South Seas Evangelical Church, the Catholic Church and ESWCHP Office were able to collectively prioritise access and use of resources. As a result, resources (such as paid staff, infrastructure in the form of staff housing, clinic facilities, vehicles, office equipment, communications equipment) remained largely at this level, rather than being funnelled through the system to rural people via the VHV. This made the organisations at the market level very powerful and comparatively resource rich.

Village leaders (at the community and family/kinship level) had a measure of power proportionally larger than VHVs but much less than those within the CHS or the ESWCHP.

\section{Family/Kinship}

There were approximately 420 VHVs within the ESWCHP. The analysis showed that VHVs had the least power and the least ability to access critical resources - even those (such as medical supplies, training, and 'in-kind' payments) that enabled them to provide the basic health service. VHVs provided the majority of basic health care services and had access to the least resources. The analysis also showed that the majority of the labour resource was provided at the family/kinship level by VHVs with some resources supplied (as 'in-kind' payment) from the community. 


\section{Summary of Resources and Power within the ESWCHP}

In summary, the analysis showed that within the ESWCHP resources and power were closely aligned. Those that had the most power had access to the most resources. The analysis showed that while policy makers had a significant level of authority, those at the senior ESWCHP and CHS level had the most power and therefore access to Project resources. The analysis also showed, that community leaders had little power or access to resources, with VHVs the least. This is illustrated in Figure 8 below.

Figure 8: Diagrammatic View of the Balance of Power within the ESWCHP

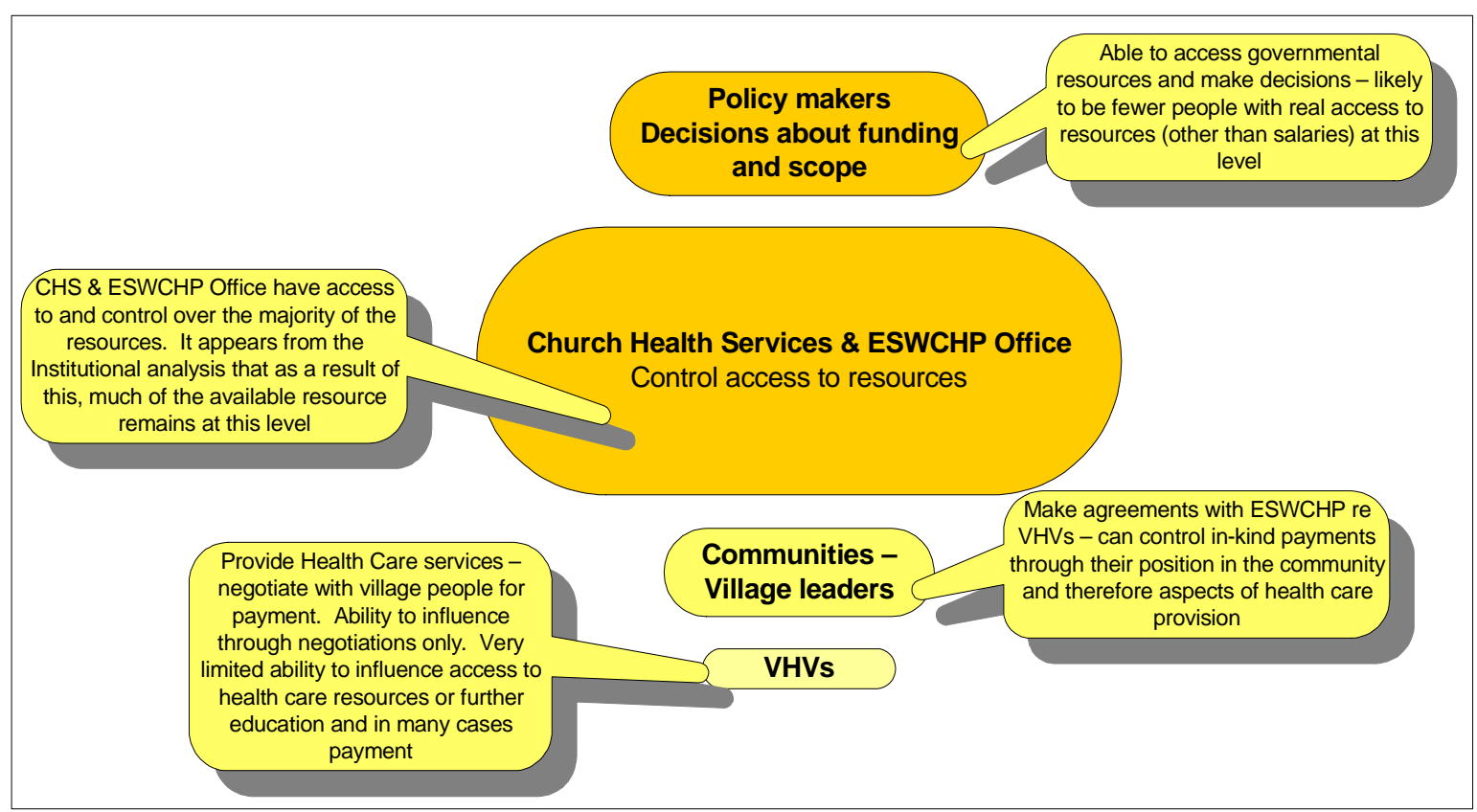

Just as resource labour did not really go 'up the chain' within the institution, in the same way funds didn't get funnelled 'down the chain'. Tthe analysis showed that resources in terms of funding remained largely at the market level of the institution, whilst resource labour (generally women voluntia) remained at the community level. This is illustrated in Figure 9 below.

Figure 9: Diagrammatic View of Resource allocation within the ESWCHP 


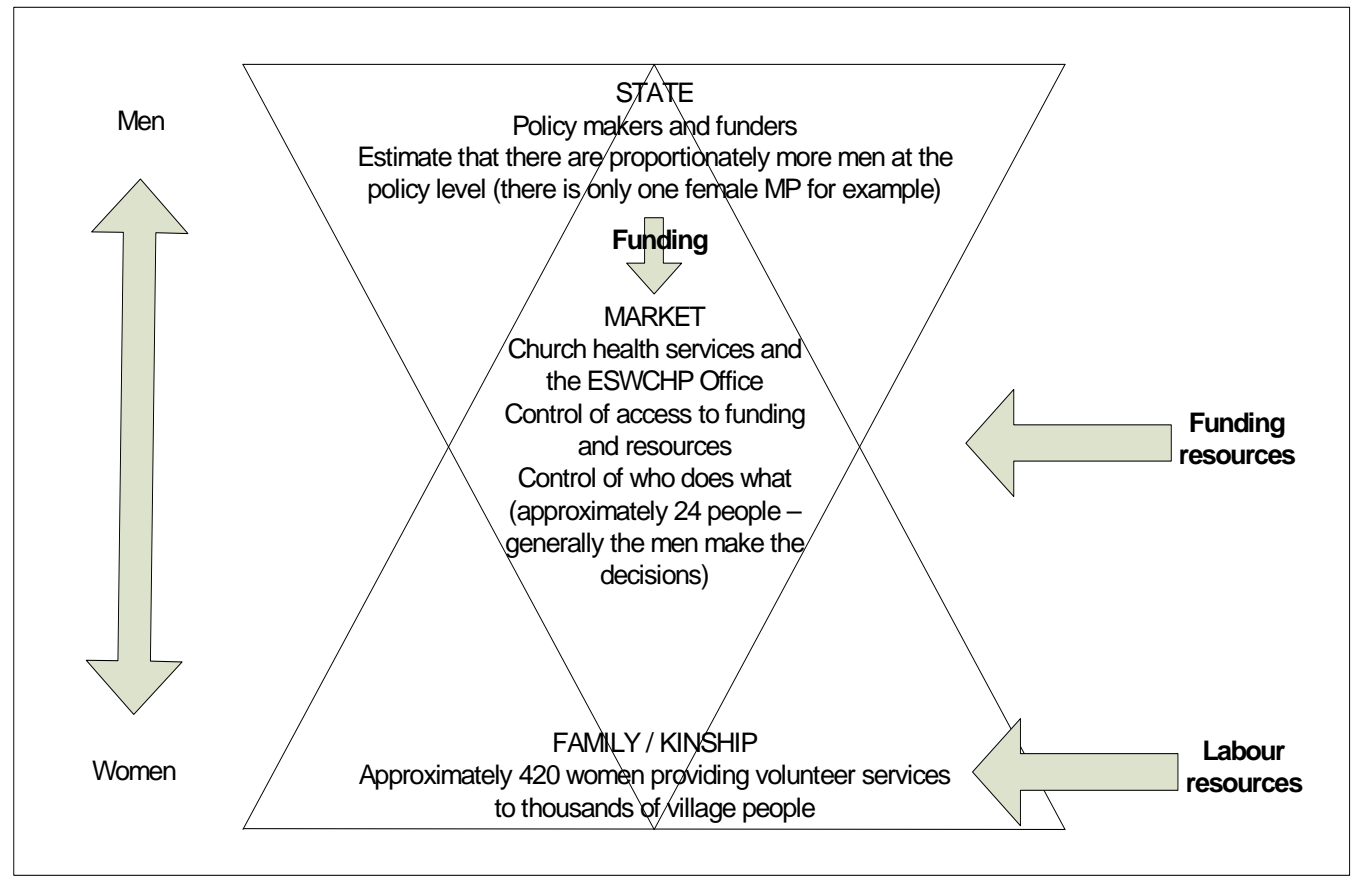

\section{Example of power dynamics - control of medical supply}

The PDoH Area Medical Supply Office (AMS) was responsible for purchasing, storing, and delivering medical supplies to the ESWCHP Office, CHS and VHVs. As a result of this responsibility the AMS manager was able to control the supply of medicines, and health equipment. The level of power experienced by the AMS Manager was evident in numerous ways: through his demeanour at Project coordination meetings, which I attended in 2006, and overwhelmingly through the data. An overwhelming number of responses signalled issues with medical supply. Frustration with the AMS was reflected in responses from all respondent types and across all aspects of the ESWCHP institution, from senior ESWCHP management staff, through to VHVs. Issues raised in responses ranged from lack of supplies, to decisions by the AMS not to deliver supplies, but to require CHS staff to collect them, shifting the cost of transport from AMS to the ESWCHP. For example, from a woman Rural Health Manager:

'Can the AMS drivers help in transporting our supplies when we need them? At times the AMS transport do not help and we find our own way to move our supplies to our various sites, eg by hiring PMV and private cars' (Heather, 2006, ppRural Health Managers10)

Control over medical supply could at times mean control over life and death, and lack of medical supply affected the well being of whole communities. For example, if critical postpartum haemorrhage medicines are not available, then a woman could die from bleeding following childbirth; a village where malaria was endemic (due to lack of 
mosquito bed nets and anti malarial treatments) notable for the general lethargy and anaemic presentation of its inhabitants, and high incidence of malaria related mortality from illnesses such as ruptured spleens (Underhill-Sem \& Peutalo, 2006). Control over the supply of medicines impacted the ability of the VHV or CHS to provide even the most basic health care and affected the status VHVs gained through administration of critical medicines to support their status and empowerment within the community.

Just before I left the East Sepik, the AMS Manager informed the ESWCHP that the AMS office was closed for the month. Apparently the AMS had 'run out of kina', so no supplies would be available for the next 4 weeks. CHS and VHVs who were scheduled to receive critical life-saving medical supplies, did not receive any that month. The levels of frustration at the office closure, and lack of consequence to the AMS office for 'running out of kina' was evident amongst all ESWCHP staff. How this had happened and where the money had gone to was not clear, but ESWCHP Office staff just shook their heads; apparently this happened at reasonably frequent intervals. There were many unanswered questions and frustrations as a result, but what did remain clear, was that the AMS Manager had the authority to manage money for medical supplies, and he could provide supplies or close the office at will.

This uncertainty around the medical supply chain produced a resulting hoarding response from nursing staff within CHS. Responses from both CHS staff and VHVs indicated that CHS would ensure that their supply was sufficient before supplying any medicines to VHVs. The analysis indicated a self perpetuating cycle that recreated power at the state level through the AMS, who controlled whether or not medical supplies were available to a community, (and had the authority over prioritisation of funding for medical supplies); a lesser but nevertheless powerful CHS who controlled what scarce medical supplies that were available and powerless VHV at the kinship/family level, who had seemingly no power over whether they received critical supplies or not.

Kabeer (2003) uses an example of an 'iceberg' to illustrate the decisions, resources and activities that are formally seen and often formally counted within an economy as shown in Figure 10 below.

Figure 10: The 'Iceberg' View of the Economy 


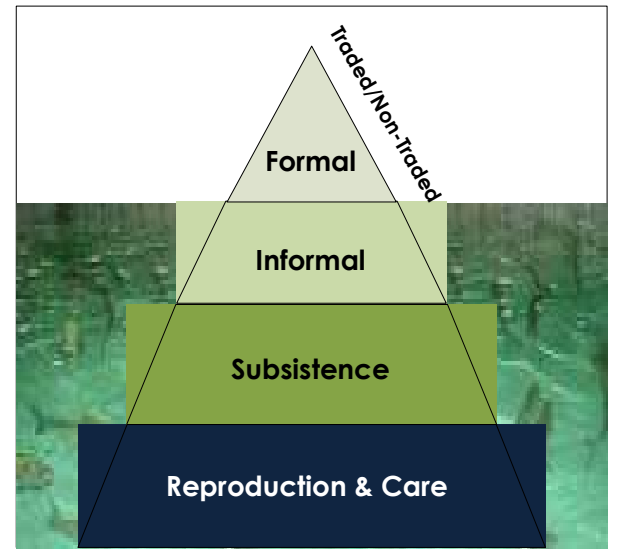

Reference: Kabeer 2007 pp 35

All activities in the 'iceberg' rely on activities of reproduction and care at the household level that ensure the production and productivity of the labour power that keeps the economy working. Applying Kabeer's 'iceberg view' of the economy to the ESWCHP institution, it could be argued that the activities surrounding decision making and access to resources existed as part of the formal activities, while VHVs participated in all other the levels - the informal (where goods and services are traded but not documented in official statistics); subsistence (where goods and services are produced for their own consumption) and reproduction and care (unpaid work of reproduction and care in the household) Kabeer (2003). This model highlights what the SRA institutional analysis showed, that whilst VHVs at the family/kinship level provide the greatest resource in terms of labour, they have the least access to formal decision-making and are least 'counted' for the work that they do. This supports Kabeer's view that 'institutions produce, reinforce, and reproduce social difference and inequalities' (March et al, 1999, pp 105).

The SRA institutional analysis of the ESWCHP highlights a pattern in that power and project expenditure remain largely in the middle of the institutional hierarchy, with project funding spent largely on salaries, and equipment at the CHS level, rather than on critical supplies and support to front-line VHVs. This repeats the national health spending pattern (Bolger et al, 2005) where the majority of expenditure went on salaries, facilities and equipment with a very small amount going to frontline health treatments.

\section{Benefits}

\section{NZAID \& Save the Children}

Kabeer's question of 'who benefits' is an important aspect of the institutional analysis. Benefit within an institution comes largely from the allocation of resources and power within it. As stated earlier, the ESWCHP, to develop the most cost effective mechanism for delivering rural primary health care, has developed a system that relies on a large 
number of volunteers, who are largely cost neutral (ie no salary or funding is supplied to the volunteers from the Project). This has been possible, by extending the existing reproductive role of rural women to encompass health care delivery to their communities thus creating the VHV system upon which the ESWCHP depends.

The question Kabeer asks 'who benefits' is a good one. Who, overall, benefits from this institutional arrangement, whereby approximately 430 VHVs with rudimentary training provide primary health care, on a voluntary basis?

As discussed in Chapter Two, NZAID sets expectations for the delivery of rural primary health care. NZAID's Ending Poverty begins with Health, 'regards primary health care as a cost effective and equitable way of improving the health status of people and combating poverty.' It states that for 'every US $\$ 1$ invested in primary health care..., there is a US\$10 rate of return (pp5)'.

VHVs rely on the rural people they serve rewarding them 'in-kind' for their services. VHVs receive no payment of any kind from NZAID, the ESWCHP or CHSs. So, for all intents and purposes, the cost of this primary health care upon which Save the Children and NZAID depend so heavily to meet their organisational goals, is largely free. What would be the ratio of expenditure to return, should an analysis be undertaken on the dollars invested in VHV's versus the rate of health dollar return?

It appears starkly clear that it is not the VHV's who benefit, but that the main benefits are going elsewhere within the institution.

What is additionally concerning, is that NZAID promotes health as a key gateway to poverty reduction, yet, relies on a system of health care delivery that does not support reduction of poverty in the very women providing that system. Ending Poverty begins with Health (NZAID ${ }^{25}$ includes a quote from Dr Gro Harlem Brundtland, Director General WHO, 1998;

'We know that the vast majority of human suffering and early deaths in the world are poverty related...Ill health leads to poverty and poverty breeds ill health. People in developing countries carry 90 percent of the disease burden yet have access to only 10 percent of the resources used for health (p1).'

If this quote is statistically correct, how then can NZAID and Save the Children support a system that relies on those in poverty to provide health care ostensibly for free (i.e. not

${ }^{25} \mathrm{http}: / /$ www.nzaid.govt.nz/library/docs/nzaid-ending-poverty-begins-with-health.pdf $\begin{array}{lll}\text { February } 2010 & \text { Page } 95 \text { of } 176 & \text { Ruth Heather }\end{array}$ 
reducing their poverty) to help reduce poverty, when the very system within which they are embedded and providing services prevents them from reducing their own poverty?

The NZAID Health Strategy 2008-2013 states that 'NZAID support for health activities will ensure that equity of health service delivery and health outcomes is a central consideration (pp4). This raises the question of what is considered equity of health service delivery. Does NZAID only look to the outcome end of primary health care or does it consider equity across all aspects of health service delivery?

Ending Poverty Begins with Health $\left(\mathrm{NZAID}^{26}\right)$ is based on the premise that health is a basic human right and that health and poverty elimination are interlinked (pp 5). However, the way the ESWCHP is set up requires us to ask the question is NZAID rather than reducing poverty through improving health, actually doing the opposite, and instead creating an ongoing cycle of poverty through its volunteer based health care delivery system in the East Sepik?' Having seen the VHVs in action, and considering their responses and conversations during my time in the East Sepik, it does not seem possible to me, that many VHVs would have the time to seek other mechanisms for reducing their own poverty when they have the compounded responsibilities of looking after children and families along with providing VHV services.

\section{ESWCHP \& Church Health Services}

There is no doubt that the ESWCHP provides great benefit to rural communities. Villagers and VHVs spoke of the many lives that had been saved as a result of VHV services, and healthier village environments and life practices resulting from VHV talks and advice to village people (Underhill-Sem \& Peutalo, 2006; Heather, 2006). It was clear from responses that VHVs and communities do derive significant benefits from the ESWCHP institution including:

a. Training, and status for VHVs with the ability to promote a healthier lifestyle for themselves and their families;

b. Greater ability to access medical supplies and resulting health benefits;

c. Healthier lifestyle and a reduction in disease as a result of improved knowledge; and

d. The ability to space families through access to family planning advice and supplies.

${ }^{26}$ http://www.nzaid.govt.nz/library/docs/nzaid-ending-poverty-begins-with-health.pdf

February $2010 \quad$ Page 96 of $176 \quad$ Ruth Heather 
However, the institutional analysis showed that those who gained the most benefit were the CHS and the ESWCHP Office staff. From an observer's perspective this was physically obvious. CHS and ESWCHP staff had more food, were physically heavier and healthier than village people, VHVs and their children, and travelled more freely across the province. Many of the VHVs were very thin, sickly, with some on the point of malnutrition. In 2006, I described the physical state of some of the VHVs (Heather, 2006), repeated here in Figure 11 below.

\section{Figure 11 Case Study of Physical State of VHVs at Kunjigini}

Case Study: VHVs at Kunjigini
The VHVs who attended looked poor and exhausted, and two women in particular looked
malnourished and tired beyond tiredness. They each had young ones of about 8-12 months
old, whom they fed constantly from seemingly empty breasts. The children looked sickly
mewling constantly for sustenance, which was eventually given out of an old bleach bottle.
On discussing this with other research team members, they stated that these women were likely
to be Catholic, with a number of other children.
My midwifery and nursing experience told me that these women, should they get pregnant
again, were at high risk of postpartum heamorrhage (as a result of their poor physical state and
the likelihood of being highly multiparous), and their children lacked the resilience to last
another 12 months within their current environment.

In summary, the benefits analysis shows that the distribution of benefits disproportionately favours NZAID, Save the Children, the ESWCHP Office and CHS in a way that does not reflect the balance of health provision labour, or the needs of VHVs and the grass-roots communities they serve.

In this chapter I have used Kabeer's institutional location methodology to define the ESWCHP institution. My definition of the ESWCHP institution included all the organisations and groups that I experienced as involved in obtaining or supplying resources from the state level to the grass roots to provide rural health care. I then identified where each organisation or group was located in the State, the Market, the Community or Family/Kinship. With the institution defined, I moved on to discuss the analyses of rules, people, activities, resources, power and benefits.

In summary, the analysis showed that within the ESWCHP resources and power were closely aligned. Those that had the most power were NZAID, SCNZ, SCiPNG, senior ESWCHP and CHS staff who had the most access to and control over Project resources. Community leaders had little power or access to resources, with VHVs the least in the institution. As a result, resource funding remained largely at the market level of the 
institution, whilst resource labour (generally provided by women voluntia) remained at the community level. Those with the greatest benefit from the institution appeared to be, in order of benefit: NZAID, SCNZ, SCiPNG, ESWCHP and CHS staff.

In the next chapter I will discuss the gender analysis considering official and unofficial gender policies, and the roles of women and men within the ESWCHP. 


\section{Gender Analysis}

Kabeer argues that all activities rely on reproduction and care (see Figure 9), and that therefore gender analysis is essential for all projects and crucial for healthcare projects (Kabeer, 1994). She argues that 'the main distinction between health care produced at home by women in their capacity as mothers and wives, and the work performed by professional health providers in state or private health service delivery, differs not in the kind of resources produced - both are concerned with different aspects of human resource (re)production - but in the very different institutional relationship which governs this form of activity' (Kabeer, 1994, pp 287).

The integration of roles of health care provider and mother can easily occur blurring the productive role of health care provider with the reproductive role of wife and mother, extending the seemingly 'natural' roles of women. Some VHVs blurred these responsibilities in their responses to the 2006 research, for example:

'Yes, I will take care of my family as volunteer' (Heather, 2006, ppVHV80)

In the above response, not only do the productive and reproductive roles blur, but the roles of primary care provider (worker) and volunteer also seem to blur.

The ESWCHP institution requires particular attention with regards to gender analysis because of the complex gendered cultural context it exists within, and because the backbone of the isolated rural health services are provided by women voluntia.

Voluntia provide services not in the context of their roles as mothers and wives, nor with the protection of being a 'professional' health provider in a formal health clinic setting, but somewhere in between. Outside formal organisational or family constructs, the potential for marginalisation and abuse seems enormous.

It seems of concern that women too may not identify the edges of production and reproduction, work and volunteering, thus making it difficult to negotiate change.

This chapter summarises some of the detailed gender-relations analysis and provides resulting discussion.

\subsection{Official gender policies}

Although the Government of Papua New Guinea has ratified the UN Convention on all forms of Discrimination Against Women (CEDAW), and it is incorporated into national policies (such as National Education Plan, The Gender Equity in Education Policy, 
National Health Plan, The Medium-term Development Strategy, the National Platform of Action and The Pacific Plan of Action (Aisi, 2008), the plight of women has not improved and the situation is one of the poorest in the world. Constraints to the development of women lie in implementation, in an environment dominated by men. The obstacles to removing inequalities for women will take time and a major shift in attitudes to improve $\left(\mathrm{NZAID}^{27}, \mathrm{pp} 8,10\right)$.

When I was working with the ESWCHP, interacting with CHS, and in the rural areas with village people, I saw no evidence of any National policies or action plans trickling down into NGO documents or local life. Instead I saw high levels of violence toward women, heavy workloads borne by women, and discrimination against women in education and employment.

\section{NZAID}

Many of the documents easily available from NZAID's website espouse gender equity and related outcomes. The NZAID Health Strategy: 2008-2013, pp 15 states 'NZAID will require health activities to address gender considerations throughout...to promote strategies which enable equality and empower women'. The NZAID Policy that describes how gender equality should be addressed is called: Achieving Gender Equality and Women's Empowerment. This policy states that the approach NZAID will take is to 'pursue a dual strategy of combining gender mainstreaming and specific support for women's empowerment to ensure gender equality is made explicit and visible in all development programmes, while addressing pervasive, systemic and entrenched gender inequalities and biases' (NZAID, pp3). On the basis of this, I assumed that explicit gender equality and empowerment of women goals would be central to the ESWCHP, which is largely funded by NZAID. However, gender equality and women's empowerment is not mentioned in ESWCHP project documentation, nor evident in staff practices or Project activities. Just prior to my arrival in the East Sepik in 2006, NZAID commissioned a review into gender in grass roots health projects in PNG (Underhill-Sem \& Peutalo, 2006). The review made explicit the Project's moves away from its beginnings of gender equality and women's empowerment and recommended that the Project should:

'Place the empowerment of women back into the core aims of the project. Rework the implementation plan to ensure the empowerment of women is made explicit...

${ }^{27} \mathrm{http} / / /$ www.nzaid.govt.nz/library/docs/nzaid-png-strategy-2008-2018.pdf

February $2010 \quad$ Page 100 of 176 
'Address gender equality and women's empowerment issues within the [ESWCHP] by closely examining work practices around hiring, capacity building, up-skilling and reskilling' (Underhill-Sem \& Peutalo, 2006, pp iii).

\section{National and Provincial Policies}

The PNG National Department of Health provides a policy framework for rural primary health care (DoH, 1991). This policy framework defines the responsibilities of the National DOH, the Provincial DOH, rural health staff, Church Health Services, the community, VHV coordinators and the VHVs. The effect these policies have on gender equality and women's empowerment within the ESWCHP cannot be underestimated. As Kabeer points out, gender inequalities cannot be attributed to poverty or patriarchy alone, but in fact represent some combination of poverty, patriarchy and public policy (Kabeer, 2003). This is discussed further in Chapter Four.

\section{Save the Children}

Save the Children have a documented policy available on their website titled: Save the Children's Policy on: Gender Equity. On page 5 the policy states:

'The Alliance will...promote a more equitable allocation of government, NGO and family resources between boys and girls. The Alliance will ensure that its principles for gender equity are mainstreamed within the organisation. The principles will be applied to structures and practices within the Alliance and to its members. The Alliance will foster an organisational culture that promotes the equitable participation and distribution of power between women and men within the organisation including on decision making bodies.'

While this is an official policy, at no time when I was in the East Sepik did I see this document, hear reference to it, or see the principles of it in action. In fact, there was some distress amongst ESWCHP and CHS staff arising from the recent visit of Yvonne Underhill-Sem and Basil Peutalo. Underhill-Sem and Peutalo (2006) raised concerns in their review report about the lack of gender awareness and equality within the Project. Discussions with Project and CHS staff signalled their distress about the report suggesting that gender inequality was 'normal' to PNG, and that external consultants coming in, were not aware of the realities at hand. There was a sense (from these discussions) that Project and CHS staff felt that there was no need to become more gender aware. I felt that their distress might have been caused by a sense of not knowing quite what to do about the recommendations in the Underhill \& Peutalo report, while they were also aware that the 
Project would continue to come under review and criticism because it did not embrace gender equality in practice.

Searching the data for any reference to gender equality, issues or awareness, I found one response. This was from a woman Rural Health Manager in response to the question: Has obstetric care improved? How do you know?. Her response was 'Not really, because the level of understanding by women in the villages is not good, eg women are still bound by gender issues and attitude problems' (Heather, 2006, ppRural Health Manager1).

It is concerning that the Project seems to have moved away from its roots in gender equality and the empowerment of women; that gender equality and gender issues are rarely mentioned or understood.

\section{ESWCHP Project Documentation}

The ESWCHP began as an initiative of a women's group ESCOW, with the early design bringing together the goals of women's empowerment and health improvement. However, since its establishment the ESWCHP has moved away from gender equality and empowerment of women as one of its central goals (Underhill-Sem and Peutalo, 2006).

Key project documents, that provide the goals, objectives and expected Project outcomes and upon which NZAID funding is based, do not mention gender equality or the empowerment of women (Save the Children, unpublished). The key ESWCHP monitoring document, the log frame, contained four Project outputs and over 70 accompanying activities. Out of all of these gender analysis, equality or empowerment is not mentioned.

During my time in the East Sepik and with ESWCHP staff, I saw or heard no evidence of gender equality policies or gender awareness discussed, and no mention of the Save the Children Gender Equity policy mentioned above. There was one exception. One of the women on the research team hailed from a matriarchal society, New Ireland. She enacted gender equality in the way she carried out activities and worked with the VHVs and communities. In her presence, and through her modelling, I saw and heard discussions through which VHVs and other community women obviously felt empowered. I remember questions to her from VHVs like... 'How can I work in the Project too?' and 'If you can do it, then can we do it too?' I felt that this woman was a wonderful resource, which was underutilised within the ESWCHP. Her very presence and way of being had an empowering effect on the women she interfaced with, and the men. The 2006 review report recommended that this woman be used to provide advice and support to the ESWCHP with regards to advancing women's empowerment across the Project. 


\subsection{Unofficial gender policies}

The analysis suggested that rules around the roles and activities of men and women occurred largely through unofficial cultural and gender policies. There was no official rule or policy that I saw or observed that required men to fulfil certain roles and women other roles. My simple observations in 2006 showed that women tended to be nurses and VHVs, while men tended to be managers, drivers and generally had access to critical resources such as vehicles, boats, fuel and medical supplies. For example, VHVs clearly stated to me that transport of a patient generally relied on a male accessing either a vehicle, a boat and fuel. This left VHVs at times having to leave the sick patient waiting alone beside the river, whilst they found a man who could help. Women did not generally have ready access to transport mechanisms.

Men tended to be involved in leadership and management roles, and women undertook the majority of family and health care roles. This obvious division in roles by gender meant that unofficial gender rules were in place throughout the ESWCHP institution.

Within the ESWCHP two churches provide the majority of health services - the Catholic Church and the South Seas Evangelical Church. Religious doctrines prescribe a range of unofficial policies surrounding social behaviour. Both Churches have representatives on Project decision-making committees. The gender roles prescribed by the Churches are very much a part of the ESWCHP, in that Church representatives participate in the ESWCHP at the decision-making and resource allocation level.

My observations of gendered roles within the ESWCHP Office setting were that women were in roles involving administration, training and support of VHVs, or involved in the Maternal and Child Health programme (all seemingly natural extensions of the role of the village woman in PNG). The one exception to this was the Acting Programme Director, who was a woman. The Programme Director had appointed her to this position on the basis of her management skills and abilities. Talk amongst male and female staff in the office expressed some surprise and disgruntlement regarding her appointment to the position. I did not go into the rationale for this disgruntlement with staff as I felt it inappropriate to do so. But it remains a question as to whether this staff disgruntlement was due to what they may have perceived a breach of unofficial gender policy.

Men within the Project Office were largely involved in management (Programme Director, Chief Accountant and Accountant), coordinating the distribution of medical supplies, or employed as drivers. 
The data analysis showed that generally the roles of women and men were divided by provision of services and management including decision-making authority and access to resources. Women across all institutions within the ESWCHP were largely involved in

providing services: health services, coordination services along with providing for their families in the traditional role of the village woman. Some women were involved in management although there were only two that I came across within the entire ESWCHP institution.

Men were generally involved wherever decisions needed to be made, or where there was authority / power over resources such as money, medical supplies, vehicle and fuel - this even extended to use of the medical facility if it was required for men's activities.

\subsection{Samples of Responses}

The 2006 data contained numerous responses that provided insights into how women were able to use their power, and situations where they were powerless. Where possible I have tried to provide samples that reflected the majority of responses, except where otherwise stated. In some cases I have altered the exact wording to make the response grammatically correct, whilst maintaining the intent of the response.

\section{Examples from the data that demonstrate women's use of power}

The following examples suggest VHV's were able to utilise the power and influence they have obtained through training and having access to ESWCHP, CHS staff and medical supplies.

From a woman Rural Health Manager:

Obstetric care has improved a lot when these VHV trainings was conducted in 1999 for the first time. There was a lot of maternal deaths and complication before this training but now this has reduced. [VHVs] were trained to help antenatal mothers and also help in assessing delivery. We have seen few or less deaths and complications' (Heather, 2006, ppRural Health Manager2).

The following quotes from village men suggest that the men have listened to the VHV's teachings about healthy communities:

'Yes we now dig the drains, make houses and also the medication house'

'The medication woman has done a very nice job and the village has changed' (Heather, 2006, ppRural People21, 23). 
'When chewing betel nut do not spit around the community' (Heather, 2006, ppRural People43).

'The VHVs are doing health promotion in the village and that is reducing sickness within the community, clean drinking water, good toilet, fighting has slowed down in the village ${ }^{28}$ (Heather, 2006, ppRural People1, 42)

'We saw the changes happening, the VHVs helped the communities. The children looked good. They helped the pregnant mothers to make good delivery so none of the babies died' (Heather, 2006, ppRural People2).

'Yes, birth control...Space children from five to six years after another one. I space my children and my family is healthy ${ }^{29}$, (Heather, 2006, ppRural People33, 35)

'Yes we use condoms to protect ourselves' (Heather, 2006, ppRural People13).

This last quote stands alone and is not representative of responses but I have included it because it is interesting. I have not noted many occasions in the ESWCHP where the men follow the women's advice. Also, the topics of Family Planning and HIV/AIDs tend to be sensitive and often problematic. However, this response suggests that in this case the man (and possibly men) has followed the VHV's advice regarding sexual health and/or family planning and is using the condoms she has provided.

From village women:

'When the VHV sees that there is not enough medicine they send them to the big hospital' (Heather, 2006, ppRural People8)

Yes, I was referred by the VHV to Boram Hospital when she can't treat me any longer when I have a big sore on my leg' (Heather, 2006, ppRural People8)

Health talk on Family Planning has helped families space their children (Heather, 2006, ppRural People34)

These responses seem to indicate that when the VHV has no supplies or sees that the problem is larger than she can treat herself, she has sufficient influence to be able to refer the patient on, and her advice is acted upon.

'VHVs work has changed the people's lifestyle' (Heather, 2006, ppRural People14)

${ }^{28}$ Two responses are blended into one example quote

${ }^{29}$ Three responses are blended into one example quote.

February $2010 \quad$ Page 105 of 176 
'Yes, VHV are very good because some people in the village are shame of telling the health workers about their sickness' (Heather, 2006, ppRural People17)

\section{From VHVs:}

'After the training I went back home and there was a change in people lives by reducing the number of sick'

'I see that the community is happy to hear the health advice and they also put it in action'

'Today our people are very happy within the communities because I taught the mothers to space their children. They accept the family planning method, tubal ligation and the pills that make them have less children' (Heather, 2006, ppVHV 2, 14)

Yes I now send all the sick people to the hospital to get help, and refer sickness like TB and snake bite (pp7, 9)

I call the small group and tell them of how to look after the place, like cutting grass, dig holes for toilets and rubbish to stop malaria' (p15

Yes, there is teamwork, when we need medicine we fill out the order form and the CHS get the medicine from Wewak (32)

Men and women work together (64)

There's no support from the Village Health District Coordinator or the Local Level Government staff, but there is support from women's groups' pp64

The community support me to buy nails for the haus meresin and give me money when attending training pp70

Many men are going for vasectomies - we are not sending them, but they go by themselves pp 75

\section{Examples from the data that demonstrate women's powerlessness}

From women Rural Health Managers: 
'Referring patients to the Health Subcentre especially Wewak is very difficult. We have boats but we have to stay for hours looking for vehicle' (Heather, 2006, ppRural Health Manager3)

'When the Ward Members invite us to their meetings we usually talk to the community about health issues and VHV issues as well' (Heather, 2006, ppRural Health Manager6).

Although this second quote seems to imply that the woman rural health manager is using her power to influence (and she is), it also shows that she waits to be invited, so is only able to influence at the request of the generally male Ward Member's invitation.

From a village man in response to a question about how health had improved as a consequence of training VHVs:

'There is no work cooperation in the village because people don't listen' (Heather, 2006, ppRural People3)

In response to the question 'what types of help do you need that VHVs could provide?', the following responses from village men suggested unrealistic expectations of VHVs, turning VHVs 'power' into 'powerlessness'. The responses suggested that village men expected the VHV to be able to use her influence to obtain additional resources for the village:

'VHVs can help us with the water tank and mosquito net'

'We want the VHV to have permanent haus meresin and a tank to supply water for the patients' (Heather, 2006, ppRural People27)

Whilst I am aware that VHVs did hand out mosquito nets on the occasions when they were available, VHVs did not generally have access to the type of resources required for village water tanks. It may be that these men saw the 2006 research as a way of negotiating for additional resources, but to me these responses were somewhat worrying. VHV's were unlikely to be able to deliver to these men's expectations. These quotes point to the types of issues where ESWCHP staff advocacy may be needed to support VHVs, and to avoid negative repercussions for VHVs from unrealistic community expectations.

From VHVs:

'No one was getting the medicine from the church' p23

'No the Maternal Child Health staff don't involve me 26 
No the CHS won't give good medicine for the treatment and makes lies to the VHV. I argue with them and they don't give me back the medicine order form 31

No sometimes we get the supplies and sometimes not, we are not receiving enough medical supplies, we have placed order and are still waiting, we know that we are waiting for five, six to eight months 35, 37, 40

It depends on the transport for us to come and get our supplies from the clinic p40

There is a problem, not allowed pills, against the church 46

Communities not giving any support, we are working on our own 47, 70

There is no haus meresin so all pregnant mothers go to the health sub centre for delivery 58

We got some problems on the delivery of the pregnant mother. Sometimes some people are not happy...they say it is not a fortnights work pp78

When we came for training, we saw that the family members of the Training Coordinator had the food that was supposed to be for us. We were not feeling good about that. Pp79

\subsection{Gender Analysis of 2006 Participants' Roles}

Analysis of the self-identified roles in the 2006 data showed that the male participants held a range of roles within the community as shown on Figure 12 below.

Figure 12 Male Participants in 2006 Research: Range of Self Identified roles

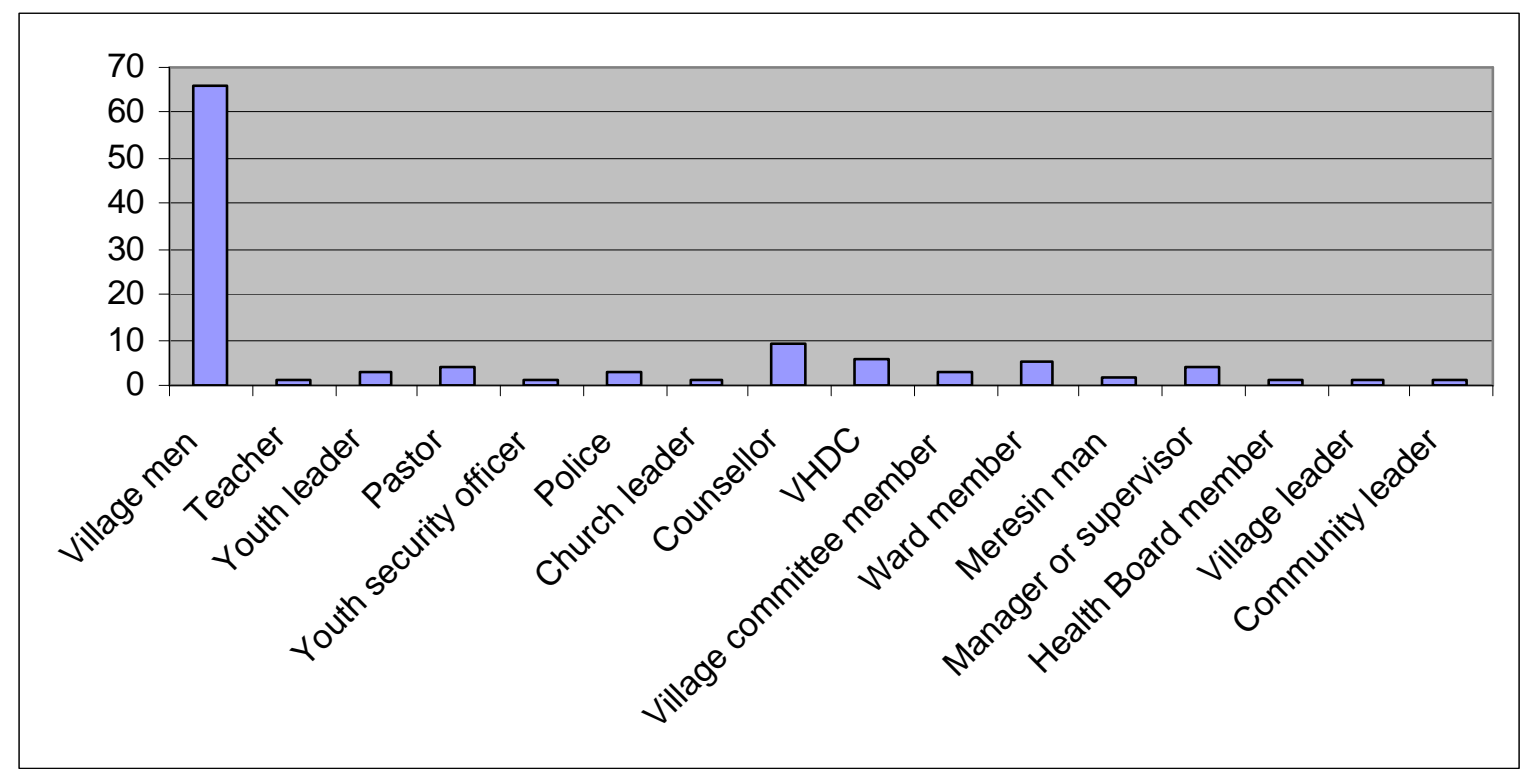


The majority of male participants identified themselves as 'village men'; 29 percent of men identified themselves as having a leadership or management role, and seven percent identifyied themselves as a health worker (such as Meresin Man) as shown on Figure 13 below.

Figure 13 Self Identified roles of Male Participants in the 2006 Research

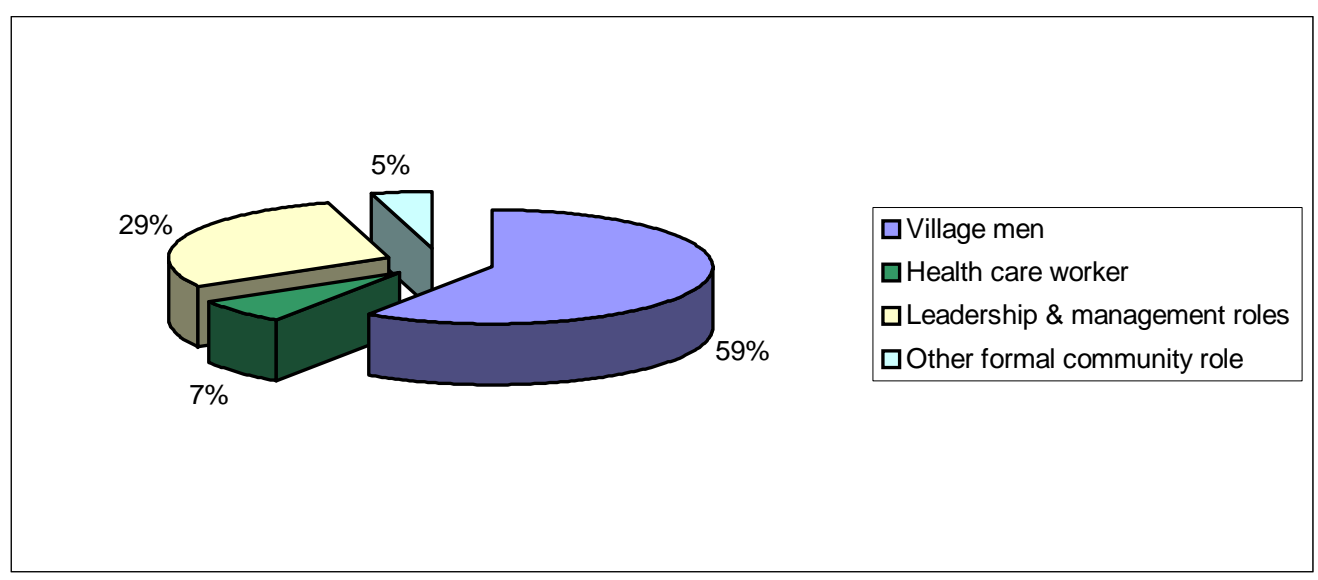

Women participants held a smaller range of roles than men within the community as shown on Figure 14 below.

Figure 14 Female Participants in 2006 Research: Range of Self Identified roles

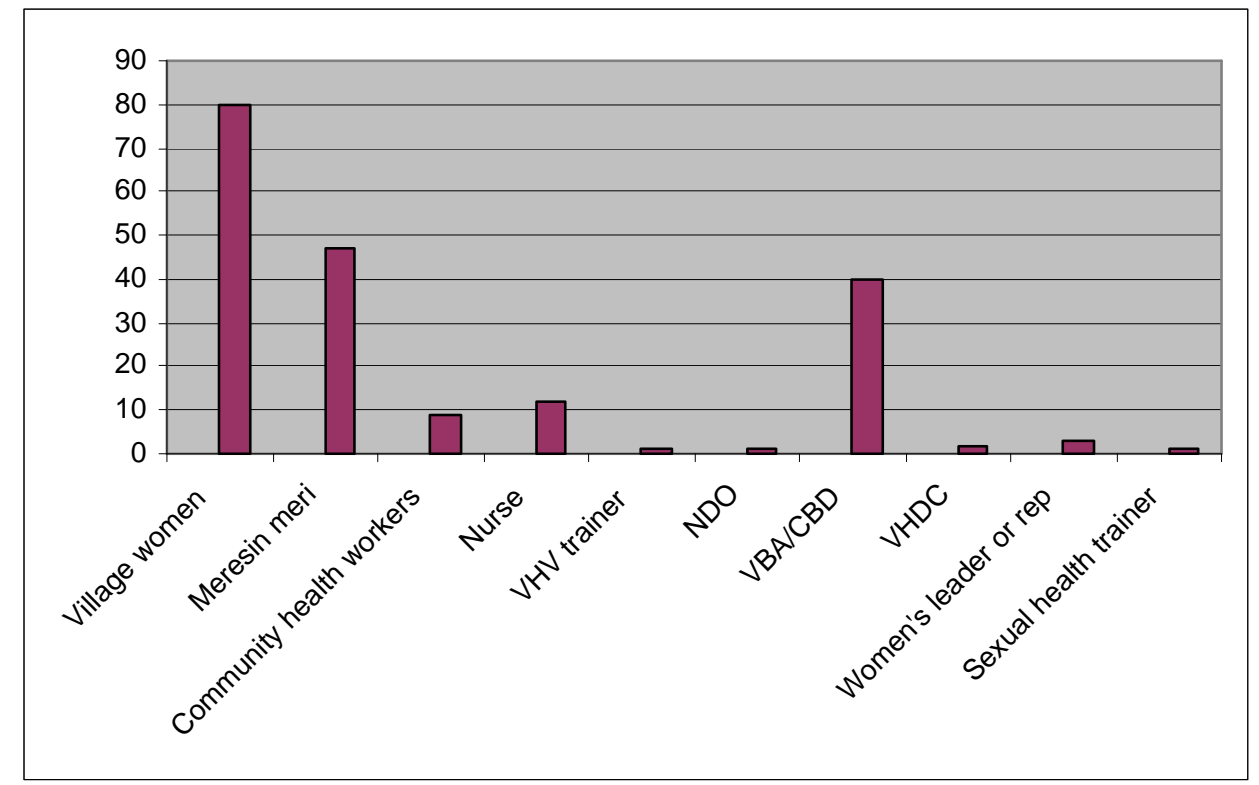

Where only seven percent of men identified themselves as health care workers, the majority of female participants (57 percent) listed themselves as nurses, VHVs, meresin meri, VHV or other health care workers. Village women were 41 percent of participants, while only three women identified themselves as having a leadership role of any kind, 
being 'women's leader' or 'women's representative' or two percent, as shown in Figure 15 below. No women identified themselves as having other formal community roles.

Figure 15 Self Identified roles of Female Participants in the 2006 Research

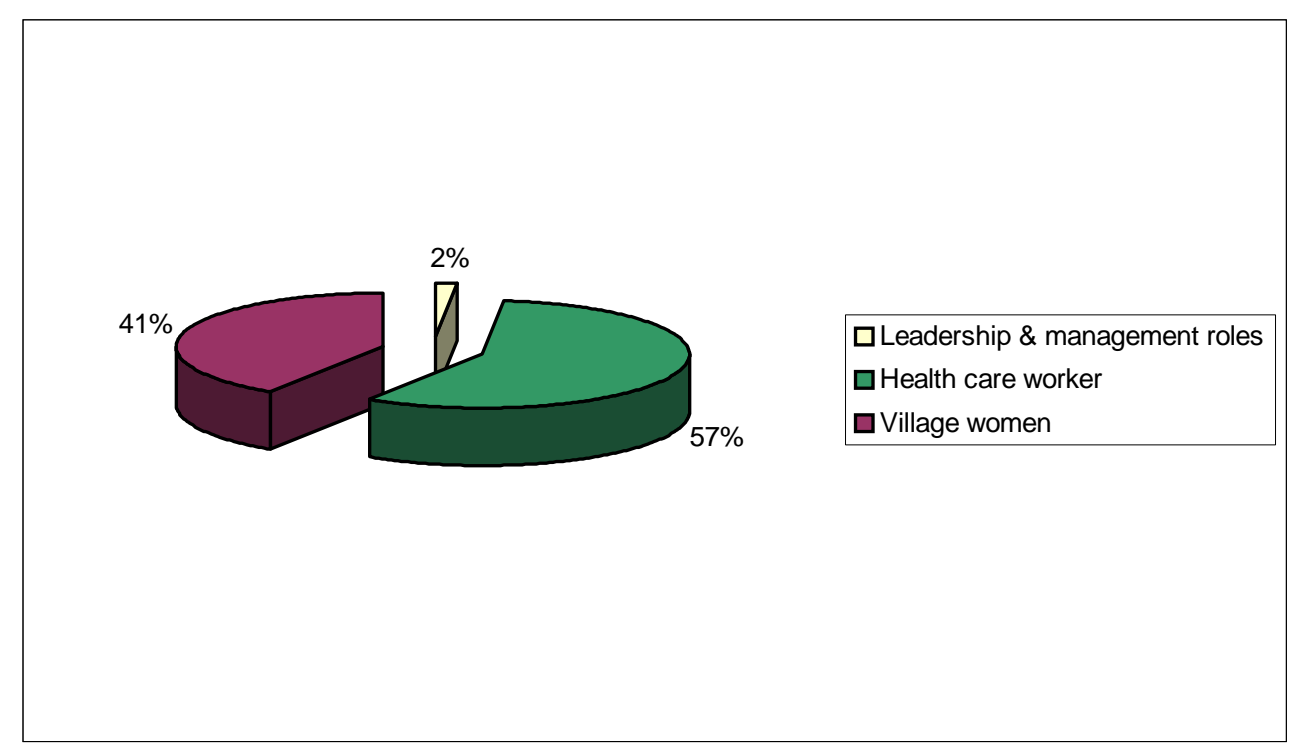

The comparison between the self-identified roles of men and women participants is shown on Figure 16 below. This comparison clearly shows that the majority of health care workers that participated in the 2006 research were women, which reflects cultural gendered roles of rural East Sepik society whereby health care is often seen as a natural extension of a woman's role. The majority of leadership roles and management roles were held by men, along with other formal roles in community such as Police, or teacher.

Figure 16 Comparison between the roles of men and women

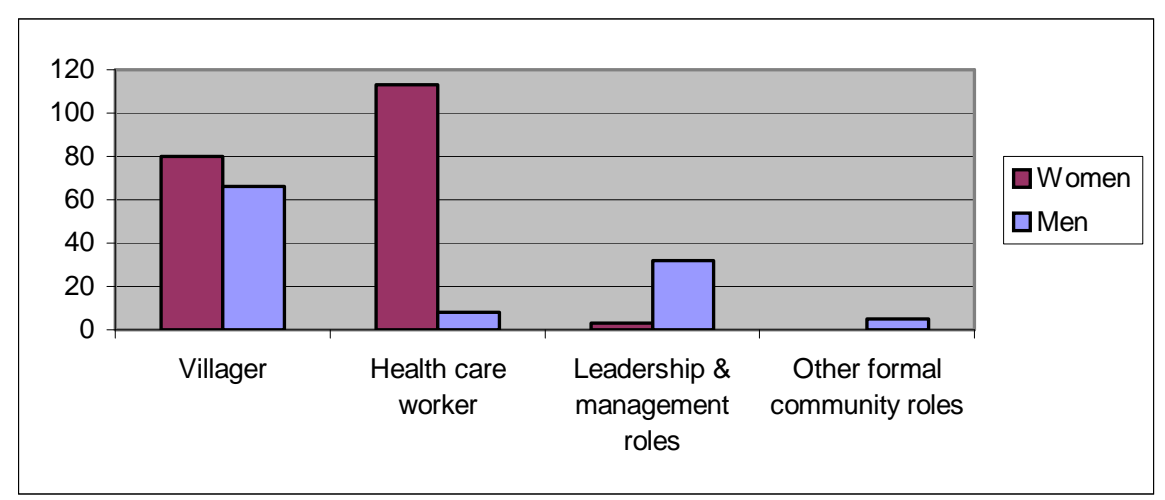

\subsection{Gender Analysis across the ESWCHP Institution}

Institutional gender biases constrain people's ability to make strategic life choices by ruling out options. Cultural or ideological norms may deny that such inequalities exist or 
that they are unjust. Subordinate groups (such as VHVs and poor women and men) are likely to accept and even collude with their lot in society if the alternative either does not appear possible or carries heavy personal and social costs (Kabeer 2003).

The gender analysis showed that organisations at the state level within PNG were largely dominated by men (Kidu, 1997; Dickson-Waiako, 2006). Figure 17 below shows the gender balance of state organisations I have defined as being within the ESWCHP. Blue indicates that the vast majority of staff within the organisation are men and green an unknown gender balance.

Figure 17: Gender Make up of ESWCHP Organisations at the State level

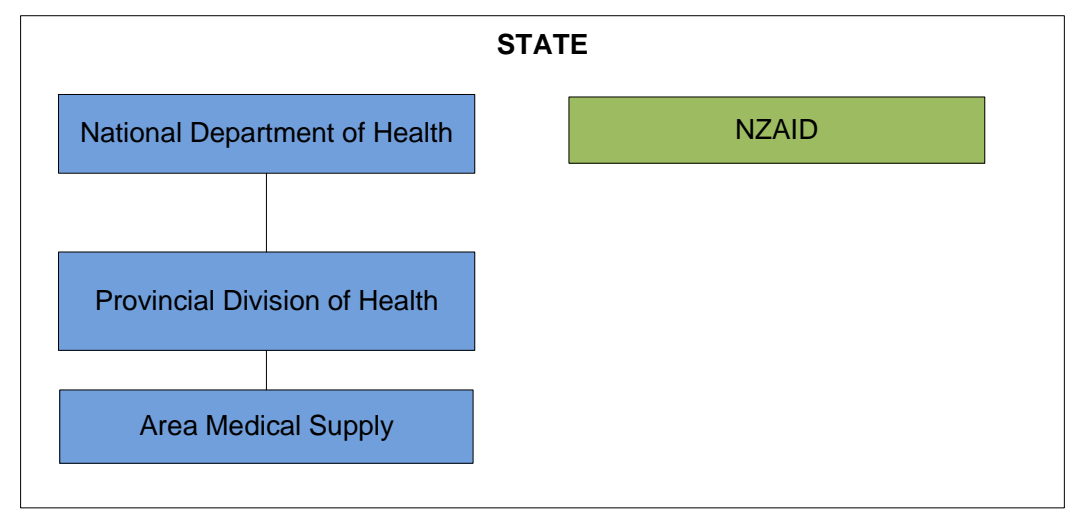

At the market level, the gender roles were easily identifiable. These was partly because this was one of the areas within which I spent most of my time in 2006, but also, because roles were startlingly clear in project documentation, and in day-to-day activities. The gender balance of organisations at the market level is illustrated in Figure 18 below. Once again the green boxes indicate an unknown gender mix, the blue boxes indicate the roles of men, and the pink, the roles of women.

Figure 18: Gender Make up of ESWCHP Organisations at the Market level

\begin{tabular}{|c|c|c|c|c|c|}
\hline & & \multicolumn{2}{|c|}{ MARKET } & & \\
\hline \multicolumn{2}{|r|}{ Save the Children in PNC } & \multicolumn{3}{|c|}{ Save the Children NZ } & \\
\hline \multicolumn{2}{|c|}{$\begin{array}{c}\text { South Seas Evangelical Church } \\
\text { Health Services }\end{array}$} & \multicolumn{2}{|c|}{ Catholic Church Health Services } & \multicolumn{2}{|c|}{ ESWCHP Co-ordinating Office } \\
\hline $\begin{array}{l}\text { Religious doctrine } \\
\text { dictating health care }\end{array}$ & $\begin{array}{l}\text { Management \& } \\
\text { Decision making }\end{array}$ & $\begin{array}{l}\text { Religious doctrine } \\
\text { dictating health care }\end{array}$ & $\begin{array}{c}\text { Management \& } \\
\text { Decision making } \\
\text { (can be overturned by } \\
\text { priest (male) }\end{array}$ & \multirow{2}{*}{$\begin{array}{c}\text { Roles involving } \\
\text { administration, VHV or } \\
\text { Maternal/Child Health } \\
\text { Coordination }\end{array}$} & \multirow{2}{*}{$\begin{array}{l}\text { Roles involving senior } \\
\text { management, finance, } \\
\text { medical supply or } \\
\text { transport }\end{array}$} \\
\hline $\begin{array}{l}\text { Nurses, VHV } \\
\text { coordinators }\end{array}$ & $\begin{array}{l}\text { Drivers - control over } \\
\text { transport }\end{array}$ & $\begin{array}{l}\text { Nurses, VHV } \\
\text { coordinators }\end{array}$ & $\begin{array}{l}\text { Drivers - control over } \\
\text { transport }\end{array}$ & & \\
\hline
\end{tabular}

Figure 18 shows that women dominated the roles most similar to their roles as mother and carer for the family. Women and men were involved in groups and organisations at the 
community and kinship levels as shown on Figure 19 below. Women's groups were as expected dominated by women, and men's groups, by men. VHVs were generally women and village leaders generally men. NGOs gender make up was uncertain.

Figure 19: Gender Make up of ESWCHP Organisations at the Community and Family levels
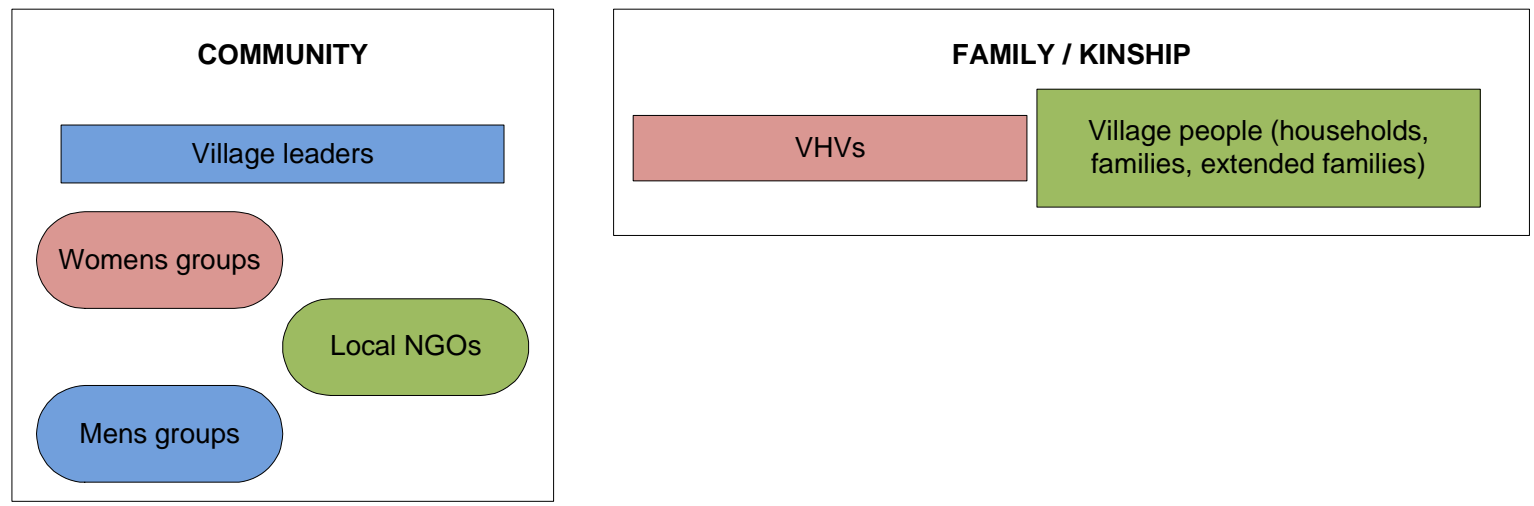

Gender seemed to prescribe the roles available to the different sexes. Women were able to hold the voluntia role as VHVs in the village, and paid roles as nurses, maids or cleaners at the CHS, or coordinators and managers at the ESWCHP. Men were able to access a range of paid roles within the village including police or teacher. Men were also able to access roles of leaders within the CHS or within the ESWCHP, drivers, coordinators and managers. Some men took on the role of VHV, known as Meresin Man (alongside the Meresin Meri) although it was very rare for men to take on the role of VHV. Men appeared to have a much greater level of access to paid roles than women.

Within the ESWCHP institution, men were typically placed in positions with greater access to power and resources creating and compounding embedded inequalities. The analysis also clarified the absence of responses of men about the need for gender equality, again bearing out Kabeer's argument that many men within institutions de-emphasise the gender inequalities that exist and through their greater access to resources, manipulate them to promote and defend their own interests (Kabeer, 1994).

\subsection{Gender Equality and Sustainability of the VHV System}

The social analysis showed that ESWCHP is faced with compounding systems of gender inequality. In PNG, the negotiation of social relationships, 'especially sexual relationships are both a finely tuned skill and the source of considerable violence. Relationships are complex, involving various kinship links and historically layered with time depths of many 
years and generations. They are also infused with personality, faith and ethics. This makes the discussion of gender issues highly sensitive and inherently political' (UnderhillSem \& Peulo, 2006, pp 7).

CHS leader's involvement at a senior level within the ESWCHP compounded this gender inequality further. Gender based assumptions about women and men's roles were openly displayed and discussed as part of religious doctrine, which was then enacted in practice. VHVs within the ESWCHP were facing compounding institutional gender inequality resulting from:

a. Gender inequality within the East Sepik cultural norms and laid down in National and Provincial policy

b. Gender inequality embedded within the SCiPNG and ESWCHP as a result of lack of gender awareness and overwhelming influence of the national cultural norms

c. Gender inequality promulgated and reinforced through the religious underpinnings of the Church Health services - a critical part of the ESWCHP institution

Since 1998, various reviews of the ESWCHP have raised issues around gender equality and the sustainability of the volunteer system (Underhill-Sem \& Peutalo, 2006). The health infrastructure within the ESWCHP assumes that VHVs can somehow not only accommodate additional activities into their every day responsibilities, but in addition, they can successfully negotiate for appropriate return for services.

The institutional analysis confirmed that VHVs have access to very little power, or support and that is it a day-by-day struggle to maintain their status within their community as the primary health provider. The ESWCHP VHV system assumes that communities will reward VHVs 'in-kind' for services provided. However, it is difficult to see how VHVs could ever successfully negotiate appropriate return for services, without the ESWCHP moving to embrace the GAD approach and addressing gender inequalities as a central project goal.

In some communities organised religion represents the most rigid constraints against women's freedom and equality (Ghodsee, 2007). Religion is known for its ability to in some communities provide the basis for discrimination, exclusion and/or marginalisation, subordination, violent and harmful practices toward women, providing an inescapable landscape for development. Development specialists are particularly concerned about the negative impact of religious fundamentalism on women worldwide. Control mechanisms are embedded in these systems to maintain power through the control of women's 
economic independence and sexuality, a control in which violence - physical, emotional, psychological, economic and religious - is rooted (James-Sebro, 2006; Ghodsee, 2007). Dollar and Gatti identify the fact that religion features as statistically significant in explaining variations in gender inequality across countries (1999). Religion is often used to deny women's fundamental human rights, and it is used to justify women's marginalisation in decision-making positions, which in turn has alienated women from participating and influencing civil and political lives (Oxfam, 2008).

In PNG there is significant social pressure to adhere to religions beliefs. This is partly due to the strong role churches play in providing national and provincial health and education services. Church agencies are responsible for the majority of primary schools and run two of the five universities in the country. In the East Sepik Province, 95 percent of the education and health services are provided by the Catholic Church (Gibbs, 2002, pp59). .

Religion is a critical factor in political formation and has been a defining factor in education, health, civil society and values. Religion is often an important defining characteristic of ethnicity (Thomas, 2002, pp7-8), and ethnicity and religion combine to determine political affiliations (Okele, 2002).

Whilst many women in PNG acknowledge the role that religion has played in the demise of their power, many women consider their faith an important aspect of who they are, and that the women's groups and committees they participate in have given them valuable leadership experience and confidence (Korare, 2002).

In this chapter I have described the official and unofficial gender policies in PNG, and within the ESWCHP institution. I have also analysed the roles of women and men within the ESWCHP. This analysis has confirmed that whilst PNG and the ESWCHP have gender policy frameworks in place, the status of women remains low, and limitations to the roles and capabilities continue to exist for women as a result of their gender.

In the next chapter I will pull all the threads explored so far together to provide reflective discussion in response to my central question and thesis objectives. I will then close by providing recommendations and suggestions for further actions and further research in Chapter Seven. 


\section{Immediate, Underlying and Structural Causes Analysis}

Completing Kabeer's SRA analysis framework requires two final steps. Concept Five: Immediate, Underlying and Structural Causes required the exploration of the immediate, underlying and structural factors, which caused the problems and the effect of these on the people involved (March et al, 1999, pp109-110). This final analysis combined and focused all previous analyses into key factors as the basis for planning a development intervention (Concept Six). As my central question centres on the sustainability of the VHV system I have focussed this final analysis on the VHV.

In this chapter I summarise the Immediate, Underlying and Structural Causes analysis. The detailed Immediate, Underlying and Structural Causes Analysis is attached as Appendix K.

\subsection{The Core Problem}

The Immediate, Underlying and Structural Causes analysis first required the identification of the 'the core problem' from findings from the previous steps of the institutional analysis as follows. I identified the core problem as:

Lack of sustainability of the VHV role in providing basic health care services to village people, with the potential to worsen as CHS take over the management of the ESWCHP and VHVs; and

Limited access to critical health resources by the majority of service provides and service users within the ESWCHP.

The cause and effects analysis then required the identification of the causes and effects that created the core problem. Causes and effects were analysed in the time locations of immediate and intermediate time location. Structural causes of the problem were analysed culminating in the overall long-term effects created. I have summarised the analysis below.

\subsection{Immediate causes and effects}

The immediate 'causes' created immediate 'effects' for VHVs. Immediate causes identified are the by now familiar issues of the increased workload of VHVs for uncertain reward, high community expectations of VHVs and inconsistent access to medial supplies. The effects of these 'causes' were fluctuations in VHV's household's incomes and reduced ability of VHVs to conduct subsistence farming and other duties expected of her as village women. 


\subsection{Intermediate causes and effects}

The intermediate causes were identified through the data as lack of VHV access to means of communication and transport in the provision of health care, the social and cultural assumptions that VHVs can and want to take on responsibilities in addition to her extensive existing responsibilities and ideological norms about female dependence and perceived low value of 'women's' work, and therefore the service provided by VHVs.

The intermediate 'effects' of these causes was the creation of gender inequality limiting VHV's: access to critical resources, ability to influence long-term health care goals, and negative health outcomes for the community as a result. This in turn created a further a cycle of effect. Because VHVs were limited, village people relied less on them, reducing their status in the community and further compounding her limitations particularly with regards to access of critical resources (such as medicines, vehicles and fuel). In response VHVs increased their efforts to access critical resources and supplies, increasing their workloads, and meaning that they were even less available to communities to provide basic health care.

\subsection{Structural Causes}

Structural causes of the core problem arise at all institutional locations within the ESWCHP. While some of these structural causes are easily located in one of Kabeer's institutional locations, those directly relating to gender inequality seem to flow seamlessly between and across all locations.

Starting with the grassroots level, structural causes of entrenched cultural and social gender inequalities within communities and intra-household power relations. Gender inequalities devalue the work of women and minimise the importance of ensuring reasonable reward for services is provided. At the community and market locations, structural causes of gender inequality embedded in ESWCHP policies and are implemented through everyday work practices across the institution. At the state, and market levels, entrenched systems of access and control ensure that resources stay largely within the ESWCHP Office and CHSs rather than flowing on to front-line grass roots health care delivery. At the state level, structural systems of hierarchy prevent VHVs from influencing the policy, resources and infrastructure by which health care is delivered. Ideologies of men as the breadwinners, gender-segmented labour allocations, gender biased institutional practices are also structural causes at the state location. 


\subsection{Long Term Effects}

From the analysis of the data, and above causes and effects combined to create significant and worrying long-term effects. VHVs will continue to face increasing workloads for little return, vulnerability to violence with little protection for them built into the health care system (through qualifications, training and support) and progressive disempowerment. As the health infrastructure is strengthened, the VHV and rural communities influence and access to critical resources is weakened. The overall long term effect appears from this analysis to be worsening health outcomes for ESWCHP recipients; the rural people of the East Sepik.

In this chapter I have summarised the Immediate, Underlying and Structural Causes analysis. The analysis showed that the problems of gender inequality and lack of participation of VHVs and rural people in planning and policy development threaten the long term sustainability of the ESWCHP, and may result in worsening health outcomes for rural people.

In Chapter Six, I provide the planned development intervention which of itself provides a suite of recommended actions to address the problems identified and central question of this thesis the long term sustainability of the VHV system of primary health care. 


\section{Recommendations for Development Intervention}

\subsection{Introduction}

Using the analysis in the previous chapter I completed the last step in Kabeer's institutional analysis, and planned a development intervention (Concept Six) (March et al, 1999, pp111). The planning process required recommending objectives, activities and indicators to address the problems, causes and effects identified through the Immediate, Underlying and Structural Causes analysis. These are provided as a Development Intervention in the table format suggested in March et al (1999, pp112-114).

The Development Intervention therefore contains specific detailed recommendations in the form of discrete objectives, activities and indicators. The recommended objectives, activities and indicators link, interweave and intertwine to make up one overall recommended intervention. For this reason, I have chosen not to repeat or try to explain the Development Intervention below. Rather, I have left the Development Intervention complete for it to be considered in its entirety as one recommendation and many.

In support of the Development Intervention, I have noted my thoughts and considerations, and in some cases recommendations for additional research and/or action to be undertaken, to advance the empowerment of women in the rural health care delivery system, and to improve the effectiveness and sustainability of rural health care delivery in the East Sepik.

\subsection{Development Intervention}

The GAD approach has at its heart, women's empowerment, which brought about the realisation that development bureaucracies and other related organisations were gendered in terms of their culture, rules and outcomes (Goetz, 1995). The institutional analysis has shown that the ESWCHP is threaded with compounding issues of gender inequality, that that threaten the effectiveness of rural health provision and the potential negative consequences for the long-term health outcomes of grass roots people.

Kabeer reminds us that 'to be useful, the institutional analysis of gender relations must be linked to the [Project] design and evaluation of policy and [Project] planning (Kabeer, 1994, pp 285)'. The Development Intervention is a planning tool that draws together provided in Table 7F below specifically targets the key themes arising from the data: the overwhelming responses from VHVs asking for more support and consistency of access to medical supplies. The Development Intervention below also draws together the implications of the entire institutional analysis. It provides recommended actions to 
address the compounding issues of gender inequality. I have written the Development Intervention as a practical model, so that it could be used as a starting point for planning Development Intervention in the field.

The Development Intervention below was created on the assumption that if VHVs were able to advance their freedoms, which as these were enhanced, so too would rural health care delivery be enhanced along with the health outcomes of rural people. This assumption has not been thoroughly tested and could provide the basis for further research. 


\section{Table 7: Development Intervention}

\begin{tabular}{|c|c|c|}
\hline Objectives & Activities & Indicators \\
\hline $\begin{array}{l}\text { Long-term objective } \\
\text { Ensuring sustainability of village based } \\
\text { basic health care provision }\end{array}$ & $\begin{array}{l}\text { Place the empowerment of women at the centre of the } \\
\text { goal and aims of the ESWCHP. } \\
\text { Revise project structure, infrastructure and documentation } \\
\text { to ensure the empowerment of women is made explicit } \\
\text { and enacted structurally }{ }^{30} \\
\text { Work, through a participatory approach, to connect policy } \\
\text { makers and VHVs and communities to revise policy } \\
\text { around the role of the VHV, rural health infrastructure and } \\
\text { funding } \\
\text { Identify and access funding mechanisms to support } \\
\text { ongoing sustainability of the role of the VHV } \\
\text { Review funding model so that funding is flexible and } \\
\text { expressly linked to health outcomes } \\
\text { Firmly establish health providers as alternatives to CHS }\end{array}$ & $\begin{array}{l}\text { Role of VHV changed to VHW (Village Health Worker) }{ }^{31} \\
\text { VHWs feel supported in their role and able to balance role of women with role } \\
\text { of VHV } \\
\text { VHWs are able to access critical resources upon which their service depends } \\
\text { (supplies, access to communications, ambulance etc) } \\
\text { Funding available to support revised policy } \\
\text { Statistics on key health indicators are routinely recorded by VHV and show } \\
\text { improved health amongst rural people } \\
\text { Policies are in place to support women VHWs as legitimate workers and } \\
\text { income earners } \\
\text { Communities actively support women in their role as VHV alongside paid } \\
\text { roles by men within villages (teacher, police, justice) and prevent the role } \\
\text { being overtaken by men } \\
\text { Extent and nature of participation in designing programme goals, objectives, } \\
\text { and directing activities and resources, conducting training programmes } \\
\text { Gender awareness at all levels and within all aspects of ESWCHP } \\
\text { VHW access to further health based training (such as nursing or medicine) } \\
\text { VHWs able to access supplies and support from either CHS or government } \\
\text { (or other) health service }\end{array}$ \\
\hline $\begin{array}{l}\text { Intermediate objective } \\
\text { Introduce participatory approach to }\end{array}$ & $\begin{array}{l}\text { Re-plan the project to include a pilot of revising project } \\
\text { structure, activities, funding and evaluation mechanisms } \\
\text { utilising a participatory approach }\end{array}$ & $\begin{array}{l}\text { ESWCHP and CHS aware of, and use participatory approaches } \\
\text { Funding support for pilot from key funders (NZAID/AusAID) }\end{array}$ \\
\hline
\end{tabular}

30 'Communities are better off with empowered women but in a Papua New Guinea setting, this needs continual external support.' (Underhill 2006, pp 15)

${ }^{31}$ In light of this recommendation, I have used VHW throughout the remainder of this Chapter.

February $2010 \quad$ Page 120 of $176 \quad$ Ruth Heather 


\begin{tabular}{|c|c|c|}
\hline Objectives & Activities & Indicators \\
\hline ESWCHP & $\begin{array}{l}\text { Identify opportunities for advancing health services } \\
\text { outside } \mathrm{CHS} \text { - this could be strengthening government } \\
\text { health services, or seeking to support non religious health } \\
\text { providers } \\
\text { Obtain key funder support for pilot and establishment of } \\
\text { alternative providers } \\
\text { Run a pilot - re-plan the project for a catchment (eg } \\
\text { Albinama) utilising a participatory approach } \\
\text { Pilot group to meet regularly with NDOH and PDOH } \\
\text { officials to translate operational challenges into policy } \\
\text { frameworks at provincial and national levels } \\
\text { Further steps to expand the pilot should be taken following } \\
\text { full evaluation of the pilot } \\
\text { Train staff in gender analysis and participatory } \\
\text { approaches }\end{array}$ & $\begin{array}{l}\text { Regular meetings between SCiPNG and other development NGOs to } \\
\text { leverage enhanced funding options to achieve greater returns from funders. } \\
\text { ESWCHP and CHS staff liaise with related development activities in the } \\
\text { province (e.g. rural water supply, transport and communication infrastructure) } \\
\text { to achieve greater efficiencies for VHV and community access } \\
\text { VHVs and communities have demonstrably more knowledge about the } \\
\text { ESWCHP and how it works } \\
\text { Regular meetings between pilot group and government officials resulting in } \\
\text { changes to policy } \\
\text { Increased ESWCHP staff time utilised in liaising with VHVs regarding } \\
\text { personal issues (illnesses, threats from community, family strains) and in } \\
\text { undertaking gender awareness and VHV advocacy within communities } \\
\text { Increased proportion of ESWCHP staff time and financial spend at VHV and } \\
\text { community level (rather than at CHS or ESWCHP level) } \\
\text { Statistics on key health indicators continue to show improved health amongst } \\
\text { rural people } \\
\text { Stabilization or reduction in spend at CHS and ESWCHP level of the project } \\
\text { Numbers of training programmes completed, extent of follow up, participation } \\
\text { of male and female staff (ESWCHP, CHS and NDOH); attention to gender } \\
\text { analysis and participatory approaches content in training programmes; } \\
\text { changes in practice as a result of training programmes } \\
\text { Alternatives to CHS in place to provide supplies and support to VHVs }\end{array}$ \\
\hline $\begin{array}{l}\text { Immediate objective } \\
\text { Immediate increased support to VHVs } \\
\text { within their communities }\end{array}$ & $\begin{array}{l}\text { Ensure regular and complete replenishment of and } \\
\text { medical supplies } \\
\text { 'Expand the basic medical kit to include materials for }\end{array}$ & $\begin{array}{l}\text { VHVs receive regular complete medical supplies } \\
\text { Increased VHV access to critical supplies and resources (eg radios and } \\
\text { ambulances) }\end{array}$ \\
\hline
\end{tabular}

February $2010 \quad$ Page 121 of $176 \quad$ Ruth Heather




\begin{tabular}{|c|c|c|}
\hline Objectives & Activities & Indicators \\
\hline & $\begin{array}{l}\text { personal hygiene (bath soap, clothes soap, bleach) as } \\
\text { well as for night work (lamps and fuel) }{ }^{32} 33 \text {, } \\
\text { Provide radios for VHVs within each catchment area to } \\
\text { connect with CHS } \\
\text { Work with communities to increase 'in-kind' payment and } \\
\text { support for VHV } \\
\text { Introduce key indicators for CHS that are linked to funding } \\
\text { that show levels of support to VHVs and that require an } \\
\text { increased distribution of critical resources to VHVs and } \\
\text { communities } \\
\text { Work with communities and NGO partners to identify } \\
\text { alternatives to CHS } \\
\text { Train staff in gender awareness } \\
\text { Introduce incentives/consequences performance } \\
\text { management to Area Medical Supply }\end{array}$ & $\begin{array}{l}\text { Increased level of VHV service to communities } \\
\text { Increased CHS and ESWCHP advocacy work with VHV and within } \\
\text { communities } \\
\text { Increased community satisfaction with VHV service and ESWCHP support } \\
\text { Numbers of training programmes completed, extent of follow up, participation } \\
\text { of male and female staff (ESWCHP, CHS and NDOH); attention to gender } \\
\text { content in training programmes; changes in practice as a result of training } \\
\text { programmes } \\
\text { Redistribution of funds to support VHVs (through access to radios, critical } \\
\text { supplies and ambulances) } \\
\text { Area Medical Supply (AMS) staff have performance agreements which } \\
\text { include key indicators for medical supply linked to incentives /consequences } \\
\text { that are important to AMS staff }\end{array}$ \\
\hline
\end{tabular}

\footnotetext{
${ }^{32}$ Underhill, 2006

${ }^{33}$ These are currently called 'incentives' in project documentation.

February $2010 \quad$ Page 122 of $176 \quad$ Ruth Heather
}




\subsection{Empowerment of Women}

The policy implications of social relations analysis involves the political project of women's empowerment. In contrast to the top-down planning approach of earlier WID and WAD approaches, emphasis is placed on women's involvement and participatory planning (Razavi \& Miller, 1995).

For gender equality to occur across the ESWCHP rural health infrastructure, significant attention must be paid to gender equality at all levels and across all activities. Gender equality and women's empowerment must be placed back at the centre of the Project's goals and activities and monitoring indicators (Heather, 2006; Underhill-Sem \& Peutalo, 2006). 'Ultimately, what is clear and what needs to be kept in mind, is that no technical tools or frameworks can take the place of, or be used in the absence of, clear objectives in relation to gender, and a commitment to these' (Warren, 2007 pp 195). Gender equality and women's empowerment must be clearly articulated as a key focus for all project activities, with explicit reference to the MDG 3 with clear objectives for how both gender equality and women's empowerment will be addressed within the project. Gender analysis can provide a critique of supposedly gender-neutral institutions and reveal male bias within the development process (Rowlands, 1997).

Experience has shown that effective and sustainable development programmes require democratic and equitable local participation (Sen \& Grown, 1987). Significant differences exist between the perceptions of local people and development workers from outside the local culture (Smith, 1994; Fountain et al, 2004, Koka et al, 2004).

Fountain (2002), and Saovana-Spriggs \& O'Collins (2002) provided examples of issues arising when development activities are planned and implemented without in depth local participation and knowledge. Fountain (2002) described how outsiders' perspectives of the 1998 Aitape Tsunami and provision of aid were at odds with the local victims' cultural understandings. Whilst aid agencies perceived the tsunami to be a natural disaster, locals perceived the disaster as intentional, and viewed aid as compensation or 'blood money', creating tension and conflict (Fountain et al, 2004). Saovana-Spriggs \& O'Collins (2002) described a micro-credit project in Bouganville, where funding was provided to individuals rather than communities. This went against the usual cultural way of families and communities working together, and caused the unexpected effect of isolation of women who had received funding.

Koka, Deane \& Lambert also provide evidence of the importance of understanding local PNG cultural and spiritual beliefs (2004). They highlight how western beliefs about the 
causes of mental health illnesses and treatment (based on psychological and physical illness) differ distinctly from local traditional beliefs that are widely centred on sorcery.

These examples highlight the critical importance of local knowledge and active participation in project definition, planning and monitoring. Without the depth of local knowledge and involvement the examples above show, not only can key problems be missed, but also even more importantly, effective solutions not be recognised.

Cornwall advices that 'The ethic of participatory development and GAD is about challenging and changing relations of power that objectify and subjugate people, leaving them without a voice' (2000, pp 28). Empowered women contribute to the health and productivity of whole families and communities and to improved prospects for the next generation (UNFPA, cited in Underhill-Sem \& Peutalo, 2006).

Transformative change is required to address the social relations of gender inequality that threaten the sustainability and effectiveness of the ESWCHP. Transformative change would involve the ESWCHP institution acting to re-address the power imbalance so that scarce health funds are channelled through the institution, to provide direct grass roots, in ways that measurably improve community health outcomes. This would be a significant challenge for the ESWCHP as this would require a significant those with the power (at the state and market locations) to re-address power relations. As Kabeer points out 'Those whose interests are served by the institutional configuration of rules and resources are also those most likely to resist, and have the capacity to resist change...[institutions] can be transformed once a sufficient proportion of those with a stake in change are prepared to challenge institutional rules and practice' (Kabeer 1994, pp 282-283). However, as the institutional analysis suggests, without taking on this challenge, the ESWCHP risks the very health infrastructure and health outcomes it is there to provide.

Transformative change would require a gender sensitive participatory approach putting VHVs and their communities at the heart of the ESWCHP. Rural people would have a central voice across all project activities (including design, planning and funding allocation). Project goals could be inextricably linked to evidenced based mechanisms for improving health statistics (such as empowerment and education of women) and the MDGs.

Working with a gender aware approach and participation requires skills of advocacy, conflict resolution and assertiveness (Cornwall, 2000). A participatory-based gender analysis should be conducted by the ESWCHP, supported by gender aware training, which would assist staff in identifying and addressing issues of gender inequality. Issues of 
gender inequality within the ESWCHP institution must be addressed by closely examining work practices around hiring, capacity building, up-skilling and re-skilling. Project staff at all levels within the ESWCHP institution must gain gender skills through training from a human rights perspective (Smyth, 1999; Underhill-Sem \& Peutalo, 2006).

Underhill-Sem \& Peutalo signalled a warning to the ESWCHP in their report by stating:

'Once an explicit goal of gender equality and women's empowerment disappears, the focus on ensuring women's issues is lost and with it the focus on the need to support the core people in this project - the women providing critical health and development services at the most distant ends of a network. Not only are their needs overlooked as critical service providers, but so too are gender issues in the organisation. The result has been a preoccupation with formal health or development issues and the demise of issues related to gender equality and women's empowerment. As a result, women (and a few men) who provide the health and development services in rural villages lose traction in their negotiations with the complex social relations that hold communities together. This could be the undoing of an otherwise immensely valuable project' (2006 pp 8).

One of the concerns I developed whilst doing the analysis was the lack of discussion, training and support about the potential problems that occurred when local cultural and spiritual beliefs clashed, and their potential impact on birth outcomes. This highlighted the lack of active participation by local people in Project planning and activities, such as the development of training material. As a midwife, I saw this as a glaringly obvious and potentially dangerous gap ${ }^{34}$ that is of concern and should be addressed by the ESWCHP.

In the East Sepik it appears that the people are willing to participate. It remains to be seen whether the development practitioners of the ESWCHP will participate with the local people. Chambers (2005) challenges development practitioners to 'accept participation as an enduring opportunity to form good relationships and to confront and transform overcentralised power...and above all to meet the overarching challenge: to enable and empower those who are marginalised, powerless and poor to gain for themselves the better life that is their right' (pp 115).

Policy Research into Paying VHVs

\footnotetext{
${ }^{34}$ VHVs could be placed in potentially dangerous situations if they are not able to successfully negotiate for western birthing methods; the woman the VHV is assisting chooses to rely on traditional methods and birthing difficulties or deaths occur. There are potentially significant implications for VHVs if communities blame the VHV for the difficulties or death, and require retribution or payback. 
Numerous responses from VHVs indicated that they were receiving a lack of support; from the Project; CHS and from their communities. Many participants directly requested payments in cash from the Project for the work that VHVs did. Responses from VHVs also indicated that they were under pressure from family and husbands to either get paid or give up the VHV work, because it did not provide a sustainable income. Whether providing cash payment to VHVs is the most appropriate method of ensuring sustainability requires further research, but without women's empowerment and utilising a gender aware participatory approach to reframing the ESWCHP, sustainable options will not easily be identified.

Rogers (cited in Kabeer, 1994) made a series of recommendations for improved planning processes for women. She noted the 'new awareness of peasants as highly rational decision-makers is still stopping at the last frontier: women (pp23)' and that planners still saw no reason for offering women incentives to participate in the development process. Using examples from a number of development interventions, she pointed out how denying incentives to women had undermined project performance stating: 'in these projects women are expected to provide a major part of the labour force...while all financial incentives [are] withheld from them' (ibid). The result (as seen so clearly from so many of the responses from VHVs) was dissatisfaction, conflict and unmet targets and potentially for the ESWCHP lack of sustainability which is one of the key stated goals of the Project (Kabeer, 1994, pp23).

In the initial stages of conducting research for this thesis, I held an informal interview with Margaret Street, who had been a missionary in PNG for many years, and was employed by USAID in the early 80 s to establish volunteer rural health programmes. Margaret went on to develop midwifery training and accreditation in PNG. Margaret was able to provide me with copies of the early training manuals and Department of Health policy documents. My discussions with her were very interesting in that she believed that rural health care providers should only ever be volunteers. Margaret's view was that should VHVs get too much in the way of reward for services, particularly in terms of money (kina) then this would put the entire rural health infrastructure at risk. She believed that should the women get paid, not only would it be likely that men would appropriate the money (either through taking over the roles or demanding the money from the women) but that at some stage, the money would 'dry up'. Payment systems in PNG are rarely reliable (Bolger, 2005) and in Margaret's view, these women would become very focused on providing a service for cash, and should this dry up, services would no longer be provided. I was left wondering, 
how does this compare against the roles of men that are paid? How much of this discourse was based in Christian ideology or Western assumptions?

Research is needed to assess the feasibility and potential social impact of paying volunteers, and whether this would potentially be sustainable. The research would need to include policy analysis at a national and provincial level, of the role and status of women in rural communities, money flows and the potential impacts of change, and the potential issues highlighted by my discussions with Margaret Street above.

This could include research into the relative values of current salaries and facilities spend by the Project against current medical supplies spend by the Project and potential payment to VHVs. The potential impact of providing payment to VHVs would have to be thoroughly examined from a range of perspectives including:

a. Impact on role, status and morale of VHVs,

b. Impact on social relations,

c. Potential for increased issues of violence as a result of changing status of the VHV,

d. Potential unreliability of financial or other payment to VHVs and

e. Impact on the health infrastructure, health services and rural health statistics.

The ideal would be to conduct research into sustainability from a community self-reliance perspective, with potential payment to VHVs being one aspect.

Leaving aside the difficulties likely in finding a consistent funding stream should VHVs be paid for services, discussions with Margaret Street, and Bill Humphreys (ESWCHP Manager) identified that there were a range of complexities to be analysed prior to establishing a sustainable solution for the payment and support of VHVs. Further research is required into the cultural complexities surrounding VHV safety and the impact on her life should a sustainable funding stream be found, and cash payments or allowances be considered. The research would need to identify the impact of a payment or allowance on social relations:

a. Men would seek to appropriate the VHV role

b. There was likely to be increased violence toward VHVs;

c. Increased cash into the rural village economies would drive other unhealthy social consequences (such as increased alcoholism); and 
d. The VHVs perceived that the impact on their lives would be positive rather than creating greater risk.

\section{VHV work experience and career progression}

It was not clear from my observations, experience or the 2006 data, how women progressed from VHV to a career in nursing, or in fact to any other position in the ESWCHP or other market activities, that leveraged off their VHV experience. Research into the effect of VHV work experience toward rural women's career progression and the effects of this career pathway on poverty and development of the village setting would be interesting. As stated earlier, close linkages exist between maternal and child mortality and morbidity, human development and poverty (NZAID ${ }^{35}$, Smith, 1994; Kabeer, 2003; Masanjala, 2007; UNICEF, 2008). Research of this nature could broaden understandings of how women's career progression affects both health and poverty indicators, and provide foundational information for projects that focus on BOTH poverty and health.

\section{Violence and the VHV}

As discussed earlier, the ESWCHP VHVs exist within a violent society. The VHV may find herself subject to violence, or be required to deal directly with the consequences of violence. This is an issue, which was not overtly mentioned or addressed in ESWCHP documentation or activities, and yet is of critical importance to the daily lives of VHVs and women in rural communities.

Urgent research is required to assess whether VHVs are at greater risk of violence as a result of their status as voluntia, and as a result of being required to balance all the responsibilities of being rural PNG women alongside the responsibilities to the community that VHVs have. Research should compare the relative protections afforded nurses and other medical staff, through their training, status and working environments (within institutions such as hospitals and clinics) with the unprotected environment of the rural village within which the VHV provides health care. Results from this research are urgently required to identify whether the ESWCHP is currently placing women who are VHVs at greater risk of violence than other village women who are not VHVs, and to provide critical input into considerations of reframing the ESWCHP and sustainability of the current VHV aspect of rural primary health care in PNG.

Also required is research into prevention, to identify measures that could be put in place alongside primary health care provision to address and prevent gender-based violence

\footnotetext{
${ }^{35}$ http://www.nzaid.govt.nz/library/docs/nzaid-ending-poverty-begins-with-health.pdf $\begin{array}{lll}\text { February } 2010 & \text { Page } 128 \text { of } 176 & \text { Ruth Heather }\end{array}$
} 
(Bott et al, 2005). 'The dearth of evidence about effective ways to address gender-based violence limits policy makers' and programme managers' ability to make informed decisions, and makes it difficult to argue for allocating increased resources for prevention and response. More rigorous evaluations are needed particularly in the area of prevention of violence (Bott et al, 2005, pp7)'.

\subsection{Improving the Effectiveness of Rural Primary Health Care}

\section{Research in to HIV/AIDs Prevention \& Care using the SRA}

Masanjala (2007) used the SRA to identify the social context of risky sexual behaviour. The SRA could be used in the East Sepik to determine who is best placed to influence sexual behaviour amongst rural people, and the context within which prevention, treatment and monitoring could best be provided.

\section{Improving the Effectiveness of Rural Health Care Delivery}

Vinding (1994) bemoans the fact that a common problem in project design is a lack of good baseline information. In 2006, my review identified that no baseline data on the ESWCHP was easily available, or in place as part of the Project monitoring and evaluation framework. There was though a range of statistical information available within the Project database, CHS databases and Provincial health databases that could be used collectively for monitoring and future Project planning and design. This information should be collated and used to establish baseline data. Greater efforts should be taken to put in place a robust monitoring process to monitor Project effectiveness against identified key health indicators.

Ascertaining progress towards the improved health of the population is hampered by lack of prioritised and clear monitoring indicators and lack of data and effective data gathering and monitoring systems (Naidu, 2006; Underhill-Sem, 2009). Research into how effective data collection and monitoring methods might be established is urgently needed to facilitate effective monitoring of maternal and child health status and driving funding to best effect across the ESWCHP and / or the health sector in PNG.

Data is available for 72 percent of MDG indicators, with baseline data available for 47 percent. Recent data (after 1999) is available for 62 percent of the MDG indicators and 53 percent of the indicators have time series data available (Naidu 2006, pp 17). In addition, CHS and Project Office staff gather detailed health statistical data. This data would provide an excellent starting point for a research project. An agreed set of key indicators, established baseline data and time series research is needed to allow for the assessment of 
trends over time, and to ensure that effectiveness measures are available for decisions for directing scarce funding to most effect.

Saovana-Spriggs and O'Collins highlight that effective aid means different things to different people. It has many variables and dependencies and can easily come unstuck (Saovana-Spriggs \& O'Collins, 2002). The 2006 research heralded the significant improvements to health as perceived by rural people, VHV's and health staff, issues with the effectiveness and sustainability of the ESWCHP also came through clearly. But, without simple indicators to measure improvements to family health, it was difficult to determine whether the Project was effective or not.

In 2004 John Bowis, the Chief Executive of SCNZ lauded the success of the project by saying:

'Volunteers in each of the 200 villages will be supported, mentored and supervised by qualified health staff of the Church Health Services and Provisional Division of Health. Extensive staff training and improvements in health facilities will ensure this sustainable model is fully integrated into existing health services in five years time. We are delighted to receive such strong support from NZAID and hope this model can be adopted by other provinces in Papua New Guinea ${ }^{36,}$

In 1991, the DoH issued guidelines for Provinces that stated 'Experience worldwide has demonstrated community participation and support of birth attendant programmes is critical to the success and sustainability of these programmes' (DoH, 1991). And yet, numerous responses from VHVs indicated the lack of support they were receiving; from the Project; CHS and from their communities. Quotes from media releases on the SCNZ website from 2004 provide the following quotes: the first from the then Associate Minister of Foreign Affairs and Trade, Marian Hobbs,

'The NZ government has committed to $\$ 4.2$ million over the next three years to lift the health status of children and women in the East Sepik Province of Papua New Guinea ${ }^{37}$ and the second from Peter Lund, then NZ's High Commissioner to PNG

'Volunteers have provided over 100,000 consultations in remote villages over the past year and it is hoped that the increased support to them will lead to a faster and more effective health service in Papua New Guinea ${ }^{38,}$

\footnotetext{
${ }^{36}$ www.savethechildren.net/new_zealand/newsroom/health_initiative_png.html

${ }^{37}$ www.savethechildren.net/new_zealand/newsroom/govt_support_png.html

${ }^{38}$ www.savethechildren.net/new_zealand/newsroom/health_initiative_png.html

February $2010 \quad$ Page 130 of 176
} 
In 2006 I could find no factual or empirical evidence to show whether the ESWCHP had either lifted the health status of women and children in the East Sepik, or led to a faster and more effective health service in accordance with these laudable aims; nor could I find evidence that these were in place as key indicators for monitoring purposes. On the other hand, I could find no evidence that the Project was not effective either.

Recent figures quoted by Mola (2009), show that the maternal mortality rate in PNG has doubled over the past decade, giving women a 1:20 chance of dying in childbirth. (In this setting family planning can only be heralded as a life saving prevention option.) HIV/AIDs rates are rising exponentially. The NZAID Health Strategy: 2008-2013 supports these figures stating:

'In PNG, maternal mortality rates have doubled over the last decade to 733 per 100,000 live births placing PNG amongst the worst performing countries in the world for maternal deaths';

'PNG has the highest rates of HIV and AIDS in the Pacific and is only one of four countries in the Asia-Pacific region to have a generalised epidemic (NZAID, pp 7)';

and commits to giving...

'special attention to improving capacity to meet the health needs of poor and vulnerable groups, to deliver effective, high quality primary health care services' (NZAID pp 12).

In this dire picture, the key indicator measurements of success must be identified and focussed on relentlessly. Careful monitoring against these key indicators would allow for the responsive prioritisation of funding to those areas that are making the most difference to rural health outcomes.

The current goals (and components) of the ESWCHP are insufficient to address this growing wave of ill-health and death that is beginning to cascade across rural PNG. Qualitative research methods should be supported by qualitative research to assess changes in maternal and infant mortality rates and the indicators of the burden of disease, and provide information required upon which to readjust and reapply funding to where it will have the greatest effect. It seems clear that the frightening health statistics amongst rural PNG people have not been sufficiently considered with regards to their potential for resulting increases in poverty amongst these largely subsistence based economies.

What is clear (from the health statistics quoted above), is that for the majority of rural Papua New Guinea people, including those in the East Sepik, life is likely to get harder, 
people are likely to become sicker as the population grows and the burden of disease increases, and people will find it harder to make a living.

NZAID and SCNZ must seriously consider their mechanisms for delivering aid and health Projects to rural people in PNG, to ensure they are structured to effectively address the significant problems faced.

NZAID has a key role to play in ensuring Project goals and measurable objectives are in place (in return for funding) and in ensuring Project delivery through effective monitoring and evaluation systems. My experience in life is that you usually achieve what you focus on. The ESWCHP seems to focus on infrastructure, which appears to be generally what the institution produces. In place of infrastructure, should be a strong focus on key health indicators (such as HIV/AIDs and maternal and infant mortality rates), and overall rural health outcomes, which after all is what the Project is funded to achieve.

\section{Structural and critical review of the ESWCHP}

The overall cost of the ESWCHP over seven years is estimated at K18 million. The prioritisation for spend within the budget is shown below (Save the Children New Zealand, unpublished).

$$
\begin{array}{lr}
\text { Facilities, equipment and salaries } & \mathrm{K} 13,550,916 \\
\text { Health care and supplies } & \mathrm{K} 3,025,000 \\
\text { Training managers health staff and volunteers } & \mathrm{K} 978,700 \\
\text { Community education and liaison } & \mathrm{K} 449,000
\end{array}
$$

It would be useful to do further research to identify whether this prioritisation delivers the most effective health service possible, or whether re-prioritisation of the spend (ie from salaries and facilities to health care and medical supplies) would enhance actual health indicators at grass roots level. It would be useful to understand community views, and in particular VHV views of how funding should be prioritised to get most effective health improvement return for Kina spend. Specific aspects of the research might include:

- Research into the value of current health spend in salaries and facilities vs medical supplies and support to VHVs

- Introducing competition between church health providers as a means of improving rural health service provision

- Structural and project mechanisms for re-allocating funding from areas of highest cost / least impact to areas of lowest cost /highest impact. 
- Effective data collection and monitoring methods to support competition, and funding flows (Underhill-Sem, 2009).

To my knowledge, three project reviews have been undertaken since 2006: the UnderhillSem and Peutalo review (2006), the Heather review (2006) and a further review completed recently (2009), each considering the impact of the ESWCHP and providing recommendations for improvement. At the time of writing, I am not aware of any changes to the ESWCHP resulting from either the Underhil-Sem and Peutalo review, or the Heather review. It remains unclear what value these reviews have had other than potentially to satisfy funders, and whether any of the problems or solutions identified by local people have been progressed. The cost of these reviews is not insubstantial, in terms of consultancy fees and travel costs, along with untold cost to participants in terms of time and travel. If these reviews hold little real value, then arguably, these funds could be better allocated to ensuring birthing kits or medical supplies are available to VHVS. Additionally, reviews without obvious results run the risk of reducing the confidence of key stakeholders in the ESWCHP creating long-term funding difficulties for Save the Children along with participant fatigue and disillusionment with the Project and reduced engagement in future reviews and/or participatory activities.

\subsection{Summary}

On the basis of the SRA's institutional analysis, the ESWCHP with its heavy reliance on VHVs is neither sustainable, nor effective in addressing the enormous health challenges facing rural people in the East Sepik Province. The development intervention provides a suite of recommended objectives, activities and indicators as a practical example that could be used, through participation, to commence a process of realignment and reframing of the rural health care delivery and infrastructure for better health outcomes. Research offers opportunities to consider options to improve the safety of rural women providing health care in isolated settings, and to create projects that reduce poverty alongside health indicator improvements.

Participation, and building the capabilities of the rural people involved is critical to the future health of rural people. Pretty et al (1995) argue that achieving sustainable development requires at the very least functional participation (pp62). The ESWCHP Project Implementation Document (Save the Children, unpublished) details its efforts to become sustainable, through building local CHS capacity accompanied by a gradual withdrawal of the Project. However, my experience, and the evidence from local responses and the SRA analysis suggests that in fact, the ESWCHP does not actually want 
to release its closely held resources to local services and communities. If its stated aims of sustainability and eventual handover were really what the Project was aiming to achieve, much greater levels of local participation would be evident within the ESWCHP institution. Locals would have a greater and growing share of the decision-making, with obvious increases in local services self-determination and independence. So on the one hand, the ESWCHP espouses sustainability, but through its institutional arrangements, reduces the likelihood of local independence and sustainability through limited participation.

The Development Intervention I have developed could be used to assist VHVs in expanding the freedoms that would add value to their lives. The responses from VHVs clearly suggested ways that they would want to advance their freedoms - through increased access to resources and participation. Women's well-being is strongly influenced by women's ability to earn an independent income, find employment outside the home, to have ownership rights, to have literacy and be educated participants in decisions within and outside the family. Knock on positive effects within communities have been shown as a result of improved women's wellbeing, particularly in the area of child survival rates (Sen, 1999, pp191/195). The responses from VHVs clearly identified areas where they wanted support. The ESWCHP faces an opportunity to utilise the voices of rural women and VHVs and redesign the Project to involve greater levels of participation and focussed effort on the enhancement of women's well-being, to the overall benefit of rural people. 


\section{Conclusion}

Kabeer's SRA has provided the framework for an analysis of gender inequality, power and resource creation and usage within the ESWCHP institution. Kabeer's institutional analysis framework has provided insights that were not identified through the 2006 research process. From the 2006 research process 2 key issues clearly stood out: VHVs were asking for more support and a greater consistency of access to medical supplies.

Kabeer's SRA has provided a framework that has highlighted considerable issues of gender inequality that threaten the sustainability of the ESWCHP system of health care delivery to rural people. Issues previously camouflaged by cultural and social norms and expectations have shone out clearly through the use of this framework.

The analysis has shown, as Kabeer predicted of most formal institutions, that poor people, often women, are excluded from allocations of resources (1994). This was most evident in the responses from VHVs calling for more support. The analysis showed that, as expected, women are part of a community, which plays a critical part of their survival strategies. The SRA institutional analysis identified that the ESWCHP is faced with compounding gender inequalities, from outside the institution and within. Gender inequality that is embedded in the East Sepik culture is replicated in Project structure, plans, funding priorities and prioritisation processes, monitoring processes and activities. Achieving gender equality requires significant and consistent commitment and the ESWCHP needs to regain the ground it has lost over the last few years through refocusing the Project on gender equality as its central goal. A renewed programme of gender training, and gender analysis needs to be undertaken across the ESWCHP institution (including CHS) with a focus on maintaining and advancing gender equality and women's empowerment.

On the basis of key health indicators and the lack of accessible data, it seems that the health care infrastructure with its current heavy reliance on women 'voluntia' is neither successful nor effective. Urgent research is required to identify a sustainable model of rural primary health care with funding streams attached. The opportunity of reframing itself awaits the ESWCHP based on: the impact assessments and reviews already completed; input from development literature; similar health projects; and participatory projects currently underway within the Pacific. Indicators such as women's literacy should be seriously considered for inclusion in Project goals, because of the known link to improvement of maternal and infant mortality rates. 
A recent article in The Age featured growing concerns about the maternal death rate in PNG and the status of health infrastructure and gynaecological and obstetric care $\left(\right.$ Chandler, 2009 ${ }^{39}$ ). Of PNGs 200,000 births a year (with a population rate that is increasing so fast that births will have doubled in 25 years) approximately 1200 are unsupervised. Between 1996 and 2006 the maternal death rate has doubled rising to 700900 per 100,000 live births, compared to, for example, eight in Australia per 100,000. Glen Mola, Professor of Gynaecology and Obstretics at Port Moresby General Hospital is quoted as saying 'Maternal mortality is the most sensitive indicator of the functioning of the total health system, and the core system outside the towns and provincial centres has virtually collapsed (ibid)'.

The escalating maternal mortality rates along with the HIV/AIDS that threaten to break over the East Sepik, along with an existing burden of diseases (eg malaria, TB, respiratory) leave the rural East Sepik people in an unacceptable position. The current health infrastructure programmes are not working. They urgently need to be reframed so that they can at least stop the situation from deteriorating even further and gender inequalities worsening.

I now believe that the communities and the women in particular, were trying to tell me that they needed to be involved. They needed to be central to the project, and have a voice over how their lives were impacted by the goals of the project, the way the project was run and that if we worked more with them, we could find some very real solutions to some very real problems.

${ }^{39}$ http://www.theage.com.au/world/a-mothers-life-20090906-fcr6.html 


\section{Appendix A: 2006 Research Key Questions}

The following key questions were developed by the Programme and Evaluation and Monitoring Managers as a result of the Evaluation Framework Workshop conducted in June 2006 involving Project staff and stakeholder agencies. The process involved:

- Updating the logframe particularly the output indicators

- Completing of an evaluation workshop with staff and partner agencies to identify and agree the key foci of the research

- Developing an evaluation framework that linked the identified key questions to output indicators

- Developing key monitoring and evaluation questions targeted to specific respondent groups

- Categorization of questions into types (either monitoring or evaluation) and sorting by type and respondent group.

\begin{tabular}{|c|c|}
\hline \# & Key Questions \\
\hline 1. & $\begin{array}{l}\text { Has the distribution of medical supplies been improved through increased integration among } \\
\text { key service providers? }\end{array}$ \\
\hline 2. & $\begin{array}{l}\text { Has the emergency response improved through greater integration among key service } \\
\text { providers? }\end{array}$ \\
\hline 3. & $\begin{array}{l}\text { Has there been an increase in PDOH funds used for } \mathrm{MCH} \text { services and for the medical supply } \\
\text { programme in rural areas? }\end{array}$ \\
\hline 4. & $\begin{array}{l}\text { How has integration among key service providers contributed to training programmes for } \\
\text { rural health staff? }\end{array}$ \\
\hline 5. & How has the integration influenced health policy development? \\
\hline 6. & How many CHS facilities undertake VHV training for their catchment area? \\
\hline 7. & How many VHVs are currently active in the network under CHS management? \\
\hline 8. & How many VHVs are receiving sufficient medical supplies from CHS? \\
\hline 9. & $\begin{array}{l}\text { What has been the result of increased participation of VHVs in addressing promotive and } \\
\text { preventative health issues on the demand for curative health aspects at health centres? Has } \\
\text { there been a decrease in preventable illnesses at the centres? }\end{array}$ \\
\hline 10. & $\begin{array}{l}\text { What health practices by rural people have changed as a result of improved services from } \\
\text { staff and VHVs? }\end{array}$ \\
\hline 11. & $\begin{array}{l}\text { What is the acceptable minimum training level required for Rural Health Staff to be effective } \\
\text { as VHV trainers? }\end{array}$ \\
\hline 12. & What is the acceptable minimum training level required for the VHVs to be effective? \\
\hline 13. & What kind of support is being given by the LLGs to the VHVs? \\
\hline 14. & What role should communities play in order to sustain the VHV network? \\
\hline 15. & What services have improved as a result of improved equipment and supply? \\
\hline
\end{tabular}




\begin{tabular}{|l|l|}
\hline$\#$ & Key Questions \\
\hline 16. & $\begin{array}{l}\text { What types of health practices are being practiced by the communities and individual } \\
\text { families reflecting their initiative to address health? }\end{array}$ \\
\hline 17. & What VHV services have resulted/improved from integration among service providers? \\
\hline 18. & Which aspects of health provision have improved as a result of training Health Managers? \\
\hline 19. & Which CHS staff would benefit communities from the training they receive? \\
\hline 20. & Which type of promotive and preventative health issues are being addressed by VHVs? \\
\hline
\end{tabular}

\section{Respondent Groups}

The following respondent groups were identified and agreed during the Evaluation Framework Workshop conducted in June 2006 involving Project staff and stakeholder agencies.

\begin{tabular}{|c|c|}
\hline Respondent Group & Abbreviation \\
\hline Area Medical Stores staff & AMS \\
\hline Health Managers & $\mathrm{HM}$ \\
\hline Health Policy Makers & HPM \\
\hline Local Level Governments & LLG \\
\hline Meresin Meris staff & MM \\
\hline National Health Information System staff & NHIS \\
\hline Project database staff & PD \\
\hline Provincial Health Information System staff & PHIS \\
\hline Rural Health staff & RHS \\
\hline Rural People & $\mathrm{RP}$ \\
\hline Village Birth Attendants & VBA \\
\hline Village Health Workers Database & VD \\
\hline Village Health and Development Communities & (VHDC) \\
\hline Village Health Workers & VHV \\
\hline
\end{tabular}




\section{Appendix B: Map of the East Sepik}

The ESWCHP Programme Manager provided this map to the 2006 research team. No reference details are known, although it was referred to as the District Map provided by the Council.

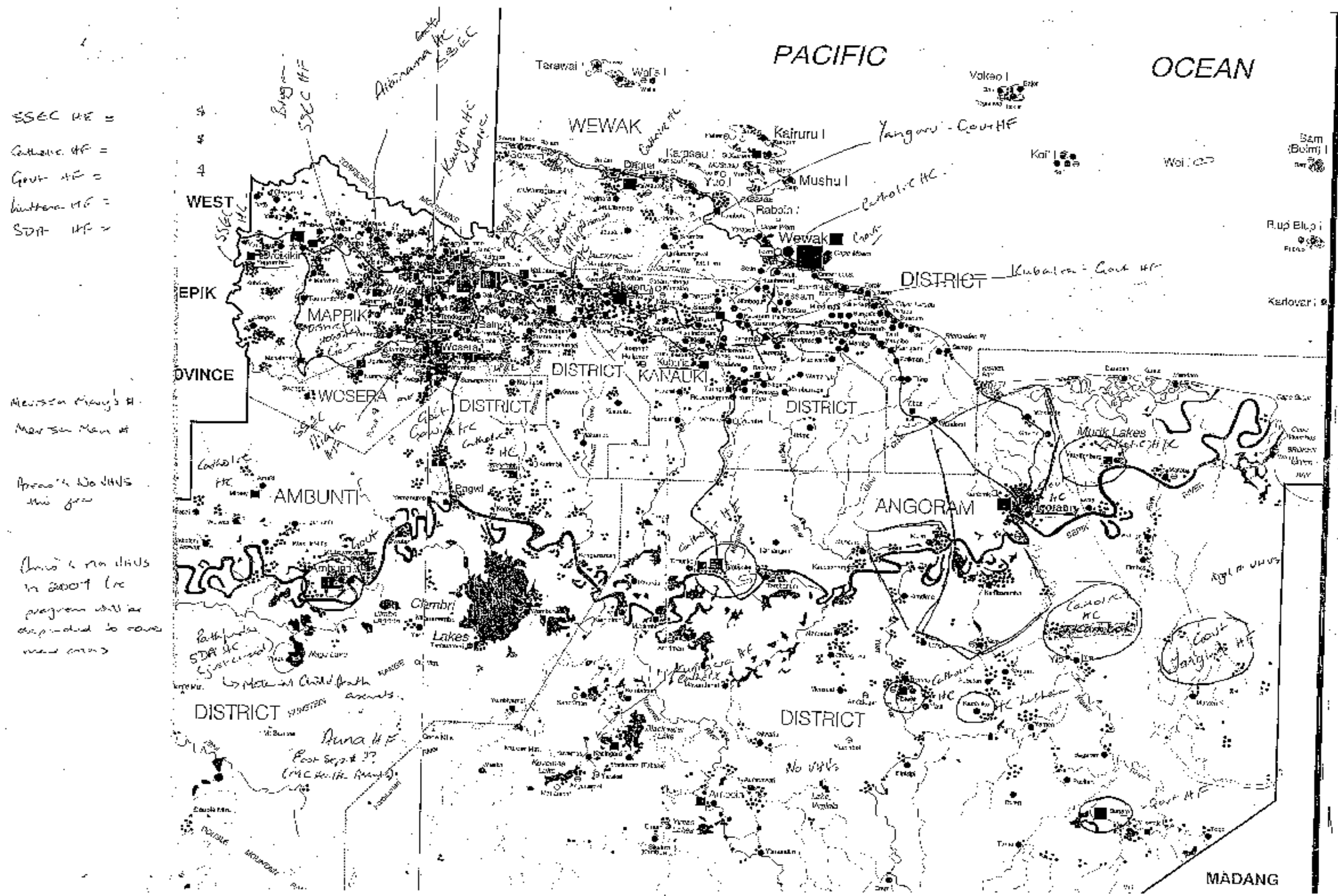




\section{Appendix C: Respondents Analysis}

\section{Men}

Village men

teacher

youth leader

Pastor

Youth security officer

Police

Church leader

Councellor

VHDC

Village committee

member

Ward member

Meresin man

Manager or supervisor

Health Board member

Village leader

Community leader

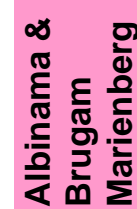

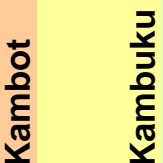

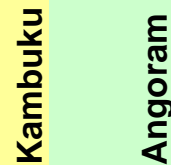

흔

혼 롱

욯

옳

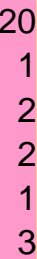

20

1

9

16

15

66

1

2

1

3

1

6

4

2

2

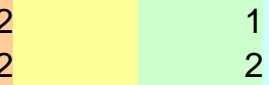

2

4

\begin{tabular}{lll}
\hline \hline & 29 & 16
\end{tabular}

$\begin{array}{lll}16 & 2 & 16\end{array}$

$\begin{array}{lll}6 & 5\end{array}$

Women

Village women

Meresin meri

Community health workers

Nurse

VHV trainer

NDO

VBA/CBD

VHDC

Women's leader or rep

Sexual health trainer
0

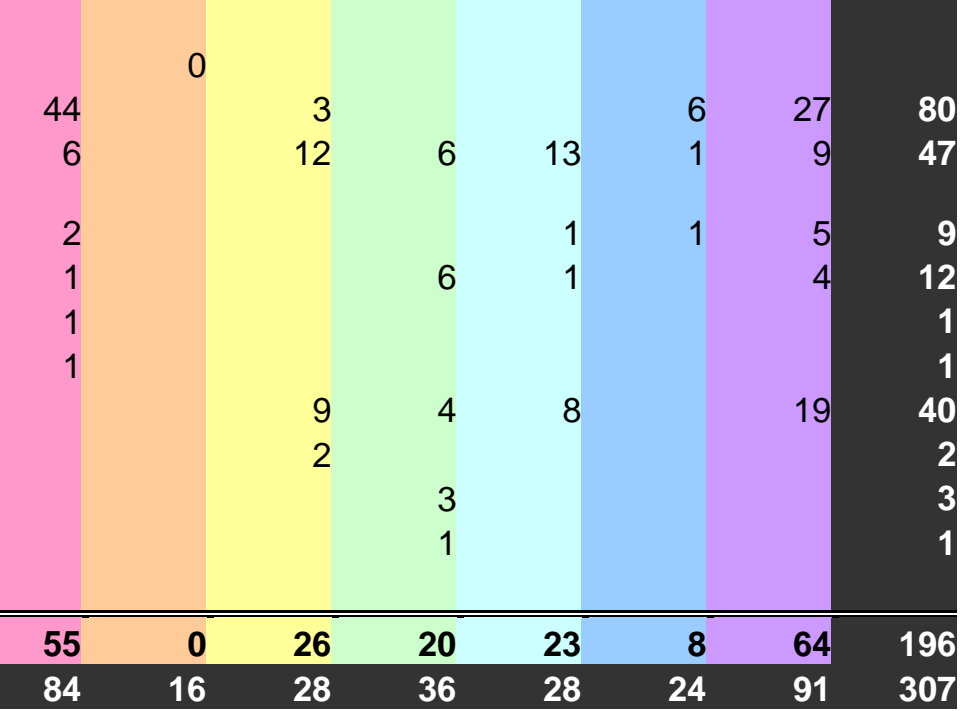




\section{Appendix D: The Millennium Development Goals, Targets and Indicators}

\section{Goal 1 - Eradicate Extreme Poverty and Hunger}

Target 1a: Reduce by half the proportion of people living on less than a dollar a day

- $\quad 1.1$ Proportion of population below \$1 (PPP) per day

- 1.2 Poverty gap ratio

- $\quad 1.3$ Share of poorest quintile in national consumption

Target 1b: Achieve full and productive employment and decent work for all, including women and young people

- $\quad 1.4$ Growth rate of GDP per person employed

- $\quad 1.5$ Employment-to-population ratio

- $\quad 1.6$ Proportion of employed people living below \$1 (PPP) per day

- 1.7 Proportion of own-account and contributing family workers in total employment

Target 1c: Reduce by half the proportion of people who suffer from hunger

- $\quad 1.8$ Prevalence of underweight children under-five years of age

- 1.9 Proportion of population below minimum level of dietary energy consumption

\section{Goal 2 - Achieve Universal Primary Education}

Target 2a: Ensure that all boys and girls complete a full course of primary schooling

- $\quad 2.1$ Net enrolment ratio in primary education

- $\quad 2.2$ Proportion of pupils starting grade 1 who reach last grade of primary

- $\quad 2.3$ Literacy rate of 15-24 year-olds, women and men

\section{Goal 3 - Promote Gender Equality and Empower Women}

Target 3a: Eliminate gender disparity in primary and secondary education preferably by 2005, and at all levels by 2015

- $\quad 3.1$ Ratios of girls to boys in primary, secondary and tertiary education

- 3.2 Share of women in wage employment in the non-agricultural sector

- $\quad 3.3$ Proportion of seats held by women in national parliament

\section{Goal 4 - Reduce Child Mortality}

Target 4a: Reduce by two thirds the mortality rate among children under five

- 4.1 Under-five mortality rate

- 4.2 Infant mortality rate

- 4.3 Proportion of 1 year-old children immunised against measles

\section{Goal 5 - Improve Maternal Health}

Target 5a: Reduce by three quarters the maternal mortality ratio

- $\quad 5.1$ Maternal mortality ratio

- $\quad 5.2$ Proportion of births attended by skilled health personnel

Target 5b: Achieve, by 2015, universal access to reproductive health

- 5.3 Contraceptive prevalence rate

- 5.4 Adolescent birth rate

- $\quad$ 5.5 Antenatal care coverage (at least one visit and at least four visits) 


\section{Goal 6 - Combat HIV/AIDS, Malaria and Other Diseases}

Target 6a: Halt and begin to reverse the spread of HIV/AIDS

- 6.1 HIV prevalence among population aged 15-24 years

- 6.2 Condom use at last high-risk sex

- $\quad 6.3$ Proportion of population aged 15-24 years with comprehensive correct knowledge of HIV/AIDS

- 6.4 Ratio of school attendance of orphans to school attendance of non-orphans aged 10-14 years

Target 6b: Achieve, by 2010, universal access to treatment for HIV/AIDS for all those who need it

- 6.5 Proportion of population with advanced HIV infection with access to antiretroviral drugs

Target 6c: Halt and begin to reverse the incidence of malaria and other major diseases

- 6.6 Incidence and death rates associated with malaria

- $\quad 6.7$ Proportion of children under 5 sleeping under insecticide-treated bednets

- 6.8 Proportion of children under 5 with fever who are treated with appropriate anti-malarial drugs

- 6.9 Incidence, prevalence and death rates associated with tuberculosis

- 6.10 Proportion of tuberculosis cases detected and cured under directly observed treatment short course

\section{Goal 7 - Ensure Environmental Sustainability}

Target 7a: Integrate the principles of sustainable development into country policies and programmes; reverse loss of environmental resources

Target 7b: Reduce biodiversity loss, achieving, by 2010, a significant reduction in the rate of loss

- $\quad 7.1$ Proportion of land area covered by forest

- $\quad 7.2$ CO2 emissions, total, per capita and per \$1 GDP (PPP)

- $\quad 7.3$ Consumption of ozone-depleting substances

- $\quad$ 7.4 Proportion of fish stocks within safe biological limits

- 7.5 Proportion of total water resources used

- $\quad$ 7.6 Proportion of terrestrial and marine areas protected

- $\quad$ 7.7 Proportion of species threatened with extinction

Target 7c: Reduce by half the proportion of people without sustainable access to safe drinking water and basic sanitation

- $\quad$ 7.8 Proportion of population using an improved drinking water source

7.9 Proportion of population using an improved sanitation facility

Target 7d: Achieve significant improvement in lives of at least $\mathbf{1 0 0}$ million slum dwellers, by 2020

- $\quad$ 7.10 Proportion of urban population living in slums

\section{Goal 8 - Develop a Global Partnership for Development}

Target 8a: Develop further an open, rule-based, predictable, non-discriminatory trading and financial system

Includes a commitment to good governance, development and poverty reduction - both nationally and internationally 
Includes: tariff and quota free access for the least developed countries' exports; enhanced programme of debt relief for heavily indebted poor countries (HIPC) and cancellation of official bilateral debt; and more generous ODA for countries committed to poverty reduction

Target 8c: Address the special needs of landlocked developing countries and small island developing States (through the Programme of Action for the Sustainable Development of Small Island Developing States and the outcome of the twenty-second special session of the General Assembly)

Target 8d: Deal comprehensively with the debt problems of developing countries through national and international measures in order to make debt sustainable in the long term

Some of the indicators listed below are monitored separately for the least developed countries (LDCS), Africa, landlocked developing countries and small island developing States.

\section{Official development assistance (ODA)}

- $\quad$ 8.1 Net ODA, total and to the least developed countries, as percentage of OECD/DAC donors' gross national income

- 8.2 Proportion of total bilateral, sector-allocable ODA of OECD/DAC donors to basic social services (basic education, primary health care, nutrition, safe water and sanitation)

- $\quad$ 8.3 Proportion of bilateral official development assistance of OECD/DAC donors that is untied

- $\quad$ 8.4 ODA received in landlocked developing countries as a proportion of their gross national incomes

- $\quad$ 8.5 ODA received in small island developing States as a proportion of their gross national incomes

\section{Market access}

- $\quad$ 8.6 Proportion of total developed country imports (by value and excluding arms) from developing countries and least developed countries, admitted free of duty

- 8.7 Average tariffs imposed by developed countries on agricultural products and textiles and clothing from developing countries

- $\quad$ 8.8 Agricultural support estimate for OECD countries as a percentage of their gross domestic product

- $\quad$ 8.9 Proportion of ODA provided to help build trade capacity

\section{Debt sustainability}

- 8.10 Total number of countries that have reached their HIPC decision points and number that have reached their HIPC completion points (cumulative)

- 8.11 Debt relief committed under HIPC and MDRI Initiatives

- $\quad 8.12$ Debt service as a percentage of exports of goods and services

Target 8e: In cooperation with pharmaceutical companies, provide access to affordable essential drugs in developing countries

- 8.13 Proportion of population with access to affordable essential drugs on a sustainable basis

Target 8f: In cooperation with the private sector, make available the benefits of new technologies, especially information and communications

- 8.14 Telephone lines per 100 population

- 8.15 Cellular subscribers per 100 population

- 8.16 Internet users per 100 population

Source: http://www.undp.org/mdg/basics.shtml 


\section{Appendix E: Papua New Guinea Governance System}

The PNG governance system is a parliamentary democracy based on the Westminster model (ie executive power with the National Executive Council (cabinet) headed by a prime minister). The members of parliament are selected through national elections. There is a decentralised system of government with three sub-national levels of administration: provincial, district and local as shown on Table 1 (Bolger et al, 2005; DFAT 2008).

Appendix D Table 1: Governance Arrangements in Papua New Guinea Political structures Administrative structures

National level

- National Parliament

- National Executive Council

- Ministries
- National Departments

- Statutory bodies

\section{Provincial level}

(20 provinces, including the national capital district)

- Provincial assembly

- Provisional executive council

- Provincial committees

- Joint provincial planning and budget priorities committee

District level

Each province is divided into districts. There are $\mathbf{8 9}$ districts in total

Joint district planning and budget priorities committee
- Provincial administration

- Provincial treasury

- Provincial audit services
District administration

District treasury

\section{Local Level Government (LLG)}

Each district is divided into LLGs. There are 284 LLGs

\section{Ward level}

Each LLG has many wards. There are 5747 wards in total

\section{Communities and villages}

Each ward is made of many hamlets, villages and non-traditional village areas. Note: of the 66-77,000 public servants in PNG, less than 1000 are at the ward and community levels

Bolger et al, 2005 pp2

The National Department of Health (NDoH) and the health sector are part of the broader system of governance and service delivery in PNG. Alongside the $\mathrm{NDoH}$ at the national level sit other agencies including the 'Departments of Finance, Personnel Management, Provincial Affairs and Local Government, National Planning and Rural Development, Community Development, the National Monitoring Authority, the National Economic and Fiscal Commission, the Churches Medical Council, the Central Agencies Coordinating Committee, the Institute of Medical Research and various education institutes' (Bolger et 
al, 2005, pp 9). Each of these agencies competes for limited resources and to ensure that its policies and priorities are not undermined by cross-governmental decisions or by the agendas of other agencies (Bolger et al, 2005; Australian Department of Foreign Affairs and Trade, 2008). 



\section{Appendix F: Rules Analysis}

Note: The analysis did not identify any rules held by NZAID, SCNZ, SCiPNG and local NGOs. As a result they are not included in the table below, but were identified through the analysis as an institutional gap.

\begin{tabular}{|c|c|c|c|c|c|c|}
\hline $\begin{array}{l}\text { NDOH } \\
\text { (gender division } \\
\text { not known) }\end{array}$ & $\begin{array}{l}\text { PDOH } \\
\text { (gender division } \\
\text { not known) }\end{array}$ & $\begin{array}{l}\text { CHS } \\
\text { Generally led by } \\
\text { men, resourced } \\
\text { by women }\end{array}$ & $\begin{array}{l}\text { ESWCHP } \\
\text { Programme } \\
\text { Office } \\
\text { (men \& women) }\end{array}$ & $\begin{array}{l}\text { VHVs } \\
\text { (generally } \\
\text { women) }\end{array}$ & $\begin{array}{l}\text { Village Leaders } \\
\text { (men) }\end{array}$ & $\begin{array}{l}\text { Village people } \\
\text { (men, women } \\
\text { and children) }\end{array}$ \\
\hline $\begin{array}{l}\text { - National health } \\
\text { policy } \\
\text { - Funds PDOH to } \\
\text { enact policy } \\
\text { - Standards } \\
\text { - Monitoring } \\
\text { requirements } \\
\text { - Training standards } \\
\text { - Allocate funding }\end{array}$ & $\begin{array}{l}\text { - Provincial health } \\
\text { policy } \\
\text { - Framework for } \\
\text { provincial health } \\
\text { care } \\
\text { - Allocate funding }\end{array}$ & $\begin{array}{l}\text { - Religious } \\
\text { framework } \\
\text { - Rules around level } \\
\text { of service, who is } \\
\text { served } \\
\text { - Priority for scarce } \\
\text { medical supplies } \\
\text { and health } \\
\text { infrastructure } \\
\text { resources } \\
\text { - Roles of men and } \\
\text { women within the } \\
\text { CHS } \\
\text { - Level of VHV } \\
\text { support } \\
\text { - Level of staffing } \\
\text { and allocate } \\
\text { funding }\end{array}$ & $\begin{array}{l}\text { - Adhere to } \\
\text { requirements of } \\
\text { funding agencies } \\
\text { to obtain funding } \\
\text { - Roles of men and } \\
\text { women within the } \\
\text { ESWCHP } \\
\text { - Role of VHV } \\
\text { - Dictate } \\
\text { coordination } \\
\text { processes } \\
\text { - Agreements with } \\
\text { village leaders for } \\
\text { VHV services } \\
\text { - Level of support }{ }^{40} \\
\text { provided to CHS } \\
\text { and VHVs } \\
\text { - Provide medical } \\
\text { supplies and }\end{array}$ & $\begin{array}{l}\text { - Role as women in } \\
\text { the village setting } \\
\text { (eg care for } \\
\text { children, garden, } \\
\text { extended family } \\
\text { etc) }\end{array}$ & $\begin{array}{l}\text { - Community } \\
\text { services } \\
\text { - Gender roles } \\
\text { within the village } \\
\text { - VHV agreement } \\
\text { and training } \\
\text { - VHV services } \\
\text { - Level of support to } \\
\text { VHV } \\
\text { - Level of } \\
\text { infrastructure } \\
\text { provided to VHVs } \\
\text { (birthing hutt and } \\
\text { /or meresin haus) } \\
\text { - Protect the VHV } \\
\text { from 'payback' if } \\
\text { things go badly } \\
\text { wrong during care } \\
\text { - Construct required }\end{array}$ & $\begin{array}{l}\text { - Receive health } \\
\text { services from } \\
\text { VHVs as required } \\
\text { - Level of support to } \\
\text { VHV } \\
\text { - Decide to pay (or } \\
\text { not) VHVs for } \\
\text { services and the } \\
\text { level of payment } \\
\text { - Decide whether to } \\
\text { instigate (or not) } \\
\text { changes to lifestyle } \\
\text { in accordance with } \\
\text { VHV training such } \\
\text { as } \\
\text { - Clean up village } \\
\text { and keep water } \\
\text { clean } \\
\text { - Create toilet }\end{array}$ \\
\hline
\end{tabular}

40 'Support' means level of resources applied. In the case of CHS this could mean funding, management input for example. In the case of VHVs it is generally used to mean 'in-kind' payment and community agreement with level and type of services provided.

$\begin{array}{lll}\text { February } 2010 & \text { Page } 147 \text { of } 176 & \text { Ruth Heather }\end{array}$ 


\begin{tabular}{|c|c|c|c|c|c|c|}
\hline $\begin{array}{l}\text { NDOH } \\
\text { (gender division } \\
\text { not known) }\end{array}$ & $\begin{array}{l}\text { PDOH } \\
\text { (gender division } \\
\text { not known) }\end{array}$ & $\begin{array}{l}\text { CHS } \\
\text { Generally led by } \\
\text { men, resourced } \\
\text { by women }\end{array}$ & $\begin{array}{l}\text { ESWCHP } \\
\text { Programme } \\
\text { Office } \\
\text { (men \& women) }\end{array}$ & $\begin{array}{l}\text { VHVs } \\
\text { (generally } \\
\text { women) }\end{array}$ & $\begin{array}{l}\text { Village Leaders } \\
\text { (men) }\end{array}$ & $\begin{array}{l}\text { Village people } \\
\text { (men, women } \\
\text { and children) }\end{array}$ \\
\hline & & & $\begin{array}{l}\text { incentives to VHVs } \\
\text { - Determine } \\
\text { integration points } \\
\text { to meet project } \\
\text { indicators (eg } \\
\text { integrate VHV } \\
\text { mgmt with Child } \\
\text { Health and CHS } \\
\text { management) } \\
\text { resulting in } \\
\text { confusing } \\
\text { relationship and } \\
\text { supply chain } \\
\text { issues for } \\
\text { VHVs, and lack of } \\
\text { clarity as to who is } \\
\text { running training } \\
\text { programmes } \\
\text { - Level of staffing } \\
\text { and allocate } \\
\text { funding }\end{array}$ & & $\begin{array}{l}\text { buildings and } \\
\text { sanitation } \\
\text { arrangements }\end{array}$ & $\begin{array}{l}\text { areas } \\
\text { - Level of } \\
\text { infrastructure } \\
\text { provided to VHVs } \\
\text { (birthing hutt and } \\
\text { /or meresin haus) } \\
\text { - Decide on a case } \\
\text { by case basis } \\
\text { whether to support } \\
\text { (or not) VHV in } \\
\text { transferring patient } \\
\text { to CHS or Wewak }\end{array}$ \\
\hline
\end{tabular}




\section{Appendix G: Resources Analysis}

\begin{tabular}{|c|c|c|}
\hline Organisation & Resources used & Resources produced \\
\hline $\begin{array}{l}\text { NDoH and } \\
\text { PDOH }\end{array}$ & $\begin{array}{l}\text { Material resources (money, land) } \\
\text { Human resources (labour, skills) } \\
\text { Intangible resources (political clout / mana, connections) }\end{array}$ & $\begin{array}{l}\text { Health infrastructure (hospitals, ambulances etc), and medical care } \\
\text { Human resources (doctors, nurses, managers etc) } \\
\text { Intangible resources (political clout / mana, connections) }\end{array}$ \\
\hline NZAID & $\begin{array}{l}\text { Material resources (money) } \\
\text { Human resources (labour, skills) }\end{array}$ & $\begin{array}{l}\text { Project infrastructure (offices and equipment) } \\
\text { Human resources (staff) } \\
\text { Intangible resources (political clout / mana, connections) }\end{array}$ \\
\hline CHS & $\begin{array}{l}\text { Intangible resources (political clout / mana, connections, } \\
\text { religious faith) } \\
\text { Material resources (money, land) } \\
\text { Human resources (labour, skills) }\end{array}$ & $\begin{array}{l}\text { Health infrastructure } \\
\text { Health services } \\
\text { Human resources (nurses, VHVs) } \\
\text { Intangible resources (growing support in the community, increased mana } \\
\text { and connections) }\end{array}$ \\
\hline $\begin{array}{l}\text { ESWCHP } \\
\text { Office }\end{array}$ & $\begin{array}{l}\text { Material resources (money) } \\
\text { Human resources (labour, skills) } \\
\text { Intangible resources (political clout / mana, connections) }\end{array}$ & $\begin{array}{l}\text { Material resources (money) } \\
\text { Co-ordination services } \\
\text { Intangible resources (political clout / mana, connections) }\end{array}$ \\
\hline VHVs & $\begin{array}{l}\text { Human resources (labour, skills) } \\
\text { Intangible resources (time, connections, place in the } \\
\text { community, mana) }\end{array}$ & $\begin{array}{l}\text { Basic health services } \\
\text { Resources in line with their role as village woman (producing food, caring } \\
\text { for family, keeping house, going to market etc) } \\
\text { Intangible resources (increased connections and mana) }\end{array}$ \\
\hline $\begin{array}{l}\text { Village } \\
\text { leaders }\end{array}$ & $\begin{array}{l}\text { Intangible resources (time, connections, place in the } \\
\text { community, clout, mana) }\end{array}$ & $\begin{array}{l}\text { Intangible resources (time, connections, place in the community, clout, } \\
\text { mana) } \\
\text { Human resources (VHV labour, skills) }\end{array}$ \\
\hline $\begin{array}{l}\text { Village } \\
\text { people }\end{array}$ & $\begin{array}{l}\text { Material resources (money, land, 'in-kind' payments) } \\
\text { Human resources (labour, skills - to build haus meresin) }\end{array}$ & $\begin{array}{l}\text { Health infrastructure within the village (haus meresin) } \\
\text { Human resources (VHV labour, skills, improved health amongst village } \\
\text { people releasing human effort and time) } \\
\text { Material resources (increased productivity of the village as a whole as a }\end{array}$ \\
\hline
\end{tabular}




\begin{tabular}{|l|l|l|}
\hline Organisation & Resources used & Resources produced \\
\hline & & $\begin{array}{l}\text { result of increased health: for example, in the lakeside village of WAGU, } \\
\text { income was earned from selling coffee and farming crocodile. This meant } \\
\text { that increased food stuffs could be purchased to supplement subsistence } \\
\text { gardening improving the diet and health of villagers. Increased income } \\
\text { also meant that in case of ill health, fuel and transport was available to } \\
\text { obtain health assistance. }\end{array}$ \\
\hline
\end{tabular}




\section{Appendix H: People Analysis}

\begin{tabular}{|c|c|c|c|}
\hline Organisation & Who is in? & Who is out? & Who does what? \\
\hline $\begin{array}{l}\text { NDoH and } \\
\text { PDOH }\end{array}$ & Not known & Not known & Not known \\
\hline NZAID & Not known & Not known & Not known but appears to be largely skills based \\
\hline CHS & $\begin{array}{l}\text { People that share the } \\
\text { same belief system } \\
\text { People with connections } \\
\text { and mana (people with } \\
\text { influence across the } \\
\text { community or political } \\
\text { clout) } \\
\text { People with skills }\end{array}$ & $\begin{array}{l}\text { People that do not share the } \\
\text { same belief system unless they } \\
\text { have political clout } \\
\text { People who challenge the belief } \\
\text { system } \\
\text { Unskilled people }\end{array}$ & $\begin{array}{l}\text { Catholics: Priest dictates dogma and at times service provision } \\
\text { Manager, most senior Nun } \\
\text { Nurses, women } \\
\text { VHV's are generally women, men taking on the role of VHV or meresin } \\
\text { man is generally frowned on } \\
\text { Women perceived to hold role of village woman which can be extended to } \\
\text { include the role of VHV }\end{array}$ \\
\hline $\begin{array}{l}\text { ESWCHP } \\
\text { Office }\end{array}$ & $\begin{array}{l}\text { People with skill base } \\
\text { and connections }\end{array}$ & Unskilled people & $\begin{array}{l}\text { Men generally act as managers, drivers or play a role in the distribution of } \\
\text { medical supplies } \\
\text { Women generally take on the roles associated with supporting VHVs and } \\
\text { Maternal / Child Health } \\
\text { In } 2006 \text {, the Acting Programme Manager was a skilled local woman }\end{array}$ \\
\hline VHVs & $\begin{array}{l}\text { Rural women with } \\
\text { connections, and } \\
\text { access to material } \\
\text { resources and } \\
\text { community support (to } \\
\text { enable them to travel to }\end{array}$ & Men and children & $\begin{array}{l}\text { Women (VHVs) provide basic health care } \\
\text { Men commonly can control use of facilities, and control access to vehicles } \\
\text { and fuel when the VHV needs to transfer a sick patient to a Church Health } \\
\text { clinic or hospital. }\end{array}$ \\
\hline
\end{tabular}




\begin{tabular}{|l|l|l|l|}
\hline Organisation & Who is in? & Who is out? & \\
\hline & $\begin{array}{l}\text { CHS, take time for } \\
\text { training and to provide } \\
\text { services }\end{array}$ & & \\
\hline $\begin{array}{l}\text { Village } \\
\text { leaders }\end{array}$ & $\begin{array}{l}\text { Men with political clout } \\
\text { and connections -often } \\
\text { older men }\end{array}$ & Women and children & Men make decisions \\
\hline Village & Extended families & Unknown & Men and women have clearly defined roles within the village. \\
\hline people & & & \\
\hline
\end{tabular}




\section{Appendix I: Activities Analysis}

\begin{tabular}{|c|c|c|c|c|c|c|}
\hline $\begin{array}{l}\text { NDOH } \\
\text { (gender division } \\
\text { not known) }\end{array}$ & $\begin{array}{l}\text { PDOH } \\
\text { (gender division } \\
\text { not known) }\end{array}$ & $\begin{array}{l}\text { CHS } \\
\text { Generally led by } \\
\text { men, resourced } \\
\text { by women }\end{array}$ & $\begin{array}{l}\text { ESWCHP } \\
\text { Programme } \\
\text { Office } \\
\text { (men and } \\
\text { women) }\end{array}$ & $\begin{array}{l}\text { VHVs } \\
\text { (generally } \\
\text { women) }\end{array}$ & $\begin{array}{l}\text { Village Leaders } \\
\text { (men) }\end{array}$ & $\begin{array}{l}\text { Village people } \\
\text { (men, women } \\
\text { and children) }\end{array}$ \\
\hline $\begin{array}{l}\text { - Sets national } \\
\text { policy } \\
\text { - Funds PDOH to } \\
\text { - Sets mont policy } \\
\text { standards and } \\
\text { requirements } \\
\text { Funds health care } \\
\text { and training } \\
\text { Provides national } \\
\text { statistical reports } \\
\text { on health status } \\
\text { Provides national } \\
\text { training } \\
\text { programmes for } \\
\text { nurses and } \\
\text { midwives } \\
\text { Pays staff }\end{array}$ & $\begin{array}{l}\text { - Provides the } \\
\text { infrastructure to } \\
\text { enable provincial } \\
\text { health care } \\
\text { (training, facilities, } \\
\text { vehicles, fuel, } \\
\text { distribution of } \\
\text { funds and medical } \\
\text { supplies by air, } \\
\text { road or river - } \\
\text { dependant on } \\
\text { availability of } \\
\text { funding) } \\
\text { Provide funding to } \\
\text { CHS } \\
\text { Fund and provide } \\
\text { health care at } \\
\text { Wewak Hospital - } \\
\text { facility and staff } \\
\text { Fund and provide } \\
\text { rural govt health } \\
\text { centres, clinics and }\end{array}$ & $\begin{array}{l}\text { - Influence policy } \\
\text { through } \\
\text { coordination } \\
\text { meetings and } \\
\text { relationships } \\
\text { - Provide rural } \\
\text { health clinics } \\
\text { - Bid for capability } \\
\text { funding from } \\
\text { ESWCHP (eg for } \\
\text { facilities or } \\
\text { vehicles) through } \\
\text { the Programme } \\
\text { Coordinating } \\
\text { Group and } \\
\text { relationships } \\
\text { - Manage VHV } \\
\text { networks and do } \\
\text { regular 'rounds' to } \\
\text { connect with VHVs } \\
\text { and offer support } \\
\text { Report on health }\end{array}$ & $\begin{array}{l}\text { - Bid for funding } \\
\text { from NZAID and } \\
\text { provide monitoring } \\
\text { reports and project } \\
\text { documentation as } \\
\text { required } \\
\text { Co-ordinate } \\
\text { relationships to } \\
\text { agree priorities for } \\
\text { funding and policy } \\
\text { through the } \\
\text { Programme } \\
\text { Coordinating } \\
\text { Group } \\
\text { Assess proficiency } \\
\text { of CHS through } \\
\text { liaison and audit, } \\
\text { and provide } \\
\text { management } \\
\text { advice, support } \\
\text { and expertise to } \\
\text { CHS }\end{array}$ & $\begin{array}{l}\text { - Provide basic } \\
\text { health care and } \\
\text { advice to rural } \\
\text { people as } \\
\text { required: } \\
\text { - Medical supplies } \\
\text { - Bed nets } \\
\text { - Referrals to } \\
\text { CHS or Wewak } \\
\text { Hospital } \\
\text { Refer very sick } \\
\text { patients to health } \\
\text { clinics } \\
\text { Seek medical } \\
\text { supplies from CHS } \\
\text { when available } \\
\text { and possible } \\
\text { - Provide education } \\
\text { and health } \\
\text { promotion to } \\
\text { village people: } \\
\text { - Health eating }\end{array}$ & $\begin{array}{l}\text { - Agree on who } \\
\text { should be trained } \\
\text { as VHV } \\
\text { - Dictate support for } \\
\text { VHV provided by } \\
\text { village people } \\
\text { - Clean the village } \\
\text { - Build village toilet } \\
\text { - Build haus meresin } \\
\text { and haus karim for } \\
\text { VHV } \\
\text { - Use health } \\
\text { buildings as } \\
\text { required for other } \\
\text { activities }\end{array}$ & $\begin{array}{l}\text { - Receive health } \\
\text { services from } \\
\text { VHVs when } \\
\text { needed } \\
\text { - Pay (or not) VHVs } \\
\text { for services } \\
\text { - Instigate (or not) } \\
\text { changes to lifestyle } \\
\text { in accordance with } \\
\text { VHV training } \\
\text { Support (or not) } \\
\text { VHV in transferring } \\
\text { patient to CHS or } \\
\text { Wewak } \\
\text { Instigate (or not) } \\
\text { changes to lifestyle } \\
\text { in accordance with } \\
\text { VHV training } \\
\text { - Clean up village } \\
\text { and keep water } \\
\text { clean } \\
\text { - Create toilet }\end{array}$ \\
\hline
\end{tabular}




\begin{tabular}{|c|c|c|c|c|c|c|}
\hline $\begin{array}{l}\text { NDOH } \\
\text { (gender division } \\
\text { not known) }\end{array}$ & $\begin{array}{l}\text { PDOH } \\
\text { (gender division } \\
\text { not known) }\end{array}$ & $\begin{array}{l}\text { CHS } \\
\text { Generally led by } \\
\text { men, resourced } \\
\text { by women }\end{array}$ & $\begin{array}{l}\text { ESWCHP } \\
\text { Programme } \\
\text { Office } \\
\text { (men and } \\
\text { women) }\end{array}$ & $\begin{array}{l}\text { VHVs } \\
\text { (generally } \\
\text { women) }\end{array}$ & $\begin{array}{l}\text { Village Leaders } \\
\text { (men) }\end{array}$ & $\begin{array}{l}\text { Village people } \\
\text { (men, women } \\
\text { and children) }\end{array}$ \\
\hline & $\begin{array}{l}\text { aid posts - facility, } \\
\text { and staff } \\
\text { - Fund and provide } \\
\text { medical supplies to } \\
\text { rural CHS, Govt } \\
\text { Health centres, } \\
\text { and aid posts - by } \\
\text { road, river or air } \\
\text { - Pay staff }\end{array}$ & $\begin{array}{l}\text { statistics based on } \\
\text { VHV, health clinic } \\
\text { and training stats } \\
\text { - Provide training } \\
\text { based on } \\
\text { ESWCHP training } \\
\text { programmes } \\
\text { - Provide medical } \\
\text { supplies to VHVs } \\
\text { when available } \\
\text { - Organise transfer } \\
\text { by ambulance or } \\
\text { air to hospital in } \\
\text { Wewak when } \\
\text { possible } \\
\text { - Conduct health } \\
\text { 'rounds' to } \\
\text { communities } \\
\text { - Provide rural } \\
\text { health clinics in } \\
\text { accordance with } \\
\text { religious }\end{array}$ & $\begin{array}{l}\text { - Determine } \\
\text { integration points } \\
\text { to meet project } \\
\text { indicators (eg } \\
\text { integrate VHV } \\
\text { mgmt with Child } \\
\text { Health and CHS } \\
\text { management) } \\
\text { resulting in } \\
\text { confusing } \\
\text { relationship and } \\
\text { supply chain } \\
\text { issues for } \\
\text { VHVs,and lack of } \\
\text { clarity as to who is } \\
\text { running training } \\
\text { programmes } \\
\text { - Pay staff }\end{array}$ & $\begin{array}{l}\text { - Sanitation } \\
\text { - Family planning } \\
\text { - Seek payment 'in- } \\
\text { kind' for services } \\
\text { rendered } \\
\text { - Organise and } \\
\text { manage patient } \\
\text { transfer to CHS or } \\
\text { Wewak Hospital } \\
\text { including vehicle } \\
\text { and petrol } \\
\text { (dependant on } \\
\text { petrol being } \\
\text { available from } \\
\text { family and vehicle } \\
\text { available }{ }^{41} \text { ) } \\
\text { - Liaise with } \\
\text { patient's family } \\
\text { Seek supplies from } \\
\text { CHS or } \\
\text { Programme Office } \\
\text { - Undertake training }\end{array}$ & & areas \\
\hline
\end{tabular}

${ }^{41}$ My experience and observation was that men tended to control vehicles and fuel. If the sick patient was a woman who was not supported by her male relatives, the VHV would not be able to conduct a transfer to hospital.

February $2010 \quad$ Page 154 of 176 


\begin{tabular}{|c|c|c|c|c|c|c|}
\hline $\begin{array}{l}\text { NDOH } \\
\text { (gender division } \\
\text { not known) }\end{array}$ & $\begin{array}{l}\text { PDOH } \\
\text { (gender division } \\
\text { not known) }\end{array}$ & $\begin{array}{l}\text { CHS } \\
\text { Generally led by } \\
\text { men, resourced } \\
\text { by women }\end{array}$ & $\begin{array}{l}\text { ESWCHP } \\
\text { Programme } \\
\text { Office } \\
\text { (men and } \\
\text { women) }\end{array}$ & $\begin{array}{l}\text { VHVs } \\
\text { (generally } \\
\text { women) }\end{array}$ & $\begin{array}{l}\text { Village Leaders } \\
\text { (men) }\end{array}$ & $\begin{array}{l}\text { Village people } \\
\text { (men, women } \\
\text { and children) }\end{array}$ \\
\hline & & $\begin{array}{l}\text { framework and } \\
\text { using ESWCHP } \\
\text { funded facilities } \\
\text { - Communicate with } \\
\text { partners/ } \\
\text { stakeholders by } \\
\text { radio } \\
\text { - Pay staff } \\
\text { - Provide facilities } \\
\text { for staff and } \\
\text { patients to stay in } \\
\text { - Access information } \\
\text { through } \\
\text { coordination } \\
\text { meetings and radio } \\
\text { connections }\end{array}$ & & $\begin{array}{l}\text { and refresher } \\
\text { courses as } \\
\text { provided } \\
\text { - Maintain usual role } \\
\text { of woman in village } \\
\text { (eg look after } \\
\text { children, garden, } \\
\text { cook meals for } \\
\text { husband and } \\
\text { children, go to } \\
\text { market etc) }\end{array}$ & & \\
\hline
\end{tabular}




\section{Appendix J: Power and Benefits Analysis}

\begin{tabular}{|c|c|c|}
\hline Organisation & Who decides? & Whose interests are served? \\
\hline NDoH and PDOH & $\begin{array}{l}\text { NDoH/PDoH decide on health infrastructure and health } \\
\text { spend }\end{array}$ & $\begin{array}{l}\mathrm{NDoH} / \mathrm{PDoH} \text { and PNG locals - how this is balanced is not know } \\
\text { and outside the scope of this research }\end{array}$ \\
\hline NZAID & $\begin{array}{l}\text { Agree the Project goals, and funding levels. Agree } \\
\text { Project outputs }\end{array}$ & NZAID, SCNZ, SCiPNG, CHS, VHVs and local people \\
\hline CHS & $\begin{array}{l}\text { Catholic - Priest and Senior Nun } \\
\text { South Seas Evangelical Church - Manager -senior } \\
\text { pastor (male) }\end{array}$ & Church health leaders, staff \\
\hline ESWCHP Office & $\begin{array}{l}\text { Shared decision making regarding resources and } \\
\text { management support }\end{array}$ & $\begin{array}{l}\text { Church health services } \\
\text { The Project expects the interests of the VHV are expected to be } \\
\text { served by the CHS, but I saw little evidence of this other than in } \\
\text { providing training, some supplies and some support }\end{array}$ \\
\hline VHVs & $\begin{array}{l}\text { CHS, Village leaders, } \\
\text { Village people (re payment 'in-kind') }\end{array}$ & CHS, Village leaders, Village people, VHVs \\
\hline Village leaders & $\begin{array}{l}\text { Village leaders } \\
\text { Men : access to material resources (money, vehicles etc) }\end{array}$ & Village leaders, village people, VHVs \\
\hline Village people & Village leaders, village people (through their actions) & Village people, VHVs \\
\hline
\end{tabular}

\section{Benefits Analysis}

\begin{tabular}{|l|l|l|l|l|l|}
\hline NZAID & $\begin{array}{l}\text { PDOH } \\
\text { (gender division } \\
\text { not known) }\end{array}$ & $\begin{array}{l}\text { CHS } \\
\text { Generally led by } \\
\text { men, resourced } \\
\text { by women }\end{array}$ & $\begin{array}{l}\text { ESwCHP } \\
\text { Programme Office } \\
\text { (men and } \\
\text { women) }\end{array}$ & $\begin{array}{l}\text { VHVs } \\
\text { (generally } \\
\text { women) }\end{array}$ & $\begin{array}{l}\text { Village people } \\
\text { (men, women } \\
\text { and children) }\end{array}$ \\
\hline
\end{tabular}

February 2010 Page 156 of $176 \quad$ Ruth Heather




\begin{tabular}{|c|c|c|c|c|c|c|}
\hline NZAID & $\begin{array}{l}\text { PDOH } \\
\text { (gender division } \\
\text { not known) }\end{array}$ & $\begin{array}{l}\text { CHS } \\
\text { Generally led by } \\
\text { men, resourced } \\
\text { by women }\end{array}$ & $\begin{array}{l}\text { ESWCHP } \\
\text { Programme Office } \\
\text { (men and } \\
\text { women) }\end{array}$ & $\begin{array}{l}\text { VHVs } \\
\text { (generally } \\
\text { women) }\end{array}$ & $\begin{array}{l}\text { Village Leaders } \\
\text { (men) }\end{array}$ & $\begin{array}{l}\text { Village people } \\
\text { (men, women } \\
\text { and children) }\end{array}$ \\
\hline $\begin{array}{l}\text { - Ability to meet its } \\
\text { targets for health } \\
\text { spend and impact } \\
\text { in PNG for } \\
\text { relatively low cost / } \\
\text { high benefit ratio } \\
\text { - Staff paid for } \\
\text { services } \\
\text { - Staff houses } \\
\text { provided }\end{array}$ & $\begin{array}{l}\text { - Staff paid for } \\
\text { services } \\
\text { - Funding and } \\
\text { Medical supplies - } \\
\text { able to control } \\
\text { what is supplied to } \\
\text { whom, when } \\
\text { Note: government } \\
\text { health services do } \\
\text { not generally benefit } \\
\text { from the ESWCHP - } \\
\text { which is a source of } \\
\text { contention to them }\end{array}$ & \begin{tabular}{|l} 
- Staff paid for \\
services \\
Staff houses or \\
residences \\
- Facilities within \\
which to provide \\
services \\
- Access to funding, \\
medical supplies \\
and support to \\
grow their \\
organisation and \\
extend their \\
religious beliefs to \\
a broader base of \\
people \\
Ability to control \\
medical supply: \\
- to ensure CHS \\
supplied first - \\
what is left over \\
to VHVs \\
- Some CHS \\
require VHVs to \\
collect their
\end{tabular} & $\begin{array}{l}\text { - Staff paid for } \\
\text { services } \\
\text { Integration seems } \\
\text { to benefit the } \\
\text { ESWCHP so that it } \\
\text { meets its indicators } \\
\text { but provides } \\
\text { questionable } \\
\text { benefit to VHVs } \\
\text { and communities - } \\
\text { respondents were } \\
\text { very confused as to } \\
\text { who was doing } \\
\text { what, and who to } \\
\text { go to for what. } \\
\text { Supply ordering } \\
\text { process meets the } \\
\text { needs of the } \\
\text { ESWCHP for } \\
\text { monitoring } \\
\text { supplies, but is } \\
\text { problematic for } \\
\text { VHVs -multiple } \\
\text { problems with } \\
\text { ordering processes }\end{array}$ & $\begin{array}{l}\text { - Access to supplies } \\
\text { which can then be } \\
\text { used at the VHVs } \\
\text { discretion (medical } \\
\text { supplies, bed nets, } \\
\text { kerosene etc) } \\
\text { - Haus meresin from } \\
\text { which to provide a } \\
\text { service } \\
\text { - Increased mana to } \\
\text { VHVs - get their } \\
\text { own Haus } \\
\text { Maresin, plus } \\
\text { respect for their } \\
\text { knowledge and } \\
\text { power through } \\
\text { ability to diagnose, } \\
\text { prescribe and } \\
\text { supply medicine, } \\
\text { and refer } \\
\text { - Receive } \\
\text { assistance and } \\
\text { therefore share } \\
\text { responsibility for } \\
\text { severely unwell }\end{array}$ & $\begin{array}{l}\text { Able to influence } \\
\text { and control VHV } \\
\text { and health } \\
\text { services provided } \\
\text { to village }\end{array}$ & $\begin{array}{l}\text { - Less sickness in } \\
\text { the village as a } \\
\text { result of VHV } \\
\text { training and health } \\
\text { care } \\
\text { - Greater access to } \\
\text { medical supplies } \\
\text { and treatment } \\
\text { - Assistance during } \\
\text { pregnancy and } \\
\text { birthing } \\
\text { - Fewer deaths from } \\
\text { childbirth } \\
\text { - Greater access to } \\
\text { family planning } \\
\text { Benefit from health } \\
\text { care from VHV } \\
\text { and can choose } \\
\text { whether to pay for } \\
\text { this care or not } \\
\text { and how much to } \\
\text { pay. } \\
\text { - Reduced cost to } \\
\text { families in } \\
\text { accessing health }\end{array}$ \\
\hline
\end{tabular}




\begin{tabular}{|c|c|c|c|c|c|c|}
\hline NZAID & $\begin{array}{l}\text { PDOH } \\
\text { (gender division } \\
\text { not known) }\end{array}$ & $\begin{array}{l}\text { CHS } \\
\text { Generally led by } \\
\text { men, resourced } \\
\text { by women }\end{array}$ & $\begin{array}{l}\text { ESWCHP } \\
\text { Programme Office } \\
\text { (men and } \\
\text { women) }\end{array}$ & $\begin{array}{l}\text { VHVs } \\
\text { (generally } \\
\text { women) }\end{array}$ & $\begin{array}{l}\text { Village Leaders } \\
\text { (men) }\end{array}$ & $\begin{array}{l}\text { Village people } \\
\text { (men, women } \\
\text { and children) }\end{array}$ \\
\hline & & $\begin{array}{l}\text { supplies...this } \\
\text { may reduce the } \\
\text { number of } \\
\text { supplies } \\
\text { provided to } \\
\text { VHVs as access } \\
\text { to CHS can be } \\
\text { problematic for } \\
\text { VHVs - having } \\
\text { to walk long } \\
\text { distances etc } \\
\text { - Choose which } \\
\text { VHVs to supply } \\
\text { Control over } \\
\text { supplies potentially } \\
\text { increases the } \\
\text { power of the CHS } \\
\text { staff - making } \\
\text { village people } \\
\text { more dependant } \\
\text { on them and less } \\
\text { on themselves and } \\
\text { their VHV } \\
\text { Access to } \\
\text { buildings and }\end{array}$ & $\begin{array}{l}\text { - Able to report } \\
\text { impact on key } \\
\text { health indicators } \\
\text { for low cost (based } \\
\text { on volunteer } \\
\text { service) } \\
\text { - Relationships } \\
\text { embedded in the } \\
\text { project } \\
\text { infrastructure keep } \\
\text { the project in } \\
\text { existence } \\
\text { - Access to project } \\
\text { resources (funding } \\
\text { and support) }\end{array}$ & $\begin{array}{l}\text { cases through } \\
\text { ability to refer to } \\
\text { CHS or Hospital } \\
\text { - Training means } \\
\text { some VHVs are } \\
\text { listened to by their } \\
\text { community and } \\
\text { have a healthier } \\
\text { lifestyle } \\
\text { - VHVs able to } \\
\text { influence the men } \\
\text { to cut the grass } \\
\text { around the houses } \\
\text { and keep village } \\
\text { tidy and sanitary } \\
\text { - Training perceived } \\
\text { as benefit to VHVs } \\
\text { Some VHVs } \\
\text { receiving } \\
\text { incentives:soap, } \\
\text { kerosene, biro, salt }\end{array}$ & & $\begin{array}{l}\text { care within the } \\
\text { village rather than } \\
\text { going to hospital } \\
\text { (many hours } \\
\text { away) }\end{array}$ \\
\hline
\end{tabular}




\begin{tabular}{|c|c|c|c|c|c|c|}
\hline NZAID & $\begin{array}{l}\text { PDOH } \\
\text { (gender division } \\
\text { not known) }\end{array}$ & $\begin{array}{l}\text { CHS } \\
\text { Generally led by } \\
\text { men, resourced } \\
\text { by women }\end{array}$ & $\begin{array}{l}\text { ESWCHP } \\
\text { Programme Office } \\
\text { (men and } \\
\text { women) }\end{array}$ & $\begin{array}{l}\text { VHVs } \\
\text { (generally } \\
\text { women) }\end{array}$ & $\begin{array}{l}\text { Village Leaders } \\
\text { (men) }\end{array}$ & $\begin{array}{l}\text { Village people } \\
\text { (men, women } \\
\text { and children) }\end{array}$ \\
\hline & & $\begin{array}{l}\text { vehicles and can } \\
\text { make decisions as } \\
\text { to how and when } \\
\text { they are used }\end{array}$ & & & & \\
\hline
\end{tabular}




\section{Appendix K: Immediate, Underlying and Structural Causes and Effects Analysis}

\begin{tabular}{|c|c|}
\hline \multicolumn{2}{|l|}{ Causes and Effects Analysis } \\
\hline Long-term effects & $\begin{array}{l}\text { - VHV role unsustainable: increasing workload for little return; vulnerability; disempowerment } \\
\text { - VHV and community disempowerment vis a vis health infrastructure hierarchy } \\
\text { - Worsening health outcomes for ESWCHP recipients (village people) }\end{array}$ \\
\hline Intermediate effects & $\begin{array}{l}\text { - Gender inequalities with regards to access to critical resources and ability to influence (power); inability } \\
\text { to influence long term health care goals and infrastructure, distribution of critical resources and } \\
\text { subsequent outcomes for communities } \\
\text { - Reduced community reliance on VHV as she manages competing priorities; gender inequality leading to } \\
\text { variable community perception of value of service and due payment; variable household income } \\
\text { - Increased reliance on Church Health clinics (at greater cost) further undermining VHV services; } \\
\text { - vulnerability } \\
\text { - Significant effort by VHV to access supplies (effort may outweigh value of supplies over time) }\end{array}$ \\
\hline Immediate effects & $\begin{array}{l}\text { - Fluctuations in household income (including food and income from market sales) dependant on } \\
\text { entrenched gender inequalities; } \\
\text { - Reduced ability for VHV to conduct subsistence farming (and other duties such as caring for family) due } \\
\text { to competing village health care needs }\end{array}$ \\
\hline The core problem & $\begin{array}{l}\text { - Lack of sustainability of the VHV role in providing basic health care services to village people - potential } \\
\text { to worsen as } \mathrm{CHS} \text { take over management of the project and the VHVs } \\
\text { - Limited access to critical health resources by the majority of service providers and service users within } \\
\text { the ESWCHP }\end{array}$ \\
\hline $\begin{array}{l}\text { Immediate causes at: } \\
\text { - Household and Community level }\end{array}$ & $\begin{array}{l}\text { - Increased workload for VHVs with inconsistent or inadequate return for services } \\
\text { - Payment for VHV services dependant on entrenched gender inequalities }\end{array}$ \\
\hline
\end{tabular}


- Increased community expectations resulting in VHV vulnerability

- Market level (NGO)

- Payment for VHV services dependant on entrenched gender inequalities

- Inconsistent supply of critical resources (incentives, medical supplies, ambulances) to support VHV services

Intermediate causes at:

- Lack of access to means of communications and transport

- Household level

- Household level

- Community level

- Market level

- VHV role seen as a natural extension to women's role of provider / carer / nurturer for family and community;

- Assumption that women can and want to take on responsibilities in addition to extensive existing responsibilities

- Ideological norms about female dependency; perceived low value of service provided by VHVs

Structural causes at:

- Household level

- Community level

- Market level

- State level

- Payment for VHV services dependant on entrenched gender inequalities

- Gender inequality enshrined in policy and implemented throughout the ESWCHP and health infrastructure

- Entrenched systems of access and control at the upper levels of management and leadership, decreasing as it goes down the chain of command

- Entrenched gender inequality restricts VHV ability to influence public health policy or infrastructure

- Disproportionate access to and control over critical funds, facilities, vehicles and supplies by those in the upper and middle layers of the health infrastructure

- Ideology of male breadwinner; gender-segmented labour markets; gender-biased institutional practices; gender inequalities in intra-household power relations 


\section{References/Bibliography}

Aisi, H., E., R. 2008 Statement to the $52^{\text {nd }}$ Session of the Commission on the Status of Women "Financing for Gender Equality and the Empowerment of Women" Independent State of Papua New Guinea. http://www.un.org/womenwatch/daw/csw/csw52/statements_missions/papua.pdf

Aitken, I., W. 1991 The health services of Papua New Guinea in Thomason, J., A., Newbrander, W., C., Kolehmainer-Aitken, R., (eds) 1991 Decentralisation in a developing country: The experience of Papua New Guinea and its health service, The Australian National University, Canberra, pp23-35.

Ashwell, H., Barclay, L. (date unknown) A retrospective analysis of a community-based health program in Papua New Guinea http://www.cdu.edu.au/gshp/documents/Aretrospectiveanalysisofacommunity-preprintcopy.pdf (accessed 1 February 2010)

Ashwell, H., Barclay, L. 2009 Outcome evaluation of community health promotion intervention within a donor funded project climate in Papua New Guinea http://www.rrh.org.au/publishedarticles/article_print_1219.pdf

Asian Development Bank, 2006 Cultures and Contexts Matter: Understanding and Preventing HIV in the Pacific, Manila.

AusAid, 2001 Papua New Guinea Social and Economic Indicators 2000, Canberra.

AusAid, 2006 Impacts of HIV/AIDS 2005-2025 in Papua New Guinea, Indonesia and East Timor: Synopsis Report of the HIV Epidemiological Modelling and Impact Study, Canberra.

Ausaid, 2001 Developing Integrated Rural Health Care Systems: An Evaluation of the Kadavu Rural Health Project in Fiji, Quality Assurance Series No. 24 December 2000, Commonwealth of Australia, Canberra.

Australian Department of Foreign Affairs and Trade, Papua New Guinea, Country Health Information -Profiles pp 311-318.

http://www.dfat.gov.au/

Axline, W., A 1991 Prologue to Decentralisation: Politics and Administration in 
Thomason, J., A., Newbrander, W., C., Kolehmainer-Aitken, R., (eds) 1991

Decentralisation in a developing country: The experience of Papua New Guinea and its health service, The Australian National University, Canberra, pp8-19.

Beazley, H., Ennew, J. 2005 Participatory Methods and Approaches: Tackling the Two Tyrannies, in Desai, V., Potter, R. (eds) 2006 Doing Development Research, Sage, London, pp189-199.

Bolger, J., Mandie-Filer, A., Hauck, V. 2005 Papua New Guinea's Health Sector: A review of capacity, change and performance issues. Discussion Paper No 57F, European Centre for Development Policy Management. www.ecdpm.org

Boserup, E., 1970 Women's Role in Economic Development, Earthscan, London.

Bott, S., Morrison, A., Ellsberg, M. 2005 Preventing and responding to gender-based violence in middle and low-income countries: a global review and analysis, World Bank. http://econ.worldbank.org

Brock, K., Pettit, J. (eds) 2007 Springs of Participation: Creating and Evolving Methods for Participatory Development, Institute of Development Studies, Brighton.

Brouwer, E., C., Harris, B., M., Tanaka, S. (eds) 1998 Gender Analysis in Papua New Guinea, the World Bank, Washington.

Butler, R. 2001 From where I write: the place of positionality in qualitative writing, in Limb, M., Dwyer, C. (eds) Qualitative Methodologies for Geographers: Issues and Debates, Arnold, London, pp264-276.

Campos-Outcalt, D., Newbrander, W., C. 1991 Planning for health in a decentralized context in Thomason, J., A., Newbrander, W., C., Kolehmainer-Aitken, R., (eds) 1991 Decentralisation in a developing country: The experience of Papua New Guinea and its health service, The Australian National University, Canberra, pp118-126.

Cant, S., Luke, G., Ndwala, S. 2009 Reducing maternal and child deaths: experiences from Papua New Guinea and the Solomon Islands, World Vision Australia, World Vision New Zealand and the Centre for International Child Health, University of Melbourne http://www.fpi.org.nz/LinkClick.aspx?fileticket=FoXp68I3J6A\%3D\&tabid=722 
Chambers, R. 1994 Paradigm Shifts and the Practice of Participatory Research and Development, Institute of Development Studies, Brighton.

Chambers, R. 2005 Ideas for Development, Institute of Development Studies, Brighton.

Chandler, J. 2009 A Mothers Life, The Age, http://www.theage.com.au/world/a-mothers-life-20090906-fcr6.html

Chant, S. 2000 Mainstreaming Men into Gender and Development: debates, reflections and experiences, Oxfam, Oxford.

Chowdrey, G. 1995 Engendering development? Women in Development (WID) in international development regimes, in Marchand, M., Parpart, J. (eds) 1995 Feminism, Postmodernism and Development, Routledge, London, pp26-41.

Cleaver, F. 2003 Masculinities Matter! Men, gender and development, Zed Books, London.

Controller and Auditor-General 2008 New Zealand Agency for International Development: Management of overseas aid programmes: Performance Audit Report. www.oag.govt.nz

Cooke, B. 2004 Rules of thumb for participatory change agents, in (eds) Hickey, S., Mohan G. From Participation to Emancipation? Zed Books, London, pp42-58.

Cooke, B., Kothari, U. (eds) 2001 Participation: The new tyranny? Zed Books, London.

Cornwall, A. 2000 Making a Difference? Gender and Participatory Development, IDS Discussion Paper 378, Institute of Development Studies, Brighton.

Cornwall, A., and Jewkes, R. 1995 What is participatory research? Social Science and Medicine, Vol 41(12) pp1667-76.

Cornwall, A. 2003 Whose voices, whose choices? Reflections on gender and participatory development, World Development, 31(8) pp1325-1342.

Cornwall, A. 2007 Pathways of women's empowerment, http://www.opendemocracy.net/node/34188/print

Cornwall, A., Pratt, G. (eds) 2003 Pathways to Participation: Reflections on PRA, ITDG, 
London.

Cox, E. 1999 Appropriate Development: Twenty-five years of changing non-government efforts and organisations, Development Bulletin 50, pp6-10.

http://devnet.anu.edu.au/bulletin.php

Cox, E. 2005 Building a local response to HIV/AIDS: Lessons from local initiatives and partnerships, Development Bulletin 67, pp48-52.

http://devnet.anu.edu.au/bulletin.php

Crang, J. 2001 Filed Work: Making sense of Group Interviews in Limb, M., Dwyer, C. (eds) Qualitative Methodologies for Geographers: Issues and Debates, Arnold, London, pp215-233.

Department of Health and Child Survival Support Project 1991 Provincial Guidelines for Village Birth Attendant Programmes, Department of Health Family Health Division, Boroko, PNG UNPUBLISHED

Dickson-Waiako, A. 1999 Civil society and development, non government organisations and churches, Development Bulletin 50, pp44-46 http://devnet.anu.edu.au/bulletin.php

Dickson-Waiako, A. 2006 Reflections on the women and development agenda in Papua New Guinea, Development Bulletin 70, pp96-99.

http://devnet.anu.edu.au/bulletin.php

Dickson-Waiako, A 2009 Women Policy Making and Development, in May, R., J. (ed) 2009, Policy Making and Implementation: Studies from Papua New Guinea, ANU Press, Canberra http://epress.anu.edu.au/ssgm/policy_making/pdf/ch15.pdf

Dollar, D. and Gatti, R. 1999 Gender Inequity, Income, and Growth: Are good times good for women? World Bank, Washington DC, www.worldbank.org/gender/prr/dg.pdf

El-Bushra, J. 2000 Rethinking gender and development practice for the twenty-first century, Gender and Development Vol 8(1), Oxfam, Great Britain, pp55-62.

Elson, Diane 1991 Male bias in the development process, Manchester University Press, Manchester.

Fernando, J. 1997 Nongovernmental Organisations, Micro-Credit, and Empowerment of women, Annals of the American Academy of Political and Social Science, Vol 554 
pp150-177.

Fountain, P. M., 2002 Christianity, Local Culture and Disaster Relief Theory and Practice in Papua New Guinea, Victoria University of Wellington, Unpublished thesis.

Fountain, P.M., Kindon, S. L., Murray, W.E., 2004 Christianity, Calamity, and Culture: The Involvement of Christian Churches in the 1998 Aitape Tsunami Disaster Relief, The Contemporary Pacific, Vol 16, 2, University of Hawai'i Press, Hawai'i, pp321355.

Garap, S. 1999 The struggles of women and girls in Simbu Province, Development Bulletin 50, pp 47-50.

http://devnet.anu.edu.au/bulletin.php

Gasper, D. 1997 Sen's Capability Approach and Nussbaum's Capabilities Ethic, Journal of International Development, Vol 9(2) Institute of Social Studies, The Hague, pp281302.

Ghodsee, K. 2007 Religious Freedoms versus Gender Equality: Faith Based Organisations, Muslim Minorities, and Islamic Headscarves in the New Europe, Social Politics: International Studies in Gender, State \& Society 2007 14(4), Oxford University Press, Oxford, pp526-561

Gibbs, P. 2002 Religion and religious institutions as defining factors in Papua New Guinea politics, Development Bulletin, Vol 59, pp15-18 http://devnet.anu.edu.au/bulletin.php

Gideon,S., Lokoloko, T., Masere D., Manoa, M., Dupar, M., Street, M. 1991 Provincial Guidelines for Village Birth Attendant Programmes, Department of Health, Boroko, Papua New Guinea, Unpublished.

Gonsalves, J., Becker, T., Braun, A., Campilan, D., de Chavez, H., Fajber, E., Kapiriri, M., Rivaca-Caminade, J., Vernooy, R. (eds) 2005 Participatory research and development for sustainable agriculture and natural resource management: A sourcebook:Volume 3: Doing Participatory Research and Development, IDRC, http://www.idrc.org.sg/fr/ev-73446-201-1-DO_TOPIC.html (accessed Dec 2008)

Gorman, S., Dorina, P., Kheng, S. 1999 Gender and Development in Cambodia: An 
Overview (Working Paper 10), Cambodia Development Resource Institute, Phnom Pen.

Government of Papua New Guinea (GoPNG) and United Nations in Papua New Guinea (UNiPNG), 2004, Papua New Guinea - Millennium Development Goals Progress Report 2004 www.un.org

Government of Papua New Guinea Department of Health and UNICEF, Crisis in Paradise: The State of Papua New Guinea's Children, Call to Action publication date and place unknown (Copy provided by Margaret Street who worked in Papua New Guinea in the 1980s and 1990s)

Gwaba, R. 2003 Reflecting on PRA, participation and gender in Cornwall, A., Pratt, G. (eds) Pathways to Participation: Reflections on PRA, ITDG Publishing, London, pp. 88-93.

Heather, R., 2006 East Sepik Women and Children's Health Project Monitoring Research Narrative Report, Unpublished.

Heather, R., 2006 East Sepik Women and Children's Health Project Monitoring Research Data, Unpublished.

Hirshman, M. 1995 Women and Development: A Critique, in Marchand, M., Parpart, J. (eds) 1995 Feminism, Postmodernism and Development, Routledge, London, pp42-55.

Hochfeld, T., Bassadien, S., R. 2007 Participation, values, and implementation: three research challenges in developing gender-sensitive indicators, Gender and Development, Vol 15, No 2, pp217-230.

Hull, T., Widayatun, D., Raharto, A., Setiawan, B. 1999 Neither dunkun nor doctor: Some problems of the village midwife programme in Eastern Indonesia, Development Bulletin Vol 48, pp17-20. http://devnet.anu.edu.au/bulletin.php

International Save the Children Alliance, 1999 Save the Children's Policy on: Gender Equity, www.savethechildren.net/alliance/resources/gender_equity.pdf

Inversen,V. 2005 Intra-household Inequality: A Challenge for the Capability Approach? in Agarwal, B., Humphries, J. and I Robeyns (eds), Amartya Sen's work and ideas: A Gender Perspective, Routledge, London, pp95-118. 
Jackson, P. 2001 Making Sense of Qualitative Data, in Limb, M., Dwyer, C. (eds) Qualitative Methodologies for Geographers: Issues and Debates, Arnold, London, pp199-214.

James-Sebro, M. 2006 Faith, Gender Equality and Development: Excavating a Hidden and Powerful Nexus, InterAction.org

http://72.3.133.142/newswire/detail.php?id=5000 (accessed 21 December 2009)

Kabeer, N. 1994 Gender Planning in Development Agencies: Meeting the Challenge in Gender-aware policy and planning: a social relations perspective, in Macdonald, M. (ed), Oxfam, Oxford pp80-97.

Kabeer, N. 1994 Reversed Realities: Gender Hierarchies in Development Thought, Verso, London.

Kabeer, N. 2003 Gender Mainstreaming in Poverty Eradication and the Millennium Development Goals: A handbook for policy makers and other stakeholders, IDRC, Ottawa http://www.irdc.ca/openbooks/067-5

Karl, M. 1995 Women and Empowerment: Participation and Decision Making, Zed Books, London.

Kelly, E. 2002 Feminism and Development in Vietnam: How One Informs the Practice of the Other, Victoria University of Wellington, Unpublished thesis.

Kennedy, A. 1993 WID - an active or a passive verb? Development Bulletin 26, pp3-5 http://devnet.anu.edu.au/bulletin.php

Kidu, C. 1997 Information and Women in Papua New Guinea, Papua New Guinea - PNG Buai Digital Information Project, Paper presented at 1997 Waigani Seminar www.pngbuai.com

Kidu, C. 2000 Reflections on change, ethnicity and conflict: Family and ethnic violence in Papua New Guinea, Development Bulletin, No 53, pp29-33 http://devnet.anu.edu.au/bulletin.php

Kindon, S. 2005 Participatory Action Research, in Qualitative Methods in Human Geography. Second Edition. Hay, I. (ed), Oxford University Press, Melbourne, pp207220 
Koggel, C. M., 2005 Globalisation and Women's Paid Work: Expanding Freedoms? in Agarwal, B., Humphries, J. Robeyns, I., (eds), Amartya Sen's work and ideas: A Gender Perspective, Routledge, London, pp165-186.

Koka, B. E., Deane, F. P., and Lambert, G. 2004 Health worker confidence in diagnosing and treating mental health problems in Papua New Guinea, South Pacific Journal of Psychology, Vol 15 (1), pp29-42.

Kolehmainen-Aitken, R.-L. 1991 Decentralization and health workforce development in Thomason, J., A., Newbrander, W., C., Kolehmainer-Aitken, R., (eds) 1991 Decentralisation in a developing country: The experience of Papua New Guinea and its health service, The Australian National University, Canberra, pp101-117.

Korare, D. 2002 Gender and perceptions of political power in Papua New Guinea, Development Bulletin, no 59, pp47-50, http://devnet.anu.edu.au/bulletin.php

Kwan, M-P. 2002 Quantitative Methods and Feminist Geographic Research in Moss, P. (eds) Feminist Geography in Practice: Research and Methods, Blackwell Publishers, Oxford, pp160-173.

Lausie, P., Thomason, J., A. 1991 A provincial perspective in Thomason, J., A., Newbrander, W., C., Kolehmainer-Aitken, R., (eds) 1991 Decentralisation in a developing country: The experience of Papua New Guinea and its health service, The Australian National University, Canberra, pp76-82.

Lee, D., Mountz, A. 2001 Interpretation, representation, positionality: issues in field research in human geography, in Limb, M., Dwyer, C. (eds) Qualitative Methodologies for Geographers: Issues and Debates, Arnold, London, pp234-247

Limb, M., Dwyer, C. (eds) 2001 Qualitative Methodologies for Geographers: Issues and Debates, Arnold, London.

Loveridge, D., Kotvojs, F. 2004 Gender mainstreaming in the Royal Papua New Guinea Constabulary, Development Bulletin, Vol 64 pp67-69. http://devnet.anu.edu.au/bulletin.php

Macintyre, M. 2000 Violence and peacemaking in Papua New Guinea: A realistic assessment of the social and cultural issues at grassroots level, Development Bulletin, Vol 53, pp34-37, http://devnet.anu.edu.au/bulletin.php 
Malcolm, L., Wright, L., Barnett, P., 1999 The Development of Primary Health Care Organisations in New Zealand, Aotearoa Health, Christchurch School of Medicine. http://www.moh.govt.nz/moh.nsf/82f4780aa066f8d7cc2570bb006b5d4d/835ed332754 31e194c25684800032638/\$FILE/pco.pdf

March, C., Smyth, I., Mukhopadhyay, M., A. 1999 Guide to Gender-Analysis Frameworks, Oxfam GB.

Martins, C., Ratanakeree, P. 1993 Pigs and Participation: Action research with hilltribe women, ILEIA Newsletter, Vol 9 No 1, pp13-14.

Masanjala, W. 2007 The poverty-HIV/AIDS nexus in Africa: A livelihood approach. Social Science and Medicine, Vol 64 University of Malawi, Zomba, Malawi, pp10321041 .

Mohammad, R. 2001 'Insiders' and/or 'outsiders': Positionality, Theory and Praxis in Limb, M., Dwyer, C. (eds) Qualitative Methodologies for Geographers: Issues and Debates, Arnold, London, pp101-117.

Mohan, G. 2002 Participatory Development in Desai, V., Potter, R., B. The Companion to Development Studies, Arnold, London, pp49-54.

Mola, G. Aitken, I. 1984 Maternal Mortality in Papua New Guinea 1976-1983, Рариа New Guinea Medical Journal, Vol 27(2), pp65-71

http:// www.popline.org/docs/0678/029748.html

Mola, G. 2009 Maternal Mortality in Papua New Guinea, O\&G Magazine, Vol 11 No 1 pp33-36 http://www.ranzcog.edu.au/publications/o-g_pdfs/O\&G-Autumn2009/Maternalpercent20mortalitypercent20inpercent20Papuapercent20Newpercent20 Guinea_Glenpercent20Mola.pdf

Moser, C. 1993 Gender Planning and Development, Theory, Practice and Training. Routledge Press, London.

Moss, P. 2002 Taking on, Thinking about, and Doing Feminist Research in Geography, in Moss, P. (eds) Feminist Geography in Practice: Research and Methods, Blackwell Publishers, Oxford, pp1-17.

Naidu, V. 2006 The Millennium Development Goals in the Pacific: progress, pitfalls and 
potential solutions, Unpublished paper.

Newbrander, W., C., Aitken, I., W., Kolehmainen-Aitken, R.-L. 1991 Performance of the health system under decentralisation in Thomason, J., A., Newbrander, W., C., Kolehmainer-Aitken, R., (eds) 1991 Decentralisation in a developing country: The experience of Papua New Guinea and its health service, The Australian National University, Canberra, pp64-75.

Nussbaum, M. 2005 Capabilities as Fundamental Entitlements: Sen and Social Justice in Agarwal, B., Humphries, J. Robeyns, I. (eds), Amartya Sen's work and ideas: A Gender Perspective, Routledge, London, pp35-62.

NZAID Achieving Gender Equality and Women's Empowerment http://www.nzaid.govt.nz/library/docs/gender-doco.pdf

NZAID Gender Equality and Women's Empowerment Factsheet http://www.nzaid.govt.nz/library/docs/factsheet-gender-equity-womensempowerment.pdf

NZAID, Achieving Gender Equality and Women's Empowerment, accessed 20 June 2009 http://www.nzaid.govt.nz

NZAID, Aide Memoire, Government of Papua New Guinea and New Zealand Agency for International Development Country Programme Strategy 2008-2018 www.nzaid.govt.nz

NZAID \& Government of Papua New Guinea, 2008, Country Programme Strategy 20082018. http://www.nzaid.govt.nz/library/docs/nzaid-png-strategy-2008-2018.pdf

NZAID, Ending Poverty Begins with Health, http://www.nzaid.govt.nz/library/docs/nzaid-ending-poverty-begins-with-health.pdf

NZAID, Health Strategy 2008-2013

http://www.nzaid.govt.nz/library/docs/nzaid-health-strategy-2008-2013-1389365.pdf

NZAID, Introduction to NZAID and the Papua New Guinea Programme www.nzpngbc.org.nz/docs/2007_nzaid_pngprg.ppt

NZAID, NZAID Priorities: Gender Equality, accessed 20 June 2009 http://www.nzaid.govt.nz/what-we-do/gender-equality.html 
NZAID, NZAID Priorities: Health, accessed 20 June 2009

http://www.nzaid.govt.nz/what-we-do/health.html

NZAID, Papua New Guinea Strategy 2002-2007

www.nzaid.govt.nz

Okafor, E., E., Abdulazeez, Y. 2007 Gender-Sensitive Projects for Sustainable Development in Nigeria: A Critical Assessment, Journal of Social Science Vol 15(3) pp235-248.

Okele, H. 2002 Political participation in a fragmented democracy: ethnic and religious appeal in Papua New Guinea, Development Bulletin, Vol 59, pp31-34 http://devnet.anu.edu.au/bulletin.php

Okele, H. 2006 Women and governance in Papua New Guinea, Development Bulletin, Vol 70, pp100-104 http://devnet.anu.edu.au/bulletin.php

Oxfam, Oxfam GB in Indonesia in Action, accessed 20 June 2009 http://oxfamindonesia.wordpress.com/2008/02/12

Papua New Guinea National Department of Health, Submission to the New Zealand Parliamentary Group on Population and Development on Improving the Status of Maternal Health Services in Papua New Guinea http://www.fpi.org.nz/LinkClick.aspx?fileticket=QUzQyWE7Glc\%3D\&tabid=722 (accessed 23 January 2010)

Parpart, J. Connelly, P. Barriteau, V., E. (eds) 2000 Theoretical Perspectives on Gender and Development, IDRC

http://www.idrc.ca/en/ev-9419-201-1-DO_TOPIC.html http://www.idrc.ca/en/ev27444-201-1-DO_TOPIC.html (accessed Dec 2008)

Paterson, R. 2008 Women's Empowerment in challenging environments: a case study from Balochistan, Development in Practice, Vol 18 (3), pp333 - 344

Pretty, J., N., Guijt, I., Thompson, J., Scoones, I. 1995 Participatory Learning and Action, International Institute for Environment and Development, London.

Rathgeber, E. M. 1990 WID, WAD, GAD: Trends in Research and Practice, Journal of Developing Areas Vol 24(4) pp489-502. 
Razavi, S., Miller, C. 1995 From WID to GAD: Conceptual Shifts in the Women and Development Discourse, UNRISD Occasional Paper No. 1 UN Fourth World Conference on Women, pp38.

Regan, A., J. 1991 The legal framework for decentralization of health functions in Thomason, J., A., Newbrander, W., C., Kolehmainer-Aitken, R., (eds) 1991 Decentralisation in a developing country: The experience of Papua New Guinea and its health service, The Australian National University, Canberra, pp36-53.

Reilly, Q. 1991 The transition to decentralization in Thomason, J., A., Newbrander, W., C., Kolehmainer-Aitken, R., (eds) 1991 Decentralisation in a developing country: The experience of Papua New Guinea and its health service, The Australian National University, Canberra, pp54-63.

Robeyns, I. 2005 Sen's Capability Approach and Gender Inequality: Selecting Relevant Capabilities in Agarwal, B., Humphries, J., Robeyns I (Eds) Amartya Sen's Work and Ideas, A Gender Perspective, Routledge, Oxon, pp63-94.

Rowlands, J., 1997 Questioning Empowerment: Working with Women in Honduras, Oxfam, Oxford.

Ruxton, Sally (ed) 2004 Gender Equality and Men: Learning from Practice, Oxfam, Oxford.

Sanderson, E., Kindon, S. 2002 Participating in Cross-Cultural Knowledge Production, Victoria University of Wellington, http://www.devnet.org.nz/conf2002/Papers/Sanderson_Kindon.pdf

Saovana-Spriggs, R., O’Collins, M. 2002 Insider/Outsider perspectives on local-level aid to Bougainville and Papua New Guinea: Dilemmas for communities, NGOs and donors, Development Bulletin Vol 61, pp71-78 http://devnet.anu.edu.au/bulletin.php

Sanderson, E., and Kindon, S. 2002 Participating in Cross-cultural Knowledge Production, http://www.devnet.org.nz/conf2002/papers/Sanderson_Kindon.pdf

Sardie, M., 2007 Lessons learned of the project 'Improvement of maternal and child healthcare by improving ability of traditional birth attendants and village health workers in Lao Cai province, Marie Stopes International, Hanoi. 
Save the Children New Zealand, East Sepik Women and Children's Health Project:

Project Implementation Document, Sept 1998 - Feb 2002, Division of Health (ESP),

Church Health Services, East Sepik Council of Women and Local Level Government Unpublished.

Save the Children New Zealand, 2004 NZ Government supports health initiative in PNG, http://www.savethechildren.net/new_zealand/newsroom/health_initiative_png.html

Save the Children New Zealand, 2004\$4.2 million from NZ Government for rural healthcare in $P N G$,

http://www.savethechildren.net/new_zealand/newsroom/govt_support_png.html

Save the Children New Zealand, East Sepik Women and Children's Health Project:

Summary Version of the Phase II Project Implementation Document, Unpublished.

Schoeffel Meleisea, P. 2009 Gender and HIV in the Pacific Islands Region, UNDPPC http://www.undppc.org.fi/_resources/article/files/HIVandGender.pdf accessed $18 / 12 / 2009$

Sen, A. 1999 Development as Freedom, Random House, New York.

Sen, G., Grown, C., 1987 Gender and Class in Development Experience, in Development, Crises and Alternative Visions: Third World Women's Perspectives, DAWN: New York pp23-49.

Simmons, P. 1997 'Women in Development': A Threat to Liberation, in Majid, R., Bawtree, V. (eds) The Post-Development Reader, Zed Books, London, pp244-255.

Singh, S. 2007 Deconstructing 'gender and development' for 'identities of women', International Journal of Social Welfare, Vol 16(2), pp100-109.

Smith, M. F., 1994 Kairuru Island: Poverty, Development and Morality in a Papua New Guinea Village, University of Hawaii Press, Hawaii.

Smyth, I. (1999) Introduction in March, C., Smyth, I., Mukhopadhyay, M., A. 1999 Guide to Gender-Analysis Frameworks, Oxfam GB, pp8-16.

St John-Ives, E. 2006 An Exploration of the Well-being of Resort Workers in Fiji: Applying Sen's Capability Approach to Well-being, Victoria University of Wellington, 
unpublished thesis.

Street, M., R., 1991 Active Birth Attendant Projects in PNG in 1991: A paper presented at VBA workshop in Goroka, Child Survival Support Project Unpublished.

Swadling, P., Hauser Schaublin, B., Gorecki, P., Tiesler, F. 1988 The Sepik-Ramu, PNG Museum, Port Moresby.

Tolich, M., Davidson, C. 1999 Starting Fieldwork: An Introduction to Qualitative Research in New Zealand, Oxford University Press, Melbourne.

Thomas, P. 2002 Introduction: Political Participation in the Pacific: issues of gender, race and religion, Development Bulletin, Vol 59, pp7-10

http://devnet.anu.edu.au/bulletin.php

Thomason, J., A., Newbrander, W., W. 1991 Health financing and budgeting in Thomason, J., A., Newbrander, W., C., Kolehmainer-Aitken, R., (eds) 1991 Decentralisation in a developing country: The experience of Papua New Guinea and its health service, The Australian National University, Canberra, pp20-22.

Thomason, J., A., Newbrander, W., C., Kolehmainer-Aitken, R., 1991 Decentralization of health services in Papua New Guinea: a critical review in Thomason, J., A., Newbrander, W., C., Kolehmainer-Aitken, R., (eds) 1991 Decentralisation in a developing country: The experience of Papua New Guinea and its health service, The Australian National University, Canberra, pp85-100.

Thomason, J., A., Newbrander, W., C., Kolehmainer-Aitken, R., (eds) 1991 Decentralisation in a developing country: The experience of Papua New Guinea and its health service, The Australian National University, Canberra.

Underhill-Sem, Y Peutalo,B. 2006 Gender Advisory Support for Grass-Roots Health Projects in Papua New Guinea, Auckland Uniservices Ltd, NZAID.

Underhill-Sem, 2009 Centre for Development Studies, Maternal Mortality in Papua New Guinea: Key issues and policy directions, University of Auckland http://www.fpi.org.nz/LinkClick.aspx?fileticket=A\%2Fel818jrE0\%3D\&tabid=722

UNICEF Papua New Guinea, 1996 Children, Women and Families in Papua New Guinea: A Situation Analysis, United Nations Children's Fund. 
UNICEF, 2008 Progress for Children, A Report Card on Maternal Mortality, No 7, UNICEF.

Veitayaki, J., Aalbersberg, B., Tawake, A. 2003 Empowering Local Communities: Case Study of Votua, Ba, Fiji, University of the South Pacific, Suva, Fiji.

Vinding, Diana 1994 Consulting and involving local women in the project design, in Macdonald, M. (ed) Gender Planning in Development Agencies: Meeting the Challenge, Oxfam, Oxford, pp113-118.

Wallace, T., 1994 Integrating gender issues into evaluation, MacDonald, M. (ed) Gender Planning in Development Agencies: Meeting the Challenge, Oxfam, Oxford, pp119126.

Warren, H. 2007 Using gender-analysis frameworks: theoretical and practical reflections, Gender and Development, Vol 15(2), pp187-198.

World Health Organisation Regional Office for the Pacific, Papua New Guinea: Country Context http://www.wpro.who.int/countries/2008/png/

World Health Organisation, Mortality Country Fact Sheet 2006: Papua New Guinea http://www.who.int/whosis/mort/profiles/mort_wpro_png_papuanewguinea.pdf

World Health Organisation, Papua New Guinea Cooperation Strategy, http://www.who.int/countryfocus/cooperation_strategy/ccsbrief_png_en.pdf

World Health Organisation, Papua New Guinea Epidemiological Country Profile on HIV and Aids

http://apps.who.int/globalatlas/predefinedReports/EFS2008/short/EFSCountryProfiles 2008_PG.pdf

World Health Organisation, Papua New Guinea, Programme Budget 2010-2011 http://www.wpro.who.int/NR/rdonlyres/F2B227BB-5514-4760-8910426A1F43B1F3/0/PAPUANEWGUINEA.pdf

Young, K. 2002 WID, GAD and WAD in Desai, V., Potter, R., B. The Companion to Development Studies, Arnold, London, pp321-325. 